\title{
NORTH CAROLINA LibRaRIES
}

Volume 74, Number 1 | Spring/Summer 2016 | ISSN 0029-2540

CLICK ON THE TITLE TO ACCESS THE ARTICLE

1 From the Pen of the Editor: Fire the Librarians First!

Ralph Scott

2 A Pathfinder for Comic Books and Graphic Novels

Hugh H. Davis, Ryan M. Smith

Incorporating Branded Academic Library Programming to Promote and Showcase Campus Research and Artistic Performances

Christian Burris, Carolyn McCallum, Molly Keener

21 Why Should I Care?: RDA and Your Library

Sonia Archer-Capuzzo

Diversity from the Inside Out:

Eight Years of the UNCG Libraries Diversity Committee

Orolando Augustus Duffus, Tiffany Henry, Jada Jones, Stacey Krim

30 61st Biennial Conference: Ogilvie Lecture \& Biennium Reports

UNC-CH Library School Master's Paper Abstracts:

Summer 2014 - Spring 2016

79 College STAR for Librarians

Clark Nall

From the Page of North Carolina Libraries:

Intellectual Freedom? Censorship in North Carolina, 1981-1985

Barbara A. Thorson

North Carolina Books

Compiled by Al Jones

Wired to the World: Browsers

Ralph L. Scott

The Charles Waddell Chesnutt Collection at Fayetteville State University William Joseph Thomas 


\section{Fire the Librarians First!}

$\mathrm{E}$ lectric utilities have a load sharing system that allows them to cut off subscribers when the system demand exceeds the resources available. It is commonly known as a "rolling blackout." That way not everyone is in the dark at once, only selected areas. This system works pretty well in that everyone shares more or less equally the pain of being without electricity. Of course those without power are unhappy, but at least they know the power will come back on when it is their turn.

Librarians are being offered a similar administrative load sharing system, only this time it is the librarians that remain in the dark forever. In school libraries, professional librarians are being treated as "extras" and not considered part of the regular teaching staff. Often libraries are phased out, or closed for most of the school day. Sometimes non-librarian staff are used to manage and run school libraries. For example in Duval County, Florida, a school media specialist staff of 39 in middle and high schools was reduced in 2015 to two librarians. Similar reductions took place in elementary school libraries. A similar situation is occurring with academic librarians, where most new contracts now are for one year, with an "option" of possible additional annual renewals. Gone are the lifetime tenure contracts. If a budget crisis were to occur these librarians on annual contract would be easy marks for non-renewal. It's like the utility load sharing system only this time only the academic librarians are affected. Curriculum instructors in say English, Computer Science, Accounting are pretty much likely to remain free from "load sharing," unless a specific program is being eliminated. Librarians in all types of libraries are seeing this type of change. Academic librarians are seen less as teaching staff and more of working in an administrative support role. These new academic librarian contracts have moved from the protections of a tenure based system, to one that offers less security, length, and respect. Public librarians are observing staff reductions, shifting of professional duties to support staff, and reductions in operating hours. Public libraries, which were once the domain of life-long learners of all classes, are now being shuttered and closed, because as we all know "everything is on the Internet."

One of the main problems with an annual (or multi-year) contract system is that it is not a meritbased system. You will instead lay off those librarians who simply by the luck of the draw came up for renewal during a period when budgets were tight. This is not a formula for creating a high quality staff. The tenure system, regardless of what you think of it, at least in theory was based on merit. Those who excelled were awarded tenure, while those who were good, but perhaps not deserving of life-time contracts, ended up with terminal year contracts. I'm not sure that the idea of working for the same institution means the same thing that it did thirty years ago. Librarians move around more now and take positions of increasing responsibility. One possible administrative theory is that if you let librarians go randomly, you will replace them with other staff that are similarly talented. Institutional memory and talent are no longer needed because again: "everything is on the Internet."

\section{Submission Requirements for North Carolina Libraries}

Eletronic articles can be submitted online at:

http://www.ncl.ecu.edu

To submit you must login; if needed you can register using the link in the header.

We use the Chicago Manual of Style (15th edition, 2003).

We have a rolling deadline, articles are juried when received.

Publication of approved articles is in about 3-9 months depending on space available.

For additional information, contact Ralph Scott at:

scottr@ecu.edu

Letters to the editor should be addressed to the editor and sent to Joyner Library, East Fifth Street, Greenville, NC 27858, or by electronic mail (scottr@ecu.edu). We reserve the right to edit all submissions. If you are interested in writing for North Carolina Libraries or would like consideration for news and product information, please send brief information to the editor at the above address. 


\section{A Pathfinder for Comic Books and Graphic Novels}

$\mathrm{T}$ his pathfinder will assist patrons in a school library as they find resources and complete research about the growing world of comic books and graphic novels. Comic books and comic book-inspired entertainment are more popular than ever; comics are increasingly a part of English/ Language Arts curriculum; and library users are more and more often seeking graphic novels (and information about them) when they go to the library. This pathfinder collects sources which help address patrons' needs regarding this subject, providing the starting points for research about comics. Patrons using this pathfinder will be introduced to a variety of sources that allow them to become familiar with the creative forces behind and the imaginative creations within comic pages. The American Association of School Librarians (AASL) has standards 4.1.2 (Read widely and fluently to make connections with self, the world, and previous reading) and 4.1.3 (Respond to literature and creative expressions of ideas in various formats and genres), and this pathfinder, for reference materials for a specific and sometimes-overlooked genre of literature, helps meet both of these standards. The Common Core Standards for English/Language Arts \& Literacy address several elements for texts which apply to comic books and graphic novels. For example, the high school standards for Reading: Literature include 9-10.2 \& 10-11.2 (Determine theme or central idea of a text and analyze in details its development over the course of the text, including how it emerges and is shaped and refined by specific details), 9.10-3 (Analyze how complex characters develop over the course of a text, interact with other characters, and advance the plot or develop the theme), 9-10.9 (Analyze how an author draws on and transforms source material in a specific work), 11-12.3 (Analyze the impact of the author's choices regarding how to develop and relate elements of a story), and 11-12.7 (Analyze multiple interpretations of a story, drama, or poem, evaluating how each version interprets the source text). The majority of materials provided to ELA teachers focuses on traditional printed texts, but the movement in education is to use a variety of sources and textual types, with graphic novels at the forefront of this movement. This pathfinder helps both teachers and students in a school library find appropriate and effective resources.

\section{Introduction}

Alternative media are becoming more widely accepted as forms of literature. Comic books and graphic novels are now mainstream, with characters and storylines appearing in movies, cartoons, video games, television shows, and more. Comics and graphic novels are a billion dollar industry that can often go overlooked in the minds of readers. The resources in this pathfinder will open readers' eyes to the universe of stories and characters that are contained in comic books. It will also give readers an idea of the rich history of the industry and the powerful impact that comic books and graphic novels have had on popular culture. In addition, it will provide teachers with a multitude of literary resources that they may otherwise overlook.

\section{Classification Numbers}

Examples of Library of Congress Classification numbers to browse:

- PN6725.S56 2003

- PN6725.W58 1989

- PN6707.C65 1993

Examples of Dewey Decimal Classification numbers to browse:

- 741 (comic books). Materials about film and television adaptations of comics and videography lists of films based on comic book properties can also be found with 741, but further DDC numbers to browse are 777 (cinematography and videography) and 791 (film adaptations).

\section{Subject Headings and Keywords}

Keywords to be used in searches include:

\begin{tabular}{|l|l|l|}
\hline comic books & visual storytelling & Archie \\
\hline graphic novels & Stan Lee & Golden age \\
\hline superheros & X-Men & Silver age \\
\hline Marvel & Superman & Image comics \\
\hline DC & superhero movies & comic adaptations \\
\hline sequential art & & \\
\hline
\end{tabular}




\section{Library of Congress Subject Headings}

\begin{tabular}{|l|l|}
\hline Class P & Language and Literature \\
\hline Subclass PN & Literature (General) \\
\hline PN6700 - PN6790 & Comic books, strips, etc. \\
\hline Class Z & Bibliography, Library Science, Information Resources (General) \\
\hline Z691 - Z692 & Special classes of materials \\
\hline Z692.G7 & Graphic Novels \\
\hline Class N & Fine Arts \\
\hline Subclass NC & Drawing, Design, Illustration \\
\hline NC1300 - NC1766 & Pictorial humor, caricature, etc. \\
\hline NC1764 - NC1764.8 & Comic books, strips, etc. \\
\hline Use for 2013 operations & $\$ 16,000.00$ \\
\hline NC1764.8 x2 & X-men (fictitious characters) \\
\hline
\end{tabular}

\section{Reference Sources}

\section{Bibliographies}

Barrier, M., and Williams, M. (Eds.). (1981). A Smithsonian book of comic-book comics. New York, NY: Smithsonian Institution Press \& Harry N. Abrams.

A companion volume to the Smithsonian Collection of Newspaper Comics, this anthology is divided into twelve sections, with historical background and bibliographic information for each subject (a noteworthy character, creation, or both from the early history of comics), followed by a reprint of a classic story or stories representing that section. This volume provides a valuable overview and resource for the Golden Age of comics, with information and stories from 1938 (and the premiere of Superman) through 1955 (and the peak of EC Horror comics). Readers can use this resource as an introduction to the classic days of early comic books.

Gravett, P. (Ed.). (2011). 1001 comics you must read before you die: The ultimate guide to comic books, graphic novels and manga. New York, NY: Universe.

The history of comics is long and varied, and this tome seeks to recommend a path of highlights through that history. Starting with examples of comic art from the nineteenth century (with the earliest sample from 1837), this book progresses from the Victorian era through the digital age with synopses, explanations, and bibliographic information on just over a thousand significant titles. The highlights include comic strips, but its focus is primarily on comic books (including single titles, story arcs over several issues, bound collections, and long-form texts written as single bound narratives). Over half of these spotlighted titles were printed since 1990, giving the reader an impressive introduction to more recent titles in the history of these books.

Gifford, D. (1984). The International book of comics. New York, NY: Crescent Books.

For the casual reader, comic books belong to the United States, with DC \& Marvel Comics dominating the domestic marketplace. However, comics are part of a global publishing industry, and this encyclopedia is an excellent introduction to graphic literature produced around the world. The entries are collected thematically (such as comics inspired by western heroes in film, or holidaybased comics, or "Superheroes at War"), with short essays providing historical and bibliographical overviews alongside a myriad of illustrations. Though this reference is now somewhat dated, it remains a solid introduction to the international world of comics.

Howard, S., and Jackson, R. (2013). Black comics: Politics of race and representation. New York, NY: Bloomsbury.

This reference is an overview of black comics, looking at both the presentation of characters of color in comic books and comic strips, and considering the history of African-American creators in the comics industry. Given the book's examination of this broad topic, it includes sections on comic strips and political cartoons, but it does also include discussions of the presence of black characters (with particular emphasis on superheroes and superheroines) in comic books. The volume sheds considerable light on the topic, which has not received as much discussion in the general overviews of comic books available. 
Lent, J. (2003). Comic art of Europe through 2000: An international bibliography. Westport, CT: Praeger.

A two-volume bibliographic record, this reference set provides its readers with a comprehensive means of finding articles written about the comics industry throughout Europe (including the British Isles). The bibliography is broken into large sections ("Global and Comparative Perspectives" and "Continental, Regional, Comparative Perspectives," as well as a series of country perspectives, dividing the reference based on the geographical subject of each article). Within each comparative section, entries are broken into a series of subsection headings: references; artistic aspects; cartooning, cartoons; cartoonists and their works; characters and titles; communication aspects; comparative aspects; conscientization aspects (looking at the beneficial use and potential of comics, such as in teaching readers about dangerous issues or in promoting causes); historical aspects; legal aspects; technical aspects; theoretical aspects; animation; caricature; comic books; comic strips; and political cartoons. These sub-headings are also found in the sections on countries with large comics industries, such as France, Great Britain, and Germany, but for those countries with smaller industries (and with fewer articles about those industries), the bibliographic entries are simply labelled under headings for the respective nations. The second volume includes an addendum of later-published works, broken down by nation. This work is an excellent starting point for readers interested in the discussion of comic books from Europe.

Lent, J. (2005). Comic art of the United States through 2000, animation and cartoons: An international bibliography. Westport, CT: Praeger.

This popular culture bibliography and index is an effective guide to the world of comics scholarship, with entries on articles and books written about comic art in many forms. The book breaks its overview into large sections, starting with one on Canada and its comic art output (broken into subsections on types of art and the media in which the art would appear), before settling into a reference about work in the United States, providing looks at Comic Art in general (which in turn breaks into sub-sections on sources $\&$ resources, the use of comic art in various media, including comic books, various locations, including schools, and as a subject of discussion in conjunction with other topics, such as war, sports, education, and political correctness), as well as the use of comic art in a variety of ways (such as for illustrations and magazine cartoons, in animation, as caricature, and for political purposes). Lent is thorough with his study, particularly in finding articles written about American comics in other countries.

Lent, J. (2006). Comic books and comic strips in the United States through 2005: An international bibliography. Santa Barbara, CA: Greenwood.

Lent's text is a bibliographic record for both comic books and comic strips, listing information on printed materials about the comics industry and its output. Like Lent's bibliography for comics of Europe (see separate entry), this volume is an invaluable resource about its subject; it narrows the focus of Lent's bibliography of comic art in the US (see separate entry) by focusing just on comic books and strips (though the two do have considerable overlap). The reference is broken into separate sections for comic books and comic sections, with each part broken into a series of subsections: General Sources; Resources; Anthologies, Collections, Reprints; Artistic Aspects; Business Aspects; Collecting; Content, Form; Criticism, Reviews; Cultural Aspects; Exhibitions, Festivals, Awards; Historical Aspects; Legal and Ethical Aspects; Media, Popular Culture Connections; Scholarship, Theory; Readership; \& Technical and Technological Aspects. An addendum keeps the book up-to-date with entries on late articles. This reference is a thorough collection of writings about comics, allowing readers to use the work as a way to find works written about comics.

Robbins, T. (1999). From girls to grrrlz: A history of $O$ comics from teens to zines. San Franscisco, CA: Chronicle Books.

Robbins' book is a short reference on the history of comics about female characters. This brief overview provides context for its specialized history and bibliography in the broader world of comics history, with Robbins noting developments in the industry that parallel those discussed in depth in the pages of this work. The world of "girl comics" is an oft-forgotten element of the broader examinations of comics, and this reference is a welcome effort to address the topic.

Weiner, R.G. (2008). Marvel graphic novels and related publications: An annotated guide to comics, prose novels, children's books, articles, criticism and reference works, 1965 - 2005. Jefferson, NC: McFarland \& Company. Retrieved from http://ebrary.com

This source contains bibliographic information, including author, artist, volume, publication date, ISBN information, and summary descriptions of each item contained, covering a forty-year span of Marvel comics. It 
contains information on Marvel history, its major and minor characters, special volumes, and related publications, as well as several scholarly works.

\section{Indexes and Abstracts}

Archie Universe. (2015). Retrieved from

http://www.mightycrusaders.net/

Though the modern comics landscape is primarily dominated by DC and Marvel Comics, the teen-friendly Archie Comics have just as long a history and have a lasting legacy on the popular culture front. This reference website provides several resources about the world of Riverdale depicted in the various Archie titles. The main page for this site, and the webpage's original focus, is the Mighty Crusaders, a superhero team created for Archie Publications during the Silver Age of comics, and several of the links are to pages about those titles and characters and their history. A casual comic book reader might not realize the extensive history of these characters, but this website rectifies that gap in knowledge, providing overviews of titles, bibliographic information on comics, biographical information on writers, reviews of unpublished work, overviews of toys and merchandise based on the superheroes, and recapping adaptations of the characters, including a thorough report on a shortlived old-time radio show based on one hero. However, the scope of the overall page is not limited just to the superheroic exploits published by Archie, as the site broadens to include reference material on the overall "Archie Universe," with the encyclopedia for Mighty Crusaders giving way to a fictional biography site of Who's Who in Archie Comics (with sub-sections for characters in the many titles published by Archie Publishing over the years) and a bibliographic overview from the history of the company. This site provides readers with a good introduction to the popular Archie series.

Thomas, R., and Schelly, B. (Eds.). (1997). Alter ego: The best of the legendary comics fanzine. Seattle, WA: Hamster Press.

The world of comic books has many facets, and one of the most significant (but often under-discussed) facets is the world of fandom. This collection highlights a category of "comics ephemera:" the fanzine. The anthology provides a collection of highlights from Alter Ego, one of the earliest fanzines (or fan-created magazines about the comics industry), with representative articles, art by both fans and industry professionals, trivia about comic books, creators, and characters, and examples of previously unpublished work and "lost" stories. This reference provides information on what would otherwise be lost material, as many fanzines have not been preserved (particularly given many were typed and photocopied, without any archives created for the issues).

Hamerlinck, P.C. (Ed.). (2001). Fawcett Companion: The Best of FCA. Raleigh, NC: TwoMorrows Publishing.

Like the overview of Alter Ego (see separate entry under Thomas \& Schelly), this reference book examines a fanzine, with this volume focusing on FCA (the fan-andcomics-historian-driven publication of the Fawcett Collectors of America), providing history, publication information, chronologies, galleries of covers, a publishers index, and information on the ongoing legacies for the publications of this publishing house (which only published comic books in the Golden Age of comics, from 1940-1953). A reader interested in Fawcett Comics would definitely be interested in this resource, as would scholars seeking examples of a particular fandom approach to comics or for information on the comics world beyond the more-often profiled Marvel \& DC Comics.

Irving, C. (2007). Blue Beetle companion: His many lives from 1939 to today. Raleigh, NC: TwoMorrows Publishing. The world of comic books is filled with significant figures, and Irving's book is an interesting example of a reference work on one of these characters. As the historical reference reveals, the superhero the Blue Beetle has had a long history (dating to the beginning of the Golden Age of comics and premiering just one year after Superman), including a variety of incarnations as well as being featured as a lead character by multiple publishers. This resource traces the history of the comic character through his many appearances in comic books, as well as detailing otherwise unknown, forgotten, or lost efforts to produce the character in comic strip and radio adaptations. The volume also includes bibliographic information on the character's appearances in different titles.

Beaty, B., and Weiner, S. (Eds.) (2012). Critical survey of graphic novels: Heroes \& superheroes. Ipswich, MA: Salem Press.

This two-volume reference set provides an overview, description, and analysis of over 130 graphic works in the superhero genre, starting with titles in the Bronze Age of comics (when the term "graphic novel" first began seeing wide use) through the modern era. The entries are alphabetical by the title of the work profiled, broken into clear sub-headings (for bibliographic information, plot, characters, artistic style, themes, and impact), and each 
entry has a "see also" line, pointing readers to further entries in this reference which relate and should be of interest. These volumes should prove valuable to both novice and experienced readers.

Beaty, B., and Weiner, S. (Eds.) (2013). Critical survey of graphic novels: History, theme, \& techniques. Ipswich, MA: Salem Press.

This volume of Beaty \& Weiner's overall series about comic books focuses on a variety of topics important to the understanding of graphic novels. With almost eighty essays about themes and concepts found in comics and about the relationship of comics to the greater world, this single-volume set is a one-stop reference for both history and legacy in sequential art. The essays are each broken into four sections: definition (a brief description of the time period or genre), introduction (offering a brief overview, making each entry accessible to all readers), the impact of the topic, and a bibliography for further reading. Of especial interest are the appendices, offering a glossary of terms and techniques, a bibliography about comics history, a guide to online resources, a timeline for comic books, major industry awards and their winners, and charts of recommended reading, providing ample opportunities for continued reading.

Beaty, B., and Weiner, S. (Eds.) (2012). Critical survey of graphic novels: Manga. Ipswich, MA: Salem Press.

This single-set volume from the Critical Survey of Graphic Novels series offers focus on the fast-growing and highlypopular Manga style of comics from Japan. Manga has taken a strong hold for many readers, and this resource examines almost seventy well-regarded works from the medium. Like Beaty \& Weiner's volumes on books from the superhero genre (see separate entry), each alphabetical entry in this reference includes bibliographic information, a publication history, an overview of the works' plot, characters, style, themes, and impact, and a listing for further reading on the topic.

Grand comics database. (2015). Retrieved from

www.comics.org

For immediate and ready information, the first source online about comic books is often the Grand Comics Database. This website is an online almanac, with data about comic publication and history, with the ability to get quick information about characters featured in comics, specific titles, and the personnel who have created these characters and titles over the years. The site is very userfriendly and has twenty search category options allowing for refinement of search terms. As an online database, the site is constantly being updated, and the one caveat a user needs to recall is that all information is provided by volunteers. However, the site has its contributors checking and double-checking each other, and much comic book history has been maintained and written by collectors and readers, so the reliance on volunteers is not unheard of. In the age of Web/Library 2.0, in fact, the use of a system in which dedicated volunteers input information is, in many ways, expected.

Image comics database. (2015). Retrieved from

http://imagecomics.wikia.com/wiki/Main_Page

This website contains thousands of entries about characters, titles, artists, writers, and history of Image Comics. Despite being a community-run wiki website, the Image database is extensive and should be a valuable asset to any library patron interested in the history of independent publishing or would like to learn more about the publishing house that has become the consistent third most popular publisher (thanks largely to the enormous popularity of titles like The Walking Dead) behind the DC and Marvel powerhouses.

Mike's amazing world of comics. (2015). Retrieved from http://www.dcindexes.com

Though it began as an online index for one avid collector's (nearly) exhaustive collection of comic books from one publisher (DC Comics, as evidenced in the URL), this website has grown to cover a plethora of publishers (the website offers nine "Amazing World of" sites for major publishers, but the database search allows the choice of fifty-three total publishers titles, with forty-eight imprints available within those publishers). The database feature allows a variety of searches for comic books, with a gallery providing cover images from the books and the story contents within each issue. One very popular feature for the site is "The Newsstand," which allows researchers to search what titles were published in a given month from 1933 to present (as of this writing, the information stops with December, 2014, but new data is added regularly, and, with the first quarter of 2015 now drawn to a close, that feature will likely update shortly to include the latest offerings). The site allows users to download information about comic books released by different publishers throughout those company's history and even features podcasts with discussions about comics and comic book history. Though it still maintains an entire category of "DC Features" on that publisher, there are also a few fun "side" features, such as a gallery of advertisements from 
comics for Saturday morning cartoons and of a specific series for Hostess desserts (featuring superhero characters). The scope and range of this site is impressive, and the information is very easy to access; the site is easily navigable for a user.

\section{Encyclopedias}

Booker, M.K. (Ed.). (2014). Comics through time: A history of icons, idols, and ideas. Santa Barbara, CA: Greenwood.

A four-volume history of comic strips and comic books, this series is a thorough encyclopedia of significant topics for the comics medium, including creators, major titles, publishers, and famous characters. Each entry provides a history of its subject, along with a "See Also" line of related entries, and a short bibliography for further reading. This reference set focuses primarily on American comics, but it does include international contributors to the industry. The expansive history provides quality entries which are both helpful as introductions to topics and for more in-depth study of each subject.

Booker, M.K. (2010). Encyclopedia of comic books and graphic novels. Santa Barbara, CA: Greenwood Press.

Many encyclopedias about comics have been produced, particularly with the growth of comics scholarship and with the success of comics-related adaptations in recent years. Booker's two-volume encyclopedia is one of the most thorough available. It also is one of the most upto-date. Its breadth and depth of coverage has caused it to supplant Maurice Horn's World Encyclopedia of Comics (1976, revised 1999) as the most thorough and effective reference for research, and it is particularly helpful in providing overviews and introductions to important writers, artists, and titles in comics history. Most entries offer recommended resources in selected bibliographies, and the encyclopedia offers a list of recommended sources about comic books in general (though it is subjective to suggest the "best" resources as it does). Though the book does skew to American comic book history, it does include entries on international publications.

DC comics encyclopedia: The definitive guide to the characters of the DC universe. (2004). New York, NY: DK Publishing. An encyclopedia of fictional characters, this large volume provides entries for over one thousand characters who have been featured in the pages of the books published by DC Comics. Each alphabetical entry provides for the character: an illustration, his/her first appearance (including the date of that publication), status (such as hero or villain), real name (if applicable), occupation, base of operations, height, weight, eye \& hair color, and any special powers/abilities. Each entry includes a history of the character. Besides being found in alphabetical order, the characters are also listed in a thorough index. Throughout the book, there are a series of two-page spreads providing short essays on key elements: Amazing Vehicles, Amazing Weapons, Amazing Bases, Alien Races, Great Team-Ups, Romantic Moments, Great Battles, and Strange Times and Places. For a reader interested in DC Comics, this book is a wealth of information.

\section{MarvelDirectory. (2014).}

Retrieved from marveldirectory.com

This website is a repository for all things related to Marvel Comics publications. The site is primarily an online encyclopedia, with tabs providing entries for individual characters, groups and teams, alien races, locations (both fictional creations and non-fictional uses of real places within a fictional context), other dimensions (the use of alternative worlds within the fiction of Marvel Comics), strength levels (as established within stories), miscellaneous (a potpourri of items which do not fit into other tabs, such as headquarters and vehicles for teams, the lost continent of Atlantis, armor for the superhero Iron Man, etc.), and a glossary (with brief definitions taken from the Official Handbook to the Marvel Universe, a limited issue comic series published in the 1980s), downloads of images and game codes for video games related to Marvel Comics. There are also tabs, with the pages stating "coming soon" for information on the Movie-Verse of Marvel Comics adaptations and for a store selling items related to the information in the directory. Within these tabs, there are other pages which simply state "Coming Soon," as the website is very much a work in progress; the links found in the locations section (which starts with a hyper-linked world map) are currently more likely to be under construction than ready. Despite some limitations, including the fact there is not an easy-to-use search box requireing site users to know exactly which category their search item might fall under or have the luck to choose the right spot), this website is a very interesting resource with considerable information available. The site is primarily an encyclopedia but also has aspects of a dictionary and an atlas, making it a sort of "one-stop shop" for Marvel Comics reference materials.

Marvel encyclopedia: The definitive guide to the characters of the Marvel universe. (2006). New York, NY: DK Publishing. Like the DC Comics Encyclopedia (see above), this onevolume encyclopedia gives detailed entries for fictional 
characters in the Marvel Universe. Each alphabetical entry for the characters provides an illustration and a short history, along with entries of key data on the figure (Real Name, if applicable, Occupation, Base, Height, Weight, Eyes, Hair, First Appearance, and Power). This volume features both alphabetical order for all character entries and a complete index. Interspersed throughout the book are two-page spreads detailing the publisher's history in each decade from the 1960s through the 2000s, respectively. This reference is an important volume for any reader looking for information on Marvel Comics.

Rovin, J. (1985). The encyclopedia of superheroes. New York, NY: Facts on File.

The scope of this encyclopedia is much broader than just comic books, but Rovin's work has a heavy emphasis on graphic creations. The book is an encyclopedia of over 1,300 characters (from comic books \& strips but also throughout literature, TV, film, and video games), with each alphabetic entry giving the character's name, appearances (noting the media in which the hero has been seen), alter ego (if applicable), first appearance, occupation, costume, tools and weapons (if applicable), and character biography, along with a characteristic quotation and a short comment section (often including a history of further appearances). The book features an impressive assemblage of characters, including appendices detailing information on superhero teams, "obscure or borderline" superheroes from the Golden Age of comics, foreign superheroes, minor superheroes (those who have appeared only once or in subordinate roles, including characters used in parodies and advertisements), and characters featured in the series Dial 'H' for Hero (a comic in which its protagonists become new and different superheroes with each issue). The reference work's introduction includes an interesting discussion of the concept of the superhero (and how the book chose to define characters for their inclusion in the encyclopedia), tracing the idea from ancient civilizations through modern comic books.

Rovin, J. (1987). The encyclopedia of supervillains. New York, NY: Facts on File.

A companion volume to The encyclopedia of superheroes, this sequel reference is an examination of the superpowered counterparts to the first book's heroic leads. Like that volume, each alphabetic entry gives the character's name, media in which he/she appears, real name, first appearance, costume description, weapons and chief henchmen (if applicable), character biography, a characteristic quotation (when available), and a short comment about the character's ongoing appearances and legacy. The entries for this work tend to be shorter than in the heroic book, allowing more villains to be profiled. The scope of this work covers many media, but the majority of entries come from the annals of comics. This work contains one appendix, detailing super-villain teams. Rovin also begins this collection with a thoughtful introductory essay about the nature of the super-villain in culture.

Rovin, J. (1994). Adventure heroes: Legendary characters from Odysseus to James Bond. New York, NY: Facts on File. The third volume by Rovin (see two previous entries), this encyclopedia covers the broadest territory, as adventure heroes are found in far more works and permutations than characters defined by superpowers. As with the other volumes, each alphabetic entry identifies the media in which the character has appeared, that character's first appearance, a fictional biography, and a short commentary (normally detailing the production and/or publication history for the figure). The reference work actually profiles fewer characters (the book boasts it has entries for more than 500) than either of the other volumes, but it does cover more far-reaching types of stories, having expanded its scope to include opera, folklore, and stage plays. Readers interested in the intersection of comics and other forms will find this an interesting encyclopedia. Perhaps one of its odder features, however, is its choice to alphabetize by first name, so that James Bond is under "J" and William Tell under "W," rather than "B" and "T," respectively; however, once readers realize this method the use of the text is simple. Once again, the introductory essay is an interesting overview of the topic.

\section{Dictionaries}

Cowsill, A. (2015). Marvel the Avengers: The ultimate character guide. New York, NY: DK Publishing.

This is an illustrated "biographical dictionary" of sorts that contains information on over 200 Marvel characters. Each character is given a short 100- to 200-word biography, as well as listing physical statistics and a 7-point ranking system for each character's attributes. The information breakdown is similar in brevity and content to a baseball card.

Don Markstein's Toonopedia. (2015). Retrieved from http://www.toonopedia.com/

This site is a sort of "biographical dictionary" for fictional characters. Toonopedia contains information for not just comic book and graphic novel characters, but 
also comic strip and cartoon characters. This website serves users who are curious as to the fictional "biography" of characters as well as background information of each character's creation. The website also lists the character's first appearance, publisher, medium (comic book, comic strip, cartoon series), and creator. Unfortunately, the website has not been updated in a few years, so new information about characters and information about new characters have not been provided. However, since this website focuses on the history of characters and their creation, the information is still very valuable.

\section{Ready-Reference}

Anchors, W. (Ed.). (1995). The superhero illustrated guidebook: A review of classic superhero television series. Dunlap, TN: Alpha Control Press.

A collection of episode guides for fantastic television series, this book collects material originally printed in Epi-Log, a fan-driven publication of episode guides and histories of science-fiction and fantasy series. This volume focuses on television series featuring super heroes, providing information on programs which adapt comic books to television and of series created for television (with several of these programs then adapted as comic books). Each guide features a synopsis of each episode, along with filmographic credits for each installment. Some of the series are also detailed in short essays about their production and history. Of particular interest to comic book readers are the essays provided alongside the episode guide for the original TV series The Flash, which detail the history of transferring the character from the comic book page to the small screen and which review the rogues gallery for the show, giving particular attention to how these villains relate to their comic book counterparts; the episode guide concludes with a discussion of an un-filmed script for the series. This reference work is a thorough example of studying the super hero in another medium.

Rogers, T. (1992). The super-hero photo guidebook. New York, NY: Image Publishing.

Rogers' visual guide to a myriad of television and film productions featuring super-hero characters offers over 150 images of these fantastic characters, along with brief filmographic information on the productions, along with a short explanation of the powers (if any) exhibited by the characters. Because the topic for this reference is super heroes, it is not limited solely to comic book adaptations, but the majority of the characters depicted have their roots in graphic fiction, and this volume is a good, though dated, resource.
Campbell, T. (2006). A history of webcomics v 1.0 - "the golden age": 1993-2005. San Antonio, TX: Antarctic Press. As the Internet has grown, so too has its influence on graphic novels. This reference, which takes a tongue-incheek approach to its subject, details the early history of web-based comics, many of which have since been printed and bound in traditional published formats. This volume is an effective overview of a burgeoning (and evolving) industry.

Daniels, L. (1991). Marvel: Five fabulous decades of the world's greatest comics. New York, NY: Harry N. Abrams.

Comics historian Les Daniels follows the history of Marvel Comics, one of the two largest comic book publishers in the world. The book actually begins with the earliest history of comic books and contextualizes the development of the Marvel imprint. Throughout this chronological approach, Daniels offers a series of encyclopedic entries for important characters created by the publisher, providing "Super Hero Profiles" of famous figures. The final chapter includes reprints of some classic stories from the first half-century of Marvel.

Daniels, L. (1995). DC comics: Sixty years of the world's favorite comic book heroes. Boston, MA: Bulfinch Press.

In a pseudo-companion volume to his book on Marvel, Les Daniels traces the history of DC Comics. Like the other book, this history is a very image-heavy book, as befits a reference on an art-driven medium. It features a series of short entries arranged in chronological order and with strong resources about the movement of comic books (through adaptations for film, television, and radio, as well as through merchandise) into the mainstream pop cultural world. This volume includes information on international publications of DC Comics characters and books, but its chief focus (and interest for the reader) is on the prevalence of DC Comics throughout the United States.

Cowsill, A., Irvine, A., Manning, M., McAvennie, M., \& Wallace, D. (2010). DC comics: Year by year-a visual chronicle. New York, NY: DK Publishing.

Using a "year by year" approach, this pictorial reference traces publisher DC Comics from 1935 and its genesis through the twenty-first century. Each year has a capsule overview before months and important publications are highlighted within each section. The selections of titles to represent key points for each year allows for otherwise forgotten issues to be illustrated for readers. Obviously, this focuses on the one publisher in its material, and that 
telescopic approach may be its one limitation, as entries do not necessarily reflect broader publishing issues of the times or possible reactions DC Comics had to its competitors to drive some of the trends exhibited.

Hofius, J., and Khoury, G. (2010). Age of TV heroes. Raleigh, NC: TwoMorrows Publishing.

Hofius and Khoury's volume is an impressive review of the televised adventures of comic book characters. After starting with a detailed "Comic Book-to-TV Hero Timeline," the reference breaks into sections based on the comic characters being adapted, with each chapter giving an overview and details about the productions which have brought these comic book figures to television. The book is concerned with live-action productions, and it impressively relates the stories behind the scenes, with background information on the transformation of comic books into a new medium. Three special sections ("Commercial Breaks") are interspersed in the book, detailing children's TV hosts who donned superhero personas, the 1980s comic-book inspired series The Greatest American Hero, and a 1970s live-action water show, "A Salute to the Super Heroes." These interludes reveal the far-reaching influence of comic books, while the entire book is a visual and textual wealth of information about the legacy of the super-hero through television and beyond.

\section{McCloud, S. (1993). Understanding comics: The invisible} art. New York, NY: HarperCollins.

Readers seeking a greater understanding of techniques and styles used to produce comic books should read McCloud's book. This book about the ways to create graphic novels is a graphic novel itself, with all of the information presented in a sequential art form, with a character representing the author narrating to the reader (through panels and word balloons) just what he or she is reading and explaining how the art of comics is produced (and how that art produces its narrative effects). Along with its short history of the medium and explanation of artistic practices, the book features a vocabulary for comics.

Hofstede, D. (1991). Hollywood and the comics: Film adaptations of comic books \& strips. Las Vegas, NV: Zanne-3. Though it is clearly dated today, this reference volume is the earliest published resource on comic adaptations for film and television, and, as such, it is a noteworthy effort to collect information on many productions. Arranged in alphabetical order, the volume provides overviews of more than fifty theatrical films and made-for-television movies. Each entry includes a cast list, a synopsis of the movie, a short review essay with a rating (based on a four-star system), and brief filmographic information (year of release, director, screenwriter, producer, studio, running time, and credits for the film's music, along with the now clearly-dated information on whether or not the production is available on videocassette). The final chapter (titled "And There's More...") details a variety of films which were not, at that time, available for home video, in a quick series listing movie serials, film shorts, (failed) TV pilots, and a few television series not discussed elsewhere.

Burke, L. (2008). The Pocket essential superhero movies. London, England: Oldcastle Books.

As its name implies, this book is a short ready reference volume about films based on comic books and superhero characters. The book is broken into chapters that separate the films by type, but it also is an effective source which gives detailed synopses of these films with overviews of the source material and trivia about each production. Although it is a fairly recent book, it is limited in that a significant number of blockbuster films based on comic books have come since this book's publication, and it could certainly stand an updated edition.

Overstreet, R. M. (2014). The Overstreet comic book price guide \#44. New York, NY: Gemstone Publishing.

The Overstreet Comic Book Price Guide is an annual publication which began with a singular purpose (to catalog current prices for issues of comic books, thus serving as a price reference for collectors). However, over the years it quickly evolved into a more thorough publication with a broader purpose. Each year, the guide is published with updated pricing information, but it also includes essays about comics history, galleries of covers, publication information on comics dating from the beginning of the medium's history (and even including data about books which were published before the recognition or naming of the genre, with facts about "proto-comic books" from early eras), and trivia related to individual issues of comics (such as notes about the appearances, in cameos and larger roles, of specific characters, or the first work by a writer or artist on a book, and even offering notes about guest artists or even ghost work by writers and artists who went un-credited at the time of publication but are now known to have worked on that issue). The latest volume of Overstreet (with Robert Overstreet's work prevalent enough that his name now functions, like Roget's, to identify his reference volume) includes, along 
with the data and prices by issue of comic titles, essays on the $75^{\text {th }}$ Anniversary of Batman and a history and overview of rare Canadian comics. For many collectors, given the volatile nature of the comic "back issue" market, this text serves more effectively as a reference for publication information and other similar facts than an absolute pricing guide (particularly with the more-immediate options available to check on the internet for online auctions and sales), though both aspects make it an important almanac of comic book information.

Schoell, W. (1991). Comic book heroes of the screen. New York, NY: Citadel Press.

An erudite overview of film and television adaptations of comic books, Schoell's history is an engaging reference which reveals both comic publication history and the popular culture effects of recreating comics on the screen (both silver and small). The chapters are organized around characters, with chronological approaches within each chapter. Four sections are devoted to single (and significant) figures in comics/comic book adaptation history: Superman, Batman, Captain America, and Captain Marvel. (Within these chapters, related productions and spinoffs are also presented and discussed.) The remaining sections then cover "Other Heroes" (those characters who, at the time of this book's early publication, had only had a few productions based on their comic books; in an updated edition, these characters would most likely have separate chapters devoted to their different adaptations), "Super-Heroic TV Shows" (revealing the influence of comic books through series which are clearly inspired by super-heroic stories), "Comic Book Cliff-Hangers" (the comic book-based and inspired serials from the 1930s $\&$ 1940s), and "Bring on the Heroes" (revealing the continued influence of comic books by detailing more recent films inspired by comic books). The book ends with a brief filmography and a brief "select bibliography" of further sources on the topic.

\section{Biographies}

Horn, M. (Ed.). (1986). Contemporary graphic artists: A biographical, bibliographical, and critical guide to current illustrators, animators, cartoonists, designers, and other graphic artists. Detroit, MI: Gale.

This three-volume reference set provides alphabetic entries on those responsible for the illustrative components of comic books and graphic novels. Each entry includes personal biographical information (including education/ training for the artists and studios, as applicable), career information, any exhibitions for the artists' respective work, awards \& honors won, a short list of biographical and critical sources for each artist, and "Sidelights," a section of further information about the artist, including trivia, as well as work the artist might have done (such as for posters or other advertisements) which is not as readily available. The first volume contains an overview of the graphic arts, wherein Horn offers a history of illustration. Perhaps the most intriguing feature of this series is that each volume contains entries for artists, A-Z, with different artists discussed in each (i.e. the first volume does not cover from $\mathrm{A}-\mathrm{H}$, then the second I-P, then the third Q-Z; instead, each volume has sections for each letter of the alphabet, with the alphabetized listing starting over each time). There is a cumulative index, telling which artist is found in which volume. The effect is that each volume can feel self-contained, but it also points to the ever-growing field of graphic art, as it shows the potential continually to expand lists of significant contributors to comics.

Comiclopedia - Illustrated Artist Compendium. (2015). Retrieved from https://www.lambiek.net/comiclopedia.html This site provides biographical information on over 12,000 comic book artists and writers and is updated daily with new entries and updates to existing entries. In addition to biographical information on each artist, entries also include notable samples of artwork for each artist. Anybody interested in the artistic and creative side of comic books, and not simply the creations themselves, will find a wealth of useful information on this site.

\section{Geographical}

Atlas of the DC universe. (2015). Retrieved from

http://www.karridian.net/dcatlas.html

Combining information from the (long out-of-print) Atlas of the DC Universe (a supplement for a role-playing game based on DC Comics, published in 1990) and the comic book Secret Files: Guide to the DC Universe (an almanac-style comic offering reference information on fictional places, organizations, and characters from DC Comics, published in 2000), this geographic source provides information on the settings found in this publisher's works. The website has also updated its information as individual comic stories have offered further information on the locales for adventures. The site offers interactive maps of the world and the United States, and users can click on highlighted areas (or on regions of the US) for hyperlinks to entries about the places. This atlas is about the fictional countries and cities that have appeared in DC Comics, but the entries do connect these 
places to real-world analogues and near-by actual places. A nearby note at the bottom of the webpage asks readers to submit updates as they find them and acknowledges the challenge of being comprehensive, given the constant output of new issues of comic books. The difficulty in staying up-to-date is the main limitation for a reference of this type, though having a website (which can be updated fairly easily) allows easy updating, as needed and as available.

Hilgart, J. (2015). Comic book cartography. Retrieved from http://comicbookcartography.posthaven.com/

This site is no longer regularly updated, but it does contain official maps, blueprints, and schematics of lands, buildings, and technological items from both Marvel and DC. Anybody interested in the maps of the comic world would benefit from seeing some of the items posted on this website.

The secret geography of the DC universe: A really big map. (2011). Retrieved from http://ifanboy.com/articles/ the-secret-geography-of-the-dc-universe-a-really-big-map/ Offering a scanned map from the 1990 out-of-print Atlas of the DC Universe (a supplement for the DC Comics role-playing game, a spinoff from the comics), this website provides a geographic reference for the locations found in comic books from that publisher. The map can be zoomed in on with a click, but that is the limitation on any interactive features. However, it does provide scans of the full United States map and a sample of the map of the New England region. As this website simply reprints the map from the role-playing resource, it is more an historic map of a comics world than a current one, but it does provide a nice introduction to the geographic possibilities for this publisher.

\section{Government Documents}

Comic Book Legal Defense Fund. (2015). Retrieved from http://cbldf.org/

This website contains the history and text of all iterations of the Comics Code Authority, the internally governing document that dictated what could and could not be included in any widely distributed comic book. It also contains case files for notable obscenity cases and several other legal documents relating to free speech, obscenity, and comic books. Anybody interested in the legal history of comic books and censorship will find a bevy of information on the topic here.

\section{Documentary Sources}

Devine, S. \& Kenny, J.M. (Producers \& Directors). (2013). Necessary evil: Super-villains of DC comics. [Documentary]. Los Angeles, CA: Warner Home Video.

Narrated by Christopher Lee, this documentary examines the rich history of super-villains within the books produced by DC Comics. The film provides background and analysis on several key antagonists, with an emphasis on more recent appearances and characters. The documentary acknowledges the changing perceptions of many of these characters over the years.

Kantor, M. \& Rosenthal, S. (Producers), \& Kantor, M. (Director). (2013). Superheroes: A never-ending battle. [Documentary]. Washington, DC: PBS Direct.

This three-part documentary series traces the evolution of superhero characters and the comic book industry, with an overview of the change in perception of comics as a kid-based milieu into one enjoyed by readers of all ages (and as one which now produces multi-million dollar revenue. The series includes interviews with comics historians, industry insiders, including many writers and artists, and with personalities and actors associated with superheroes and comics and their related adaptations.

Welch, S, \& Eckholm, J. (Producer), \& Carter, M. (Director). (2010). Secret origin: The story of DC comics. [Documentary]. Los Angeles, CA: Warner Home Video.

A documentary detailing the history of DC Comics, this film provides a compelling overview of the publisher's history, with interviews with writers and artists from the company and insight from comics historians. The history touches on the origins of the medium and on some of DC Comics' competitors, but its primary strengths come in the presentations of images and illustrations from throughout the DC Archive. Narrated by Ryan Reynolds (who in that year starred in the DC Comics-based film Green Lantern), the documentary does provide a sort of advertisement for more recent adaptations, but it also offers views of a variety of aspects of DC Comics and its legacy.

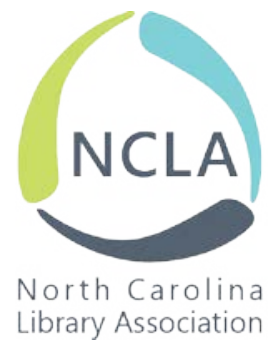




\section{Incorporating Branded Academic Library Programming to Promote and Showcase Campus Research and Artistic Performances}

$\mathrm{L}$ ibrary programming is an essential function of public libraries. On any given day, public libraries across the country are hosting a variety of programs for users of all ages and abilities. Programming connects users with public library staff, spaces, and materials. Historically, however, academic libraries have focused on the strength of their collections for connecting with users.

\section{What Others are Doing}

The Z. Smith Reynolds Library at Wake Forest University (WFU) incorporated branded library programming as one new area to emphasize our "third place" connection to campus. In seeking to know what other academic libraries have done regarding programming, it became clear that while academic libraries offer programming of a wide variety, ongoing programming

\section{6... academic libraries are proving their relevance to campus communities beyond being warehouses of knowledge.}

Presently, though, academic libraries are proving their relevance to campus communities beyond being warehouses of knowledge. Ray Oldenburg's concept of "third place" 1 inspired some to reframe the academic library to become their campus constituents' third place. Envisioning the library as a campus meeting place where everyone could come, listen, share and discuss ideas, current events, and one's research occurred simultaneously with library renovations that fostered group collaboration and study, casual spaces, and coffee shops. Bringing people into the building for more than the collections became a goal of many academic libraries, particularly those striving to maintain relevance in an ever-increasing digital knowledgebase. series were less common--at least as represented in published literature. This observation is confirmed by Timothy Hackman in his article about the creation of the University of Maryland Libraries' sponsored speaker series known as Speaking of Books... Conversations with Campus Authors. $\mathrm{He}$ states, "While the 'book talk' is a perennial favorite subject for public librarians, there is almost nothing published on the author talk in the academic library as a method of connecting with faculty." 2

Within the articles published on academic library lecture series, the authors commonly focused on lessons learned in planning, organizing, and successfully executing a successful library lecture event or series, as well as how these outreach initiatives help to integrate libraries more fully into the academic community of a university. ${ }^{3-10}$ As pointed out by Irene M. H. Herold, "nothing in library school or working as a front-line academic librarian provided preparation for event planning." 11

As organizers of two branded programs in an academic library, employees of the Z. Smith Reynolds Library (ZSR) present the following case study of the peaks and pitfalls of library programming, particularly in light of Herold's assessment that we were not, in fact, prepared for event planning in graduate school. Through nearly a decade of programmatic outreach, the logistics of coordinating and presenting a semesterly lecture series and annual student scholarship showcase have been honed.

\section{Branded Programming}

In 2004, Wake Forest University (WFU) hired a new library director who, shortly after her arrival, shared her desire for the ZSR Library to become more than just a place for students to study and a warehouse for books. One of her goals was to increase the Library's visibility on campus and to all of its constituents-administration, faculty, staff, and students. She envisioned ZSR as a campus meeting place where all are welcome to come and learn as well as share and discuss ideas, current events, and even one's personal research. In August 2005, a new Marketing Committee was established and charged with making that goal a reality. ${ }^{12}$ One idea presented by 
the committee was to host a series of lectures in ZSR, and with the director's approval, the committee moved forward. ${ }^{13}$

Eight lecture events and a musical performance by one of the University's all-male a cappella groups were hosted during the 2005-2006 academic year, and the response garnered, to what has now become known as the ZSR Library Lecture Series (ZSR LLS), was overwhelmingly positive and marked by excellent attendance from the Wake Forest community. ${ }^{14}$ It was not uncommon for members of the greater Winston-Salem community to be present in the audience. Due to its success, it was decided the ZSR LLS should continue the following academic year. In 2006-2007, ZSR Library's Marketing Committee sponsored and hosted 10 lecture series events. ${ }^{15}$

To reduce the load of the Marketing Committee, a separate Library Lecture Series Committee (LLSC) was formed in 2007. ${ }^{16}$ This new committee was given a new charge: "plan lectures and discussions that will support the current curriculum; address current issues and events; acknowledge and accentuate the current collection and bring together the many diverse points of view found in our community." 17

A second branded program at ZSR Library, the Senior Showcase, highlights exemplary undergraduate student research. Arising independently from the Library Lecture Series, the concept for the Senior Showcase was originally proposed by a WFU senior who wished to see greater recognition by the campus community for his fellow classmates' research. He believed the Library to be well-positioned to provide such recognition. Planning for the Showcase commenced in late January 2010, and the first annual Senior Showcase was presented in April 2010.

Support for the Senior Showcase grows each year, both in nominations and attendance. Each year, the pool of nominees includes representation from at least one new department, with 50 faculty from 23 departments nominating their students for the Showcase through 2015. Increasingly, the audience includes friends and family members of the selected students, in addition to WFU faculty and staff. The Provost, Vice Provost, Associate Provost for Research, and Dean of the College have attended, as well as the Dean and Associate Deans of the Library, lending invaluable administrative support to the Showcase program. The addition of the Library Auditorium has benefited the Showcase, as well as the Library Lecture Series, as it has provided a dedicated venue for both programs.

\section{Library Lecture Series: Logistics}

The number of ZSR Library employees on the LLSC varies, but typically six or seven individuals comprise its annual makeup, which includes a chair or two co-chairs appointed by ZSR Library's Associate Dean. When the LLSC began filming its lecture events as authorized by the speakers themselves, ZSR's Multimedia and Digital Production Services Coordinator became a permanent member of the LLSC. The Library's artistic Preservation Librarian, who designs and creates all publicity materials for the LLSC, has served as an ex-officio member since its beginning. Starting in 2010, the LLSC welcomed the Wake Forest Fellow, a paid internship position assigned to work in ZSR Library, as a new, standing member to its committee's roster.

Speakers who received an invitation from the LLSC to present on a specific topic or their recently published work or research have come from both the campus community (including students, faculty and staff) as well as the surrounding community of Winston-Salem and nearby localities. Most readily accepted the committee's invitation and appreciated the opportunity to share their knowledge in their areas of expertise. A few individuals declined their initial invitations to speak for various reasons, such as teaching abroad at one of WFU's overseas houses, taking a sabbatical, or even a prior commitment, but were willing to participate in the ZSR LLS the following semester. Notable participants have included Dr. Anthony Atala, Director of the Wake Forest Institute for Regenerative Medicine; Mike Riley, Chief Executive Officer and Editor in Chief of the Chronicle of Higher Education; and past North Carolina Poet Laureate, Joseph Bathanti.

As the popularity of the ZSR LLS has grown, the committee has been approached by individuals familiar with the series who would like to partner with the Library to present, for instance, a lecture about one of WFU's campus programs or a current exhibit. By partnering with the Library through the lecture series, these events received a level of exposure that they may not have had on their own.

Publicizing lectures has changed considerably from its beginnings. Press releases drafted by the lecture series committee for distribution to external media outlets, such as the WinstonSalem Journal, have been dropped due to changes in the external communication policy for the University. Today, lectures are promoted internally by means of email to the administrative assistants of all academic departments as well as library staff, paper flyers that are posted around campus by student assistants, a sandwich board in front of the Library, and postings to the University calendar and the Professional Development Center for the University. 
Programs for the lecture series have also been advertised through social media such as Facebook and Twitter. Additionally, bookmarks that include the lecture series' line-up for an entire semester are printed and distributed at all lectures and in specific locations throughout the Library.

Most events sponsored by the ZSR LLS have been traditional lectures, with individual presenters speaking about a subject in his or her area of expertise followed by a short question and answer period. However, other types of events have been hosted by the lecture series:

- Panel discussion. These have addressed specific topics with involvement by members from both inside and outside the WFU community, and have addressed current events as well as topics that could be deemed controversial. Topics for these discussions have included the Don't Ask, Don't Tell policy of the United States Armed Forces, food insecurity in Forsyth County, North Carolina, and the achievements made by women in the field of science and mathematics.

- Book signings. Several members of the WFU community as well as authors who were presenting in the Winston-Salem area have discussed their recently published books. A few of these have included book signings at the conclusion of the presentations, giving the audience a chance to purchase the book for themselves and to personally meet the author. Books have ranged from academic to mass marketed pressings, with a variety of authors including Emily Giffin, Lev Grossman, Joseph Bathanti, Deborah Harkness, Charlie Lovett, Shannon Gilreath, Gregory Parks, Blake Morant, and Margaret Supplee Smith.
- Art and performance. The visual arts have been represented by faculty in the Art Department, the director of the on-campus Charlotte and Philip Hanes Art Gallery, and staff from the nearby Reynolda House Museum of American Art. Musical performances have included faculty from the Music Department, a local jazz trio, and a bona fide local rock band who operated a music camp for children during the summer. There was even a live performance of the famed "balcony scene" from Shakespeare's Romeo and Juliet, with actors utilizing a portion of the Library's atrium while they delivered their lines.

The ZSR LLS has also included new types of events within its lineup as well as new methods of dissemination of its content such as streaming video for some of its events. The lecture series collaborated with other library committees to produce a one-day symposium called "The Big Disruption: The Coming Transformation of Higher Education." 18 Members of the LLSC used their collective experience to assist with the planning of the event and participation during the symposium itself.

\section{Budget}

Before 2012, the ZSR LLS operated without a budget, although this circumstance did not present any serious challenges to attracting potential speakers. In one sense, the University has lent itself as an unofficial "Speaker's Bureau." The LLS becomes not only a venue for faculty to publicize their research to the greater campus community, but also another means for faculty to add a service entry to their respective personal vitae. However, in one LLSC annual report to library administration, committee co-chairs remarked, "Although the lecture series was able to meet its goals with the programs for the 2010-2011 academic year, the committee has reached a plateau for what could be achieved without sources of funding. As a result, this prevents the committee from bringing in speakers who in turn could attract a larger audience." ${ }^{19}$ In response to these statements, ZSR Library's Dean (formerly titled director) earmarked a small amount of funds from the Friends of the Library account to be used at the discretion of the cochairs for expenses incurred (e.g. refreshments or speaker fees) by the ZSR LLS until continual funding was obtained. ${ }^{20}$

The nature of the lecture series has not been one where outside funding sources would be necessary. Because the speakers have been available on campus and in the surrounding area, their presentations were done on a volunteer basis with the recognition being an entry on their personal documentation. The ZSR LLS has not hosted any significant speakers outside of the campus community who have requested compensation for their appearances, so there has been no need to pursue any grant programs to sponsor a famous author or lecturer. However, this possibility could be explored with external programs, such as those sponsored by the American Library Association as mentioned in an article by Smith, Hunter and Eckwright or the National Endowment for the Humanities, if circumstances warranted that outcome. ${ }^{21}$

As previously mentioned, the ZSR LLS has hosted a few New York Times bestselling authors (e.g. Lev Grossman, Deborah Harkness) via the Authors in Schools \& Community program sponsored by Bookmarks, a local, nonprofit literacy organization which produces the annual Festival of Books and Authors held in Winston-Salem, North Carolina. ${ }^{22}$ Organizational 
connections made by several members of ZSR Library's staff, who are also Bookmarks' volunteers, allowed the Library the opportunity to provide a venue for a few of Bookmarks' sponsored book talks and signings.

\section{Challenges}

Along with its popularity, success, and longevity, the ZSR LLS has faced challenges in several areas: scheduling, speakers, planning the series, and space.

When the ZSR LLS began to promote itself as a series at the beginning of each semester, the previous methodology of event planning and scheduling of speakers had to change. The LLSC started thinking in terms of long-range planning (i.e. a semester in advance) as opposed to planning for a singular event whenever an opportunity for an event or idea presented itself. As a result, spring lecture series events were planned during the fall semester, and fall events were planned during the spring and sometimes even into the summer months. This long-range planning required committee members to regularly check the University's calendar, as new events are posted on a daily basis. Active participation by the LLSC is also needed on the day of lecture events in order to fulfill roles such as directing foot traffic, counting attendees, assisting with the needs of speakers, and recording events.

Most speakers, as mentioned before, have readily accepted the committee's invitation to speak and responded within a day or two regarding their availability. However, if the initial invitation generated no response from a potential speaker, then additional emails have followed in order to determine that speaker's interest to present at the lecture series. Should those subsequent emails remain unanswered, it has been understood that this inaction is essentially a "thanks, but no thanks" response from the potential speaker. Persistence often pays off with receiving a response from the potential speaker, but committee members have been mindful not to appear overbearing in a manner that would alienate the speaker from participating in the series entirely.

Wake Forest University's calendar is filled with a broad range of departmental and university sponsored events from which the campus community can choose to attend. Scheduling a date and time that has been convenient for a speaker without conflicting with other campus events can often be difficult. ZSR LLS sponsored events have been presented Monday through Friday, beginning between 2:00 p.m. and 5:30 p.m. On a rare occasion, the ZSR LLS has hosted a few lectures during the noon to 1 p.m. lunchtime hour. Flexibility is also key in scheduling lecture events because a speaker-or the Library or University-may have a conflict arise which necessitates rescheduling. Conflicts can often occur without any advanced warning, so contact with the speaker has been essential for accommodating these changes.

While there has been little difficulty in finding individual speakers, there have been challenges with coordinating a panel of speakers. Panel discussions can be especially difficult to schedule, as the event coordinator needs to find a specific date and time when all invited panelists are available to participate. Further, if one panelist is forced to cancel his or her appearance, it has been nearly impossible, in our experience, to find a replacement at a moment's notice. A panel's diminished size could also lead to underrepresentation of alternative viewpoints which could potentially create an unbalanced discussion. If this situation should occur, an acknowledgment regarding the absentee panelist should be given by the moderator before the panel discussion begins.

The issue of space was a huge challenge faced by the LLSC when scheduling lectures. Initially, three library venues were used for lectures, and each had its own set of problems. Inadequate space, seating, and furnishings as well as student displacement-these issues combined clearly demonstrated a need for a permanent and designated space where the ZSR LLS sponsored events could be held. Following graduation ceremonies in May 2011, construction of a 118-seat Library Auditorium commenced, alleviating all of the space issues faced by the LLSC. Opening that September, the ZSR LLS "had a permanent location to showcase its programming." 23

\section{Senior Showcase: Logistics}

Senior Showcase nominations are solicited from faculty in mid-February and submitted in mid-March. The extant list of faculty receiving the Library's e-newsletter is leveraged to disseminate the call for nominations. Nominations are submitted online, via a web form that includes free text fields for explanation.

In the nomination, faculty advisors speak to the originality of the work, the potential impact of the work upon the field, and the overall worthiness of the work to merit distinction. ${ }^{24}$ Students are notified of their nominations after the submission deadline has passed, and have one week to submit a copy of their work for review. The review panel consists of five library faculty, one for each division of the undergraduate College.

Reviewers evaluate submissions using three categories of criteria: Research, Presentation, and Impact. Under Research, works are assessed for their clear statement of purpose, evidence of thorough research, credible 
sources, and development of the idea. The Presentation criteria cover both written works — well-organized, wellwritten, and soundly reasoned-and artistic works - skills/aptitude, and interpretation-in recognition that honors projects from the Arts may be completed in a variety of mediums of expression. The final category, Impact, looks to the works' originality, creativity, and importance to the field, with emphasis on the strength of the faculty advisor's recommendation, summarizing the Impact criteria. From student submission to student notification, the review panel has approximately two weeks to review and assess all nominations.

The Showcase is coordinated by the Scholarly Communication Librarian, and became a part of this position's job responsibilities in the first year of the position's establishment at ZSR Library. As such, communications, reviewer recruitment, nominations and work submissions, meetings, and the Senior Showcase itself are all coordinated by one individual. Each year, the framework used for organizing Showcase logistics has been adjusted to streamline workflows, particularly with regard to the reviewers' time commitments to review meetings, and to ensure that the work required to host the Showcase remains manageable over the course of the spring semester. Although the Showcase is always held in mid-to-late April, planning commences in October with determining dates and recruiting reviewers.

\section{Budget}

The Senior Showcase began without a budget. As a student-initiated program, pitched to the Dean of the Library, the Showcase benefited from administrative support from inception, but in a library known for its entrepreneurial spirit, that support did not equate to a budget. A small amount of money was allocated toward refreshments for a reception following the Showcase, which were purchased at a local grocery store using a purchasing card from the University.

In the second year of the Showcase, the Undergraduate Research and Creative Activities Center of the University began sponsoring the reception that follows the Showcase, and assisting with ensuring the call for nominations reaches the attention of faculty working with undergraduate researchers. And since 2013, the Library has awarded each Showcase winner a $\$ 1,000$ prize in additional recognition of his or her accomplishment. ${ }^{25}$ Currently, the $\$ 5,000$ prize money is drawn from the Library's general budget. The hope is that the Senior Showcase will become an endowed program within the Library, ensuring the continued celebration of undergraduates' honors research.

\section{Challenges}

As with any program, the Senior Showcase is not without its share of challenges. One of the biggest challenges is timing, particularly working within a narrow timeframe between the nomination deadline and the decision deadline. Wake Forest University does not have an honors college or unified honors program; therefore, the requirements for undergraduate honors theses and projects vary across departments. This creates discrepancies in the number of eligible students in different disciplines. As was expected, some faculty have leveled criticism at the Showcase for the timeframe for eligibility. Reassuringly, though, other faculty offered constructive advice on how the Showcase timeframe could be adjusted to expand eligibility to more students and departments. The timeframe established for the Showcase will never fully accommodate all departments' schedules, which is an unfortunate reality; however, it is generally understood among faculty that the Showcase is striking the best possible balance between delaying the nomination deadline with giving the selected students sufficient time to prepare for a campus-wide presentation for which they were previously not expecting to present. Furthermore, student works do not have to be finalized in order to be considered, which expands eligibility to disciplines with late spring honors project deadlines.

Beyond knowingly constraining our potential field of nominees, the timing of the Showcase puts pressure on the reviewers to complete thorough reviews of an unknowable number of projects in 10 to 12 days. Students' works are due on a Friday, and final decisions are usually made by little more than a week later. Depending on the number of nominees, reviewers may need several hours to read and evaluate the body of student works. A two-to-three hour selection decision meeting is usually necessary to arrive at final decisions.

Timing during the academic year creates additional challenges for the Showcase. In order to enable the broadest possible nominee pool, nominations are not due until the Friday of spring break, which falls the second full week of March each year. Students have until the following Friday to submit their works for review. As the Showcase is normally held on the third Tuesday of April, which is a week to 10 days before the last day of classes, reviewers strive to give students at least three weeks to prepare their Showcase presentations, as students were not anticipating a campus-wide presentation in their study scheduling. The Tuesday afternoon, 3:00 p.m. start time for the Showcase generally reduces competition with other campus programs, but also limits the ability of 
faculty and students to attend, as many classes are held well into the afternoon. However, shifting to an evening program, or even a later afternoon program, would place the Showcase in greater competition for campus attendance.

\section{Conclusion}

The creation, success, and longevity of the Z. Smith Reynolds Library's branded library programming increases ZSR's visibility on Wake Forest University's campus and solidifies the Library as the "third place" of campus life, offering another venue for students, faculty, and staff to meet and interact around a unique framework of programming. Increases in programming budgets and participation by campus constituents attest to the importance and value of both branded programs. Additionally, the programs' brand recognition has aided in the fostering of partnerships with other campus departments, and has created opportunities for ZSR Library to work with units of the University outside of the traditional academic environment, positioning the Library as an outlet for the output of specific subjects to be presented to a much wider campus audience.

Tracked since the fall of 2009, over 3,000 individuals have attended ZSR LLS events, with the average lecture attracting an audience of at least 25 people. Eleven lectures were presented during the 2014-2015 academic year, bringing 455 people into the Library, with an additional 90 viewers through live-stream. Presentation and discussion of current, and at times controversial, topics and events in an academic context deepened the conversation for many attendees, broadening awareness and understanding of research conducted by Wake Forest faculty.

The Senior Showcase has also quickly gained recognition as a campuswide platform for highlighting the culminating scholarly experience of Wake Forest undergraduates. As the former ZSR Library Dean observed at the April 2014 Showcase, the Senior Showcase is the final stage of a threestep process of engaging new students with programs, helping students succeed in their studies through instruction, and celebrating their scholarly achievements as they prepare to graduate. ${ }^{26}$

Academic libraries continue to play vital, yet increasingly non-traditional, roles in fostering scholarship as well as assisting in the development of critical thinking skills through the purchasing, collecting, and instructional support of numerous resources for their campus constituents. The creation of branded programming by academic libraries that highlights the combined output of our faculty and student scholars further elevates and focuses attention on the foundational support of libraries, demonstrating how academic libraries continue to be essential centers of scholarship in our campus communities.

\section{References}

${ }^{1}$ Ray Oldenburg, The Great Good Place: Cafés, Coffee Shops, Community Centers, Beauty Parlors, General Stores, Bars, Hangouts and How They Get You Through the Day (New York: Paragon House, 1989).

${ }^{2}$ Timothy Hackman. "Speaking of books... connecting with faculty through a campus author series," Electronic Journal of Academic and Special Librarianship 10, no. 1 (2009), http://southernlibrarianship.icaap.org.go.libproxy.wakehealth. edu/content/v10n01/hackman_t01.html (accessed August 23, 2014).

${ }^{3}$ Carole Ann Fabian and others. "Multiple models for library outreach initiatives," The Reference Librarian 39, no. 82 (2003), doi:10.1300/J120v39n82_04, http://search.ebscohost.com/login.aspx?direct=true\&db=aph\&AN=127988 26\&site=ehost-live (accessed September 6, 2014).

${ }^{4}$ Irene M. H. Herold. "Planning and executing an annual library lecture," Library Administration \& Management 20, no. 3 (2006): 131-134. http://search.ebscohost.com/login. aspx?direct=true\&db=llf\&AN=502888173\&site=eho st-live (accessed August 23, 2014).

${ }^{5}$ Michele C. Russo and Nancy Wootton Colborn. "Something for (almost) nothing: public relations on a shoestring in an academic library," Library Administration \& Management 16, no. 3 (2002): 138-145. http://search.ebscohost. com/login.aspx?direct=true\&db=llf\&AN=502883323\&site=ehost-live (accessed August 23, 2014).

${ }^{6}$ Justine Cotton and Heather Pfaff. "The secret lives of professors: connecting students with faculty research through a faculty lecture series,” Feliciter 55, no. 6 (2009): 254-256. http://go.libproxy.wakehealth.edu/login?url=http:// search.ebscohost.com/login.aspx? direct=true\&db=llf\&AN=502970635\&site=ehost-live (accessed August 23, 2014).

7 "Case study: University of Texas at Arlington, Arlington, TX," in Library Success: A Celebration of Library Innovation, Adaptation and Problem Solving, ed. Leslie Edmonds Holt, Glen Holt, and Stratton Lloyd (Ipswich, MA: Ebsco, 2006), 100-102. http://search.ebscohost.com/login.aspx?direct=true\&db=lih\&AN=30063607\&site=ehost-live (accessed August 23, 2014). 
${ }^{8}$ Cathy Carpenter. "Transforming the Georgia Tech Architecture Library into a social space," Art Documentation: Bulletin of the Art Libraries Society of North America 30, no. 1 (2011): 79-83. http://search.ebscohost.com/login.as px?direct=true\&db=llf\&AN=503013562\&site=ehost-live (accessed August 23, 2014).

${ }^{9}$ Catherine Soehner, Christy Hightower, and Wei Wei. "Changing mission, strengthened focus: a new use for the current periodicals room at the University of California, Santa Cruz," Issues in Science \& Technology Librarianship no. 44 (2005), doi:10.5062/F48913T2, http://www.istl.org/05-fall/article2.html (accessed August 23, 2014).

${ }^{10}$ Rochelle Smith, Ben Hunter, and Gail Z. Eckwright. "Open house in the ivory tower: public programming at an academic library," Electronic Journal of Academic and Special Librarianship 10, no. 2 (2009), http://southernlibrarianship. icaap.org.go.libproxy.wakehealth.edu/content/v10n02/smith_r01.html (accessed August 23, 2014).

${ }^{11}$ Herold, 134.

${ }^{12}$ Renate Evans. “'O This Learning, What a Thing It Is!,” Library Gazette 18, no. 4 (2006): 7-8. http://zsr.wfu.edu/ files/library-gazette-2006.pdf (accessed June 18, 2014).

${ }^{13}$ Mary Scanlon (Research and Instruction Librarian for Business and Economics, former Chair of Z. Smith Reynolds Library Marketing Committee), in discussion with co-author Carolyn McCallum, June 18, 2014 in Z. Smith Reynolds Library, Winston-Salem, NC.

${ }^{14}$ Evans, 8.

${ }^{15}$ ZSReads newsletter (Fall 2006) http://zsr.wfu.edu/term/zsreads-fall-2006/ (accessed September 13, 2014); ZSReads newsletter (Winter 2007) http://zsr.wfu.edu/term/zsreads-winter-2007/ (accessed September 13, 2014).

${ }^{16}$ Scanlon discussion.

17 “Library Committees." http://zsr.wfu.edu/about/committees/ (accessed July 16, 2014).

18 "Future of Higher Education Symposium-The Big Disruption: The Coming Transformation of Higher Education," http://zsr.wfu.edu/outreach/future-of-higher-ed/ (accessed September 18, 2014).

${ }^{19}$ Christian Burris, e-mail message with attachment "LLS 2010-2011 Annual Report" written by Christian Burris and Carolyn McCallum to Carolyn McCallum, September 28, 2012.

${ }^{20}$ Lynn Sutton, e-mail message to Kristen Morgan, Christian Burris, Carolyn McCallum, Wanda Brown, and Susan Smith, June 17, 2012.

${ }^{21}$ Smith, Hunter, and Eckwright, http://southernlibrarianship.icaap.org.go.libproxy.wakehealth.edu/content/v10n02/ smith_r01.html

22 "Authors In Schools \& Community." http://bookmarksnc.org/authors-in-schools (accessed March 23, 2016).

${ }^{23}$ Christian Burris, e-mail message with attachment "LLS 2011-2012 Annual Report" written by Christian Burris and Carolyn McCallum to Wanda Brown, Susan Smith, Lynn Sutton and Carolyn McCallum, June 15, 2012.

24 “Senior Showcase," Z. Smith Reynolds Library website, http://zsr.wfu.edu/events/senior-showcase/, (accessed July 15, 2014).

25 "Highlights from the Fourth Annual Senior Showcase." ZSReads newsletter (Summer 2013), http://zsr.wfu.edu/2013/ highlights-from-the-fourth-annual-senior-showcase/, (accessed July 15, 2014).

${ }^{26}$ Hubert David Womack, Susan Sharpless Smith, and Mary Beth Lock. "Large-scale, live-action gaming events in academic libraries: how and why," College \& Research Libraries News 76, no. 4 (2015): 210-214. http://crln.acrl.org/ content/76/4/210.full (accessed June 30, 2015).

\section{Selected Bibliography}

Bookmarks, "Authors In Schools \& Community," http://bookmarksnc.org/authors-in-schools.

Carpenter, Cathy. "Transforming the Georgia Tech Architecture Library into a social space," Art Documentation: Bulletin of the Art Libraries Society of North America 30, no. 1 (2011): 79-83. http://search.ebscohost.com/login.aspx?direct $=$ true $\& \mathrm{db}=11 \mathrm{f} \& \mathrm{AN}=503013562 \&$ site=ehost-live (accessed August 23, 2014).

"Case study: University of Texas at Arlington, Arlington, TX," in Library Success: A Celebration of Library Innovation, Adaptation and Problem Solving, edited by Leslie Edmonds Holt, Glen Holt, and Stratton Lloyd, 100-102. Ipswich, MA: Ebsco, 2006. http://search.ebscohost.com/login.aspx?direct=true\&db=lih\&AN=30063607\&site=ehost-live (accessed August 23, 2014).

Cotton, Justine, and Heather Pfaff. "The secret lives of professors: connecting students with faculty research through a faculty lecture series,” Feliciter 55, no. 6 (2009): 254-256. http://search.ebscohost.com/login.aspx?direct=true\&d 
$\mathrm{b}=1 \mathrm{ff} \& \mathrm{AN}=502970635 \&$ site=ehost-live (accessed August 23, 2014).

Evans, Renate. “'O this learning, what a thing it is!,” Library Gazette 18, no. 4 (2006): 7-8. https://zsr.wfu.edu/files/ library-gazette-2006.pdf (accessed June 18, 2014).

Fabian, Carole Ann, Charles D’Aniello, Cynthia Tysick, and Michael Morin. "Multiple models for library outreach initiatives," The Reference Librarian 39, no. 82 (2003). http://search.ebscohost.com/login.aspx?direct=true\&db=ap h\&AN=12798826\&site=ehost-live (accessed September 6, 2014).

Hackman, Timothy. "Speaking of books... connecting with faculty through a campus author series. Electronic of Academic or Special Librarianship 10, no.1 (Spring 2009). http://southernlibrarianship.icaap.org.go.libproxy. wakehealth.edu/content/v10n01/hackman_t01.html (accessed August 23, 2014)

Herold, Irene M. H. "Planning and executing an annual library lecture." Library Administration \& Management 20, no. 3 (2006): 131-134. http://search.ebscohost.com/login.aspx?direct=true\&db=llf\&AN=502888173\&site=eho st-live (accessed August 23, 2014)

"Highlights from the Fourth Annual Senior Showcase." ZSReads newsletter (Summer 2013), http://zsr.wfu.edu/2013/ highlights-from-the-fourth-annual-senior-showcase/ (accessed July 15, 2014).

“Library Lecture Series," ZSReads newsletter (Winter 2007) http://zsr.wfu.edu/term/zsreads-winter-2007/ (accessed September 13, 2014).

Oldenburg, Ray. The Great Good Place: Cafés, Coffee Shops, Community Centers, Beauty Parlors, General Stores, Bars, Hangouts and How They Get You Through the Day. New York: Paragon House, 1989.

Russo, Michele C., and Nancy Wootton Colborn. "Something for (almost) nothing: public relations on a shoestring in an academic library," Library Administration \& Management 16, no. 3 (2002): 138-145. http://search.ebscohost. com/login.aspx?direct=true\&db=llf\&AN=502883323\&site=ehost-live (accessed August 23, 2014).

Scanlon, Mary. 2014. Interview by Carolyn McCallum. June 18. Z. Smith Reynolds Library, Winston-Salem, NC.

Smith, Rochelle, Ben Hunter, and Gail Z. Eckwright. "Open house in the ivory tower: public programming at an academic library," Electronic Journal of Academic and Special Librarianship 10, no. 2 (Summer 2009), http:// southernlibrarianship.icaap.org.go.libproxy.wakehealth.edu/content/v10n02/smith_r01.html (accessed August 23, 2014).

Soehner, Catherine, Christy Hightower, and Wei Wei. "Changing mission, strengthened focus: a new use for the current periodicals room at the University of California, Santa Cruz," Issues in Science \& Technology Librarianship no. 44 (2005), doi:10.5062/F48913T2, http://www.istl.org/05-fall/article2.html (accessed August 23, 2014).

“2006-07 Library Lecture Series," ZSReads newsletter (Fall 2006) http://zsr.wfu.edu/term/zsreads-fall-2006/ (accessed September 13, 2014).

Womack, Hubert David, Susan Sharpless Smith, and Mary Beth Lock. "Large-scale, live-action gaming events in academic libraries: how and why," College \& Research Libraries News 76, no. 4 (2015): 210-214. http://crln.acrl.org/ content/76/4/210.full (accessed June 30, 2015).

Z. Smith Reynolds Library, "Future of Higher Education Symposium-The Big Disruption: The Coming Transformation of Higher Education," http://zsr.wfu.edu/outreach/future-of-higher-ed/.

Z. Smith Reynolds Library, "Library Committees," http://zsr.wfu.edu/about/committees/.

Z. Smith Reynolds Library, “Senior Showcase,” http://zsr.wfu.edu/events/senior-showcase/.

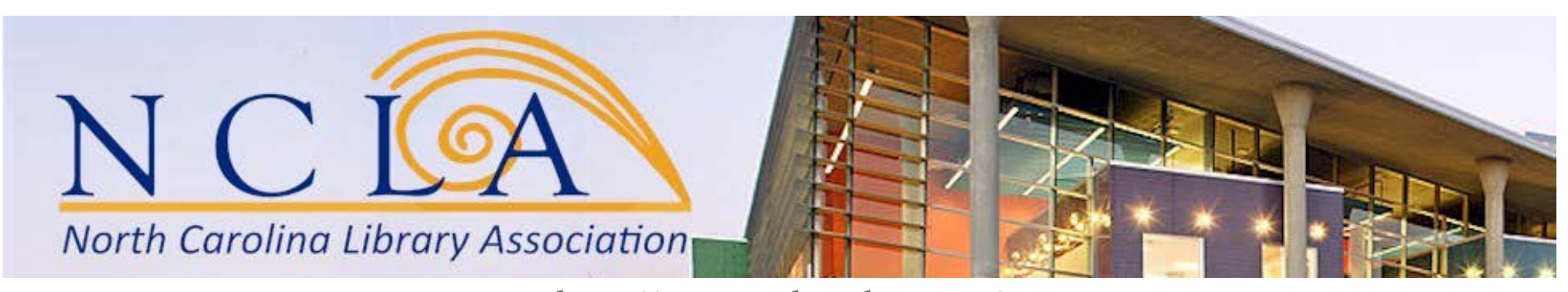

http://www.nclaonline.org/ 


\section{Why Should I Care?: RDA and Your Library}

$\mathrm{B}$ y now, an American librarian would have to be living under a rock to miss hearing about Resource Description and Access (RDA). Even if you have nothing to do with cataloging or technical services, you likely have heard technical services librarians venting some of the strong emotions the new cataloging standard evokes. There are three main mindsets about RDA that I observe most commonly among librarians of any area. First, there are those who embrace the change, enthusiastically learn all they can about the new standard, and start working with RDA as soon as possible. We seem to be somewhat few and far between. Second, some librarians reluctantly make the change to RDA but try to maintain as much of the "things as they've always been" status quo in the catalog as possible. Many of these people, with time, discover the many good things RDA has to offer and become more comfortable with the changes. Finally, a large number of librarians try to avoid dealing with RDA at all costs. In some cases, this takes the form of denial, figuring that if one doesn't look too closely at those catalog records, one does not have to deal with change. In others, the resistance to RDA takes an almost militant tone. Here's the thing, though: RDA is here to stay. The change is already happening. By avoiding, resisting, or denying it, we are simply putting ourselves and our patrons at a disadvantage because we are not learning how to utilize RDA's capabilities to make our libraries even better. This essay is an opinion piece in I will discuss some ways in which I believe librarians can use RDA to improve library catalogs and services.

\section{A Bit of Background}

In the 1990s, members of the cataloging community began work on a major revision of the Anglo-American Cataloging Rules $2^{\text {nd }}$ Edition, Revised (AACR2). The modifications were necessitated by two main changes in our libraries: 1) the move from card catalogs to online public access catalogs (OPACs) and 2) the increasing variety of materials, especially electronic and online materials, which needed to be cataloged (Maxwell 2013, 1). However, as revisions progressed, it became increasingly obvious that, rather than a set of revisions, this project would result in a significantly different cataloging standard. Work on RDA (as opposed to AACR3) began in 2004 and was led by the Joint Steering Committee for Development of RDA (JSC) (JSC Archived Site, "Background"). RDA was published in 2010 and adopted by the Library of Congress and a number of other libraries in the United States in 2013.

RDA is a content standard, meaning that it provides rules about what information to include in a catalog record but does not provide instructions about the display or encoding of that information. This is meant to make RDA more flexible so it can be used in a variety of libraries and countries and with a number of different encoding standards beyond the typical Machine Readable Cataloging (MARC). RDA is based on Functional Requirements for Bibliographic Records (FRBR), published in 1998. FRBR is a conceptual model, which means that it does not provide specific rules for cataloging, which is where RDA comes in. RDA draws upon the FRBR entityrelationship model, which means that catalogers have two main goals: first, to describe the entity in hand (e.g., a book), and second, to describe the relationships that link multiple entities to one another (e.g., the relationship between a book and its author). RDA's focus on relationships is meant to reflect the way we think about information and do research, which usually involves using known entities to find unknown ones (e.g., an author's name to find other books by that author), nonlinear browsing (e.g., following links from one web document to another), and keyword searching.

In addition to providing a new way of thinking about cataloging in the Anglo-American library world, RDA is increasingly becoming an international standard. RDA Toolkit, the manual for RDA cataloging, is now available in English, Finnish, French, German, and Spanish, and translations into other languages are underway (www.rda-rsc.org). Additionally, the JSC is morphing into the RDA Steering Committee (RSC), a process that began on November 6, 2015, and will continue into 2019. The RSC will be made up of representatives from several broad regions: Africa, Asia, Europe, Latin America and the Caribbean, North America, and Oceania. This reflects the increasing international appeal of RDA as a cataloging standard. In a way, embracing RDA in our American libraries is a first step to membership in a more international library community.

The fact that most library catalogs today are electronic and many library materials are not traditional print books affected the development of RDA. Since we do not have to squeeze a bibliographic description onto a 
catalog card, catalogers now have more freedom to include extra information in records. We can also utilize authority records, controlled vocabularies, linking capabilities, and granular information encoding in new and creative ways in electronic catalogs. The fact that we are pointing our patrons to everything from books to e-books to DVDs to websites means that we have to describe these different formats carefully to create access and avoid confusion.

The new and revised rules and capabilities built into RDA are, in many cases, long and detailed and do not need to be addressed in this essay. ${ }^{1}$ Catalogers will need to learn to navigate and follow these new rules to varying degrees depending on their institution and the materials being cataloged. However, no matter how well catalogers learn these rules, and no matter how detailed their RDA records, that information will mean little if it is not utilized in the entire library. To that end, technology specialists, public services librarians, administrators, and other library workers need to have a basic understanding of the new features in RDA and their potential for improving patrons' experiences. In the following sections, I will outline a few areas that I think bear this type of scrutiny.

\section{Display}

Now that we do not have to cram a bibliographic record onto a $3 \times 5$ inch catalog card, we can add a great deal of information to our catalog records and record that information differently. RDA reflects this change in a few different ways. First, RDA does away with most (but not all!) abbreviations, especially those in Latin, making catalog records easier for our patrons to read. This is a display change that few of us really need to think about, as RDA records will simply include terms like "pages" and "illustrations" in the correct fields in our records, and our OPACs will display those terms with little to no difficulty.

Where we run into difficulty is with the numerous new fields that RDA, in partnership with MARC, has added to our catalog records. While these pieces of information can be incredibly valuable for searching and sorting records, as I will discuss later, they are often confusing for patrons (and some librarians!) to see in the catalog. For example, books are defined as having a media type of "unmediated" in RDA. This term makes sense to catalogers, and it is a controlled vocabulary term, so it also makes sense to our Integrated Library Systems (ILS) if we program them to read these fields. However, the term makes no sense to our patrons and can be distracting. Some catalogs, like that of the New York Public Library, display this information and more. Example 1 provides a screenshot of a record from the New York Public Library with the content, carrier, and media types displayed (outlined with a box). Other catalogs, like WorldCat Local, do not display this information. Example 2 is a screenshot of the WorldCat Local display of the same record in Example 1, this time without the content, carrier, and media types displayed. Deciding whether to display new RDA/MARC fields, like those for media or content type, is something that each library and/or ILS must do on its own. Weighing the needs of our patrons for more versus less information can guide us as we choose what to display in the catalog record.

$$
\text { See Figures } 1 \text { \&2 }
$$

\section{Searching and Sorting}

Because it is designed for an electronic catalog environment, RDA utilizes numerous coded fields and provides a high level of granularity. If our ILSs can take advantage of this granularity, we will be able to sort and search information in new and interesting ways. Keyword searches can already be used to find information in these new RDA/ MARC fields, but this only scratches the surface.

The new content, carrier, and media types are provided for every single RDA record. This means that everything, from books to CDs to headphones, is described more precisely than it was in an AACR2 record. The content type tells us what sort of form the information in the resource takes (for example, text or audio). The carrier type defines the object that contains that information, like a volume (book) or an audio disc (CD). The media type describes the medium needed to access the information. For books this is "unmediated" because you do not need a special device to access the information, but if you had an e-book, the media type would be "computer" because you would have to use a computer to access the book. The content, carrier, and media types are a more granular, exact take on the general material designation (GMD), which used to display in square brackets after the title of a video or audio recording, e-book, or other non-print resources. For example, "Sherlock [videorecording]" or "Little women [electronic resource]."

Many librarians are unhappy about the replacement of the GMD, as we and our patrons are used to seeing things like "electronic resource" and "sound recording" displayed with the title in our records. However, I argue that we can use the content, media, and carrier types to provide our patrons with more and clearer information. For example, rather than depending on a somewhat vague term like "videorecording," we could use the combined information from the new fields to create an icon for a DVD, which 


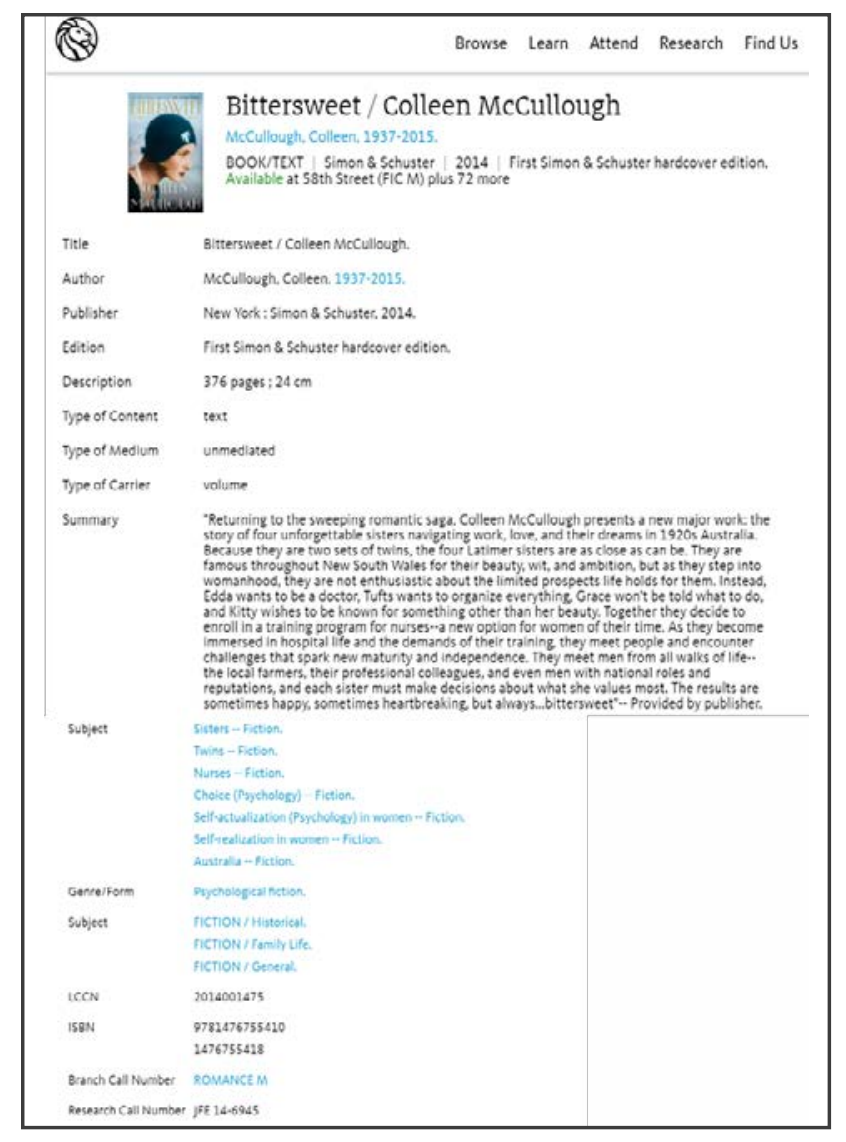

Figure 1: New York Public Library Catalog Display (with content, carrier, and media types)

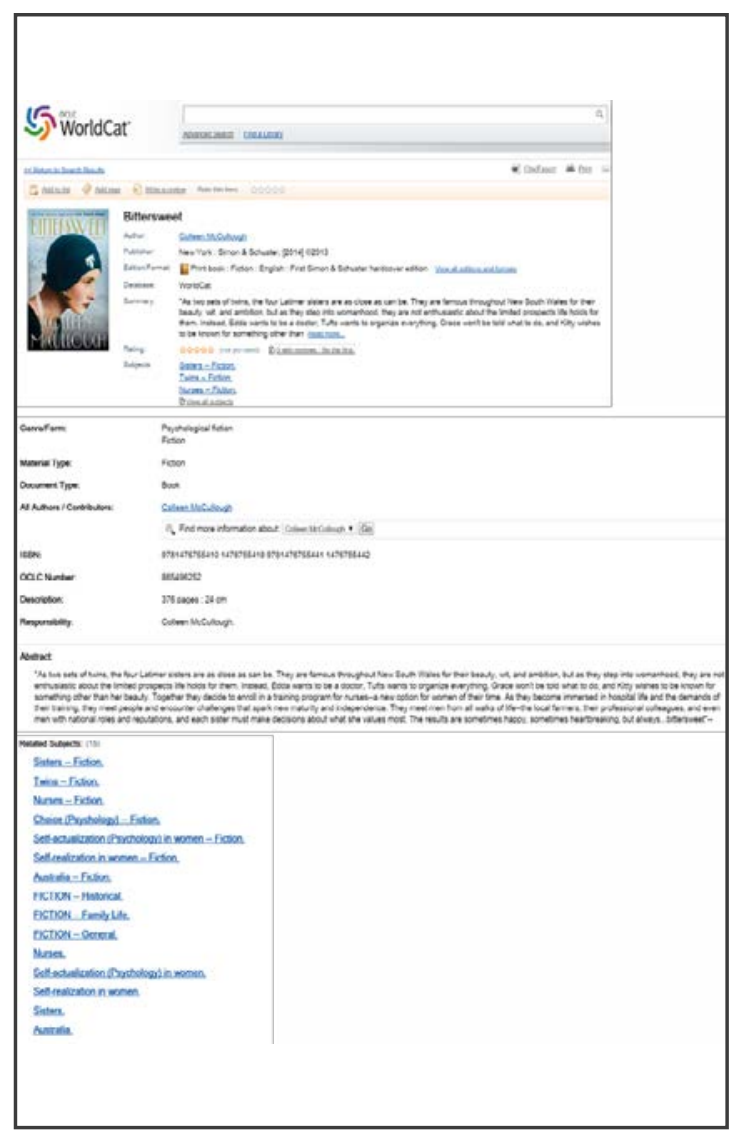

Figure 2: WorldCat Local Catalog Display (without content, carrier, and media types) could differ from that for a VHS. Similarly, the differing content types for a book on CD (spoken word) and a music CD (performed music) could allow us to differentiate between the two in searches and in our display. So even if you decide not to display terms like "unmediated" in your catalog, using them to aid in searching, sorting, and generation of display icons can be invaluable.

When it comes to non-book resources, we have even more new fields at our disposal. Some of these fields record information about the digital encoding of information on the resource, how sound is stored on the resource, and/or how video is stored on the resource. Others provide a place where we can define whether an audio recording is stereo or mono, digital or analog. Some fields also provide us with a way to differentiate between a
DVD and a Blu-Ray disc. All of this information, recorded in distinct subfields in the MARC record, can be used to search for very specific types of resources. For example, a patron could look for only Blu-Ray discs in surround sound and stereo. Similarly, this information could also be used to sort or narrow results, allowing patrons to choose e-books with smaller file sizes or streaming audio instead of CDs.

\section{Relationships}

The importance of relationships in RDA cannot be overstated. Humans tend to think of information in terms of relationships: this book is about that subject; this musical piece is performed by that musician; this review is of that book. Many relationships were informally acknowledged in AACR2. For example, we recorded the author's name in a book record, outlining the relationship between the two. However, in RDA, we become much more overt in our emphasis on recording relationships. This includes the use of relationship designators in our records and the utilization of authority records to provide linkages between resources that are related to one another, either directly or indirectly.

Using authority records as a way to link similar resources is not new. When we use an approved form of an author's name in a MARC 100 field, for example, we link that bibliographic record to all other records that include that author's name in a linking field, such as a 100 or 700 field. Where RDA differs from previous practice in this case is in its emphasis on using these types of devices to bring out relationships. While catalogers are not required to include linking fields (7XX, etc.) for all of these types of relationships, since 
RDA's creators recognized that this is a time- (and, thus, money-) consuming activity, we are encouraged to include this information if possible. This makes our records more useful in an online environment where using relationships to link between different works adds much to the searching experience.

Additionally, authority records are becoming far more detailed in RDA. I imagine a library catalog where authority records can move out of the background, allowing patrons to access that valuable information. Picture a catalog where a patron can click on an icon beside an author's name and see a pop-up of the author's date(s), profession(s), and so on. In addition to providing a link between related entities, authority records in RDA could become a bibliographic resource in and of themselves.

The use of relationship designators is new to RDA. At this time, relationship designators are really just a way to articulate why a name or title is important in a bibliographic record. This is especially helpful in records for resources like DVDs, where a large number of people may be involved in generating the final product. Rather than looking at a long list of names on records, patrons, through relationship designators, can now see why each of those people is listed. I theorize that using relationship designators as ways to add to searches would be an excellent way to take their functionality to a new level. For example, if a patron wishes to look for movies in which George Clooney has acted but does not wish to see any he directed, relationship designators might be a great way to focus a search.

Relationship designators can also come in handy when we are looking at works that are related to one another. If a movie is based on a novel, a link to the novel with a relationship designator of "Based on" could lead patrons to a new favorite book. Classical music recordings often include a number of different works by different composers, and some of those works may even be based on still other works. Outlining these relationships and providing links to other versions with other titles or different performers can be immensely helpful for our patrons. In short, the use of linking entries, such as 240 and 7XX fields, and relationship designators can lead patrons to a wealth of helpful information.

\section{The Potential of RDA}

RDA has the potential to create more functionality in our electronic catalogs. By generating more opportunities to search for a variety of types of information, to sort and display that information, and to link related resources, RDA can give our patrons a better library experience. This potential cannot be reached, however, without different library departments working together. It is not just about creating high-quality catalog records. The ILS must be designed and maintained in such a way that it utilizes the capabilities of those catalog records. Public services librarians need to understand the new and improved capabilities of RDA and how to introduce them to patrons. The transition has already begun. Many catalogers have already received training and begun creating and using high-quality RDA records. Now, all librarians should join together to try to reach the full potential of RDA cataloging in each of our libraries and as we move into the future.

\section{References}

1 For more detailed information on RDA, see the resources cited in the Suggested Readings list at the end of this essay.

\section{Suggested Readings}

Anhalt, Joy and Richard A. Stewart. "RDA Simplified." Cataloging o Classification Quarterly 50, no. 1 (2012): 33-43.

Brenndorfer, Thomas. "RDA in 10 Easy Steps.” Presentation. Available at http://www.ala.org/alcts/confevents/upcoming/webinar/ cat/ 110712

Joint Steering Committee for Development of RDA. "RDA: Resource Description and Access." Archived Site: JSC, RDA. http://www.rda-jsc. org/archivedsite/rda.html (Accessed 10 May 2016).

Joudrey, Daniel N., Arlene G. Taylor, and David P. Miller. Introduction to Cataloging and Classification. $11^{\text {th }}$ edition. Santa Barbara, California: Libraries Unlimited, 2015.

Maxwell, Robert L. Maxwell's Handbook for RDA: Resource Description \& Access. Chicago: ALA Editions, 2013.

Oliver, Chris. Introducing RDA: A Guide to the Basics. Chicago: American Library Association, 2010.

Picco, Paola and Virginia Ortiz Repiso. "The Contribution of FRBR to the Identification of Bibliographic Relationships: The New RDA-Based Ways of Representing Relationships in Catalogs." Cataloging \& Classification Quarterly 50, no.5-7 (2012): 622-640.

RDA Steering Committee. "Welcome to the RDS Website.” RSC: RDA Steering Committee. www.rda-rsc. org (Accessed 10 May 2016).

RDA Steering Committee, American Library Association, Canadian Library Association, CILIP: Chartered Institute of Library and Information Professionals. RDA Toolkit: Resource Description and Access. www.rdatoolkit.org (Accessed 10 May 2016). 


\section{Diversity from the Inside Out: Eight Years of the UNCG Libraries Diversity Committee}

$\mathrm{T}$ The Diversity Committee of UNC-Greensboro Libraries, founded in 2007, develops and supports activity relating to diversity and inclusion. Recognizing that the most successful change begins from within, the Committee's strategy for promoting diversity began with internal library staff development, and expanded over time to international representation of library faculty. Examples of diversity-related programs undertaken by the committee range from staff development focused on providing support to unique populations on campus, to the creation of the Diversity Resident Librarian position. In this article, members of the UNC-Greensboro Libraries Diversity Committee will discuss the programs that this committee developed and sponsored, beginning with training from within the Libraries for staff, expanding to regional, national, and international representation.

\section{Diversity and Institutional History: An Introduction}

The University of North Carolina at Greensboro (UNCGreensboro) enjoys the reputation as an institution that embraces values of diversity and inclusion. Originally chartered as the State Normal and Industrial School for White Girls in 1891(McIver Records), ${ }^{1}$ UNC-Greensboro presently stands among the top three of sixteen UNC higher education campuses in terms of highest population of ethnic minority students. Additionally, twelve percent of the student body self-identify as LGBTQ. With such a varied student body, the University Libraries of UNC-Greensboro actively seeks ways to understand and meet the needs of its primary patron population.

UNC-Greensboro Libraries formed an Ad Hoc Committee on Exploring Diversity Issues, which released a report in 2007, including several suggestions on how to best meet the needs of students and promote an inclusive institutional environment within the Libraries. Among the proposed recommendations was the development of a Diversity Coordinator position, which would serve as chair of an official University Libraries (UL) Diversity Committee. Reference Librarian, Gerald Holmes was appointed to this position, and the official UL Diversity Committee was formed in 2008. The UL Diversity Committee was among the first committees on the entire UNC-Greensboro campus created for the principle purpose of addressing diversity issues. In fact, being among the first of such committees, the UL Diversity Committee supported the establishment of the UNC-Greensboro Chancellor's Advisory Committee on Equity, Diversity, and Inclusion, which formed in 2009.

\section{From the Inside: Staff Development}

When the UL Diversity Committee initially met in 2008, members agreed that for an institution to earn attention as an ally and promoter of diversity and inclusion at the community, national, and international levels, such standards must be entrenched as part of the work ethic of library employees. This necessitated that the Committee establish staff development opportunities, which would promote equity, diversity, and inclusion as fundamental values to be considered and applied to staff and faculty work in all library departments. The Committee identified two staff development objectives to strengthen these values within the library: 1) cultivate an inclusive environment by opening dialog among employees, and 2) develop skills and crosscultural competencies that can be incorporated into daily workflows.

Although "cultivating an inclusive environment by opening dialog" sounds as though it should be the easiest to accomplish of all the proposed goals, it is deceptively difficult to implement in a practical manner. First, one must entice people into a conversation (no small feat for introverted library-types). Additionally, topics of discussion may involve volatile issues, in which people may be afraid of offering their opinion for concern of hurting someone's feelings, or conversely, some individuals may over-share their perspective, thus alienating everyone in the process. Finally, creating an inclusive environment for library employees means establishing that everyone benefits from the promotion of equity and diversity, which can be challenging to persuade a homogenous workforce.

The UL Diversity Committee organized two types of events to promote dialog among library staff. Among the most popular of these was the UL Diversity Movie Series. The movie series features a video about some aspect of diversity followed by a discussion among attendees. The first of such films shown was Voices of North Carolina (2005), 
a documentary highlighting the richness of linguistic diversity throughout the state. This served successful for initial "buy-in" of support from library employees, as everyone has a dialect or accent, so all staff could relate to this aspect of diversity. In addition to the movie series, the UL Diversity Committee sponsors "Lunch and Learns," in which staff are encouraged to spend their lunch break listening to presenters from within the Libraries or externally speak on a topic of some relevance to diversity. An example of a typical "Lunch and Learn" includes a panel discussion held by Middle Eastern students, describing and discussing the differences between libraries in their home countries and the libraries in the United States. As UNC-Greensboro supports a large international student presence, including a substantial body of Middle Eastern students, the program was both enlightening about cross-cultural practices and of practical application in understanding the knowledge barriers Middle Eastern students may experience when accessing UNC-Greensboro Libraries.

\section{The University Libraries holds a unique} position in being able to address and support the needs of campus students, faculty, and staff... 99

The second objective of the UL Diversity Committee was to develop the diversity and inclusion skillsets of library employees through specialized training and cultural competency programs. In order to incorporate such specialized training for staff, the UL Diversity Committee collaborated with various offices on campus, including the Office of Accessibility Resources and Service and UNC-Greensboro Safe Zone (the LGBTQ education trainers). UL Diversity Committee has organized workshops for library staff relating to supporting a wide variety of patrons, such as those with mobility issues, learning challenges, speech and communication challenges, LGBTQ students, and students at high risk. Such training educates library staff in better understanding the needs of these students and provides practices that can be incorporated into daily work routines. When these workshops are held, the Committee schedules at least three sessions at different times of the day to make certain day and evening staff can attend.

\section{Expanding from the Library to the Campus} The UL Diversity Committee seeks not only to promote the values of diversity, equity, and inclusion among library staff, but strives to be known as a leader in engaging the UNC-Greensboro campus community on these issues. The University Libraries holds a unique position in being able to address and support the needs of campus students, faculty, and staff, seeking to publicize relevant services and resources. The committee raises campus visibility of the Libraries' diversity initiatives by creating information resources and providing educational presentations. Committee members create research guides, aggregating library, campus, and online resources devoted to relevant issues. Among the research guides maintained by committee members are those for Accessibility Resources and Services $^{2}$, Bullying ${ }^{3}$, and Safe Zone ${ }^{4}$. Additionally, as diversity is an emphasized facet of the Libraries' strategic plan, library faculty and staff in departments that perform outreach frequently provide education presentations. These presentations range from information literacy and research techniques to institutional history. Presentations relating to diversity in institutional history are particularly popular. These include sessions on the history of African Americans on campus, the history of the LGBTQ community on campus, and the history of students with disabilities on campus.

\section{Expanding from the Campus to the Community}

While the UL Diversity Committee has spearheaded a number of campus-based programs, expanding to the community is deemed equally as important. In October of 2009 the Diversity Committee presented a panel at the North Carolina Library Association (NCLA) annual conference. The title of the presentation was "The Library Diversity Committee: Serving Knowledge, Serving You." The goals of the presentation were to educate librarians and administrators on the benefits and process of creating a diversity committee at their libraries, to help generate ideas for programming, and to assist in identifying collaboration opportunities to the greater campus community and beyond.

In 2008, the University Libraries hosted two librarians from the Shanghai University of Finance and Economics (SUFE) Library in China. The librarians participated in several outings and events including a visit to Claxton Elementary School in Greensboro. The librarians presented to three classes of second and third-graders about life in China and Chinese culture.

In December of 2010, the Diversity Committee along with other UL librarians held a holiday drive in which school supplies and monetary donations were collected to help support Hampton Leadership Academy in Southeast 
Greensboro. Hampton Leadership Academy, an elementary/university partnership magnet school, partnered with North Carolina Agricultural and Technical State University (NCA\&T) in 2010. Hampton encourages an educational environment in which students are challenged, excellence is expected, differences are valued, and exposure to higher education is integrated into the culture of the school. Three boxes and $\$ 106.66$ of school supplies were collected and delivered to Hampton in January, 2011.

Throughout all of the community initiatives, the Academic and Cultural Enrichment (ACE) Scholars have played an active role. The ACE Scholars Program is a collaborative effort between UNC-Greensboro and nine other academic libraries in North Carolina that was created to increase cultural diversity amongst graduating librarians. The initiative, which was funded by the Laura Bush 21st Century Library Grant, assists with the recruitment, mentorship and support of members of under-represented communities in the United States in their pursuit of a Masters of Library and Information Science (MLIS) degree. Past ACE Scholars have assisted with campus and community events and have presented at several local and national conferences. Graduates have gone on to serve as library media specialists, education librarians, fine arts librarians, instructors, youth services librarians, reference librarians, and doctoral candidates at prestigious universities.

\section{Diversity Residents' National Contributions}

Since the inception of the Diversity Resident Librarian position, UNC-Greensboro Libraries have hosted and mentored four diversity residents. A diversity resident is an early career librarian from an underrepresented group who has recently received the MLIS degree from a program accredited by the American Library Association. The residency program is mutually beneficial. The resident will grow and development professionally; in return, the library will benefit from special skills, ideas and initiatives of the new librarian. The length of residency programs varies depending on institution. At UNC-Greensboro, each resident serve a two year appointment, however, programs typically range from 1-3 year appointments.

During their appointments, all four residents made significant contributions to the library profession both locally and nationally. The first diversity resident, Jason Alston, was appointed in spring of 2008. He served on the Executive Board of the Black Caucus of the American Library Association. He also served as logistical co-chair for the planning of the National Conference of African American Librarians in 2010. The second diversity resident, LaTesha Velez, served from 2010-2012. She presented at three doctoral recruitment webinars hosted by ALA's Office for Diversity. Nataly Blas, was the third diversity resident from 2012-2014. She is the current convener for ACRL Residency Interest Group. Orolando Duffus is the current diversity resident librarian for 2014-2016. He co-presented with four other former and current residents at the annual conference of the American Library Association in June, 2015. He spoke about his diversity initiatives (including a Diversity Expo that he planned) at UNC-Greensboro and advocated for residencies by sharing some mutual benefits that have resulted from his experience.

\section{Diversity Initiative: Diversity and Global Engagement Expo}

As libraries across the globe are making a firm commitment to support diversity, librarians are adopting and supporting new services and programs that attract diverse users. Since the appointment of a permanent Library Diversity Committee in 2007, the University Libraries at UNC-Greensboro have been re-emphasizing a commitment to diversity.

With the support of the UL Diversity Committee, the current Diversity Resident Librarian decided to create a more interactive and student centered library outreach initiative in the form of a Diversity Expo. He invited student organizations including numerous multicultural student groups into UNC-Greensboro's main library to share their initiatives, collaborate with other organizations and recruit new members. The event created a spotlight for the multicultural students groups which enabled them to generate lots of membership interest. It gave new and existing students an opportunity to learn about and join various student organizations while engaging in the diversity on campus. Students love that they were able to learn about other cultures, sample exquisite cuisines and listen to global melodies while cultivating shared experiences.

A survey methodology was used to collect data from participants at the Expo. The survey responses helped to identify some critical areas that the Libraries needed to improve in order to create a more welcoming and inclusive library environment. We learned that aesthetics or sensory cues weigh heavily on students' perceptions of the library and their willingness to approach librarians. Students, both foreign and local, indicated that visual cues such as multinational flags/banners and artifacts of cultural or historical significance are helpful in reducing anxiety and creating a sense of belonging.

The event was well attended by over two hundred students with participants representing all inhabited continents. Most of the survey respondents (53\%) indicated that they were a native of a country other than the United 
States. In addition, just over $60 \%$ of the respondents indicated that they learned something new about another culture. This speaks volumes to the level of cultural diversity and interactions and prompted participants to request that the event continue annually.

The event concluded with a panel discussion where students, student leaders and members of UNC-Greensboro's administration and faculty convened to discuss global issues affecting society. The panelists included the department heads of the sponsoring units and were moderated by an associate professor representing the Department of African American and African Diaspora Studies. The Diversity Expo was extremely successful mainly due to the contributions of numerous campus organizations. These organizations were instrumental for funding, promotion, and program ideas. Diversity dialogues are beneficial for libraries because they creates an atmosphere where students, faculty and staff can learn from other members of the university community, work through assumptions and biases that might affect work performance, and workplace interactions, not only with staff but with library patrons. ${ }^{5}$

This outreach initiative has resulted in long-term collaborations among students, faculty and staff. It is low cost and the time commitment is comparative to planning a book swap. The return on investment is exponential, since it provides an opportunity to market library products and service, create strategic alliances or partnerships with stakeholders, create advocates, and expand the library's outreach efforts.

\section{International Partnerships and Presentations}

Libraries all over the world are facing many of the same challenges related to collection management, human resource management, and more. It is imperative that librarians build relationships with librarians in other countries to enhance user experience in our libraries. The benefits of these exchanges could include sharing information about best practices, exchanging materials and expertise, and working together on mutually advantageous projects.

The University Libraries have been encouraging these exchanges by hosting visiting scholars and supporting international travel for librarians annually. The University libraries have hosted several visiting librarian scholars from countries such as China and Moldova. The visiting librarians interacted with library faculty and staff (both in the library and Library and Information Studies department), exchanged their work experience, shared library best practices, and presented sessions on library projects in their countries.
Many of our librarians attended and presented at international conferences such as the International Federation of Library Associations and Institutions (IFLA). One of our librarians was invited to China as a part of the "Think Globally, Act Globally” project. In 2012, Beth Filar Williams, our former Distance Education Librarian, was invited as a guest lecturer at the Digital Libraries Learning (an international Master's program for "elite information professionals") program in Norway. ${ }^{6}$ She then presented with the group in Italy and Estonia. Most recently, in September 2015, three members of UNC-Greensboro's Special Collection and University Archives spoke on a panel at the Women's History Network Annual Conference in Canterbury, UK. The tile of their presentation was "Behind the Lines: Mobilization \& Activism of American Women in the Great War," which highlighted women's socio-economic and political contributions to the Great War. Many librarians have made significant contribution to international librarianship via presentation and or committee work since the establishment of the Diversity Committee in 2007.

The Library Diversity Committee is currently in the second year of the University Libraries' five year Strategic Diversity Plan. The goals of the plan include creating and sustaining a welcoming, supportive and inclusive campus climate; developing programming and outreach for the Libraries and the community in support of diversity; supporting diversity in the UNC-Greensboro curriculum; creating a library environment that reflects diversity; preparing UNC-Greensboro students to live and work in a diverse global world; and developing and executing a comprehensive Diversity and Inclusive Communication Plan. The Libraries' Diversity Committee records and monitors its progress and reports it annually.

\section{Conclusion}

From its inception in 2007 as an Ad Hoc Committee, the UNC-Greensboro UL Diversity Committee has grown considerably. Its impact has expanded across campus, the Greensboro community, the state of North Carolina, and across the globe. By committing time and energy to fostering diversity in librarianship, engaging others in thoughtful discussion, and lending support to similar initiatives, UL Diversity Committee has been able to leave its mark. As the UL Diversity Committee moves forward with new programs and initiatives, it aims for continued progress and success. 


\section{References}

1 "Bill to Establish the Normal Industrial School", UA2.1 Charles Duncan McIver Records, 1855-1906, Martha Blakeney Hodges Special Collections and University Archives, University of North Carolina at Greensboro, NC, USA.” 2015. Accessed December 29. http://libcdm1.uncg.edu/cdm/ref/collection/ui/id/7324.

2 Minerva, Irma. 2015. “Research Guides: Accessibility Resources and Services: Home.” Accessed December 29. http://uncg.libguides.com/accessibility_services.

3 Holmes, Gerald. 2015. "Research Guides: Bullying: Home.” Accessed December 29. http://uncg.libguides. com/c.php?g=83306.

4 Krim, Stacey. 2015. “Research Guides: Safe Zone Resources: Home.” Accessed December 29. http://uncg. libguides.com/safezone.

5 Winston, Mark. 1999. Managing Multiculturalism and Diversity in the Library: Principles and Issues for Administrators. Psychology Press.

6 "Study online or on campus." Oslo and Akershus University College. last accessed December 30, 20015. http://dill. hioa.no/programme/.

\section{North Carolina Libraries}

Official Publication of the North Carolina Library Association

ISSN 0029-2540

All issues are available online free-of-charge at

Back issues are available from the North Carolina Library Association office at 1811 Capital Blvd., Raleigh, NC 27604 , for $\$ 8$ an issue for those years prior to going online in 2002, or $\$ 50$ for the annual print compilation beginning with Vol. 60 (2002).

\section{Looking for help with collection development?}

If you want to expand your library's collection of novels set in North Carolina, you should visit the Read North Carolina Novels blog hosted by the North Carolina Collection at the University of North Carolina at Chapel Hill (http://blogs.lib.unc.edu/ncnovels/).

If your interest in North Caroliniana is more general, the North Carolina Collection at UNC-Chapel Hill regularly posts lists of new additions to their collection at this address: http://blogs.lib.unc.edu/ncm/index.php/ whats-new-in-the-north-carolina-collection/. 


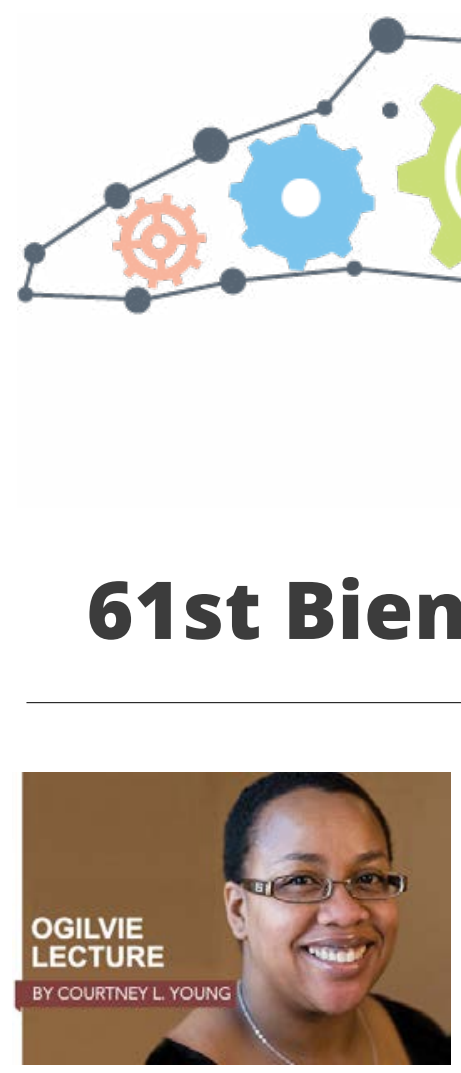

NORTH CAROLINA LIBRARY ASSOCIATION 61st Biennial Conference, Greensboro, N.C.

\section{MAKE IT MATTER}

ment to the profession and the Association sets me apart. I want to sustain the initiatives we have in place, engage all facets of our membership, and demonstrate the value of membership and of librarianship."

Cood afternoon! It is so great to be There for NCLA's $61^{\text {st }}$ biennial conference and to participate by delivering the Ogilvie Lecture. I am deeply honored by this opportunity not only because of the importance of Phil Ogilvie to North Carolina libraries, but because of the role North Carolina libraries and librarians have played during my year as ALA President.

You see, before 2015 I had never been to North Carolina. This calendar year I've been to North Carolina three times: first as a guest of the University of North Carolina Greensboro University Libraries, second as a guest of North Carolina Central University's School of Library and Information Sciences to celebrate their $75^{\text {th }}$ anniversary, and now this week for the North Carolina Library Association conference. With each visit I have been welcomed with open arms and open hearts. This conference's theme could not be more fitting - "Make It Matter" - because everyone I have met this year has made North Carolina's library community matter to me.

So my goal this afternoon is to offer perspectives on "Make It Matter": from making in libraries, making libraries matter to our users and our communities, making our associations matter to our professional development and professional practice.

In my role as ALA President, I worked with members from all types of libraries and in all types of libraryrelated roles to highlight areas of interest and emphasis within ALA's Mission and Vision: diversity, career development, and engagement and outreach. I believe these things are what bring value to the association and the work we do in our libraries. They also help us have a positive impact on our communities. I know firsthand as an academic librarian working with students, faculty, and staff this has helped me do my job better and be a change agent for those I teach. For me, it is what matters.

Why is this so important? Because $21^{\text {st }}$ century library users need and deserve $21^{\text {st }}$ century libraries. Libraries of all types - public, academic, school, and special - play a critical role in supporting the needs of our users. We see an increased demand for different types of services, resources, and spaces hand in hand with a need to educate on basic and emerging literacies. Our ecosystem of libraries speaks to the importance of all types of libraries transforming. Each type of library has the potential to create and foster lifelong library use.

Libraries are a vital link in the chain to connect people with the information access and critical resources they need to support education and lifelong learning. The five Es of libraries education, employment, 
entrepreneurship, empowerment, and engagement - are the necessities that libraries play a critical role in providing and supporting. Libraries are indispensable in supporting the needs of their community members in virtually every aspect of life. This is reinforced by those national, regional, and local partners who increasingly associate these things with librarians and library services.

I ask you to indulge me for a moment and allow me to share how libraries have played a transformational role in my life. I am a lifelong library user, and in many ways I believe it led me to this profession. I have memories of going as a class in elementary school to the school library and picking out books to read. I participated in summer reading programs hosted by the public library; always bittersweet when it ended, I discovered I could actually keep on reading library books the other three seasons of the year - and I did just that. It started with the usual children's books with authors like Richard Scarry and Ezra Jack Keats. Books including Clifford the Big Red Dog, Frog and Toad are Friends, and Aesops Fables. As I got older, I learned the library could be a source for developing knowledge, and reading books about famous people like the Reverend Dr. Martin Luther King, Jr., topics like mythology, or even how to make friendship bracelets.

My first job as a teenager was shelving books at a branch of the public library. My emerging technology skills and interest in customer service extended that role into helping out at the circulation desk. In college I worked all four years in the library, and as a library school student as a circulation desk assistant at a theological library.

My continued deepening use and understanding of libraries transformed me into a reader, an employee, a lover of technology, a collaborator, and a thinker. In all those roles I came to appreciate the impact of libraries and library staff on a community. When I became a librarian, it allowed me to continue that community-centered role, one that in my day to day work as an academic librarian I often refer to as student-centered. And while library use may not always create library employees, it always has the potential to create lifelong learners, library advocates, and transform lives.

Society is changing in the way it consumes information. Libraries are evolving with these changes in order to serve the public and to continue to fulfill their role in leveling the playing field for all who seek information and access to technologies.

In a conference presentation titled "Skills for the librarian of the future," regional information resource officer at the U.S. Department of State, Alka Bhatnagar noted, "The relationship between libraries and their communities is at a critical intersection. There has never been a more rapid period of change affecting libraries and their communities. As a result, there has never been a better opportunity for library employees to act as leaders for positive change." This means we must take an active role as leaders to make it matter.

She went on to note the service philosophy for $21^{\text {st }}$ century libraries as providing "user-centric, high quality resources and services to meet the exponentially growing recreational and knowledge needs of the globally networked current, potential, and future diverse community users in a conducive environment." When it comes to our role as the library, focused on our respective community's needs, it is the intersection of those resources and services to support the educational, social and personal needs that connects them with the world, recognizes and celebrates diversity, in all the right locations outfitted appropriately.

Staff, volunteers, and library supporters also have a role to play in making our libraries matter. We know libraries are places of innovation, evolving as their communities evolve. The rapid changes going on around us demand that we too also change and be innovative.

Libraries have long served as trusted and treasured institutions, and librarians today can leverage that strong position for the betterment of their communities. Today's libraries are turning outward, partnering with local community groups to provide nontraditional library services, and mirroring the needs of the communities that they serve.

Many people depend on their libraries to access resources and information. The work done in libraries and the resources made available are constantly changing. As more and more of that information goes online, the ability to connect increases in importance. As society changes the way it consumes information, libraries - as early adopters of technology - are evolving with these changes in order to serve the public and to continue to fulfill their role in society.

Libraries are increasingly being known as innovation spaces where library users are becoming content creators. There is an increased focus on resources and services that go beyond the scope of what people see or think of as traditional library services - makerspaces, which increasingly feature 3D printers, offer the opportunity for active learning, invention, sharing of expertise, collaboration, and use of technology by community members of all ages; employment centers - for those who are looking for jobs as well as those turning to their libraries to develop small businesses; access to electronic books and streaming media; 
and presentation recording rooms with green screens. These new services and resources are part of $21^{\text {st }}$ century libraries and reflect the types of skills needed by $21^{\text {st }}$ century citizens around the world.

While rapid changes in technology, particularly internet and handheld devices, has significantly impacted the work that all library workers do and the way we provide resources and services. As important to this concept as the products and services is your leadership, our leadership in the community and the profession. Libraries have a long history of leading the way: preserving our nation's cultural heritage, advancing research and scholarship, supporting literacy and lifelong learning, fostering innovation and creativity. All while embracing and usually juggling a variety of formats and changing resources to accomplish these goals. And more importantly, providing personal service and assistance finding these materials.

That demand for library services has increased significantly with the growing need for access to and training for digital and online information - such as continuing education resources and employment opportunities. In the next decade, it is estimated that nearly $80 \%$ of jobs will require digital skills, yet the Federal Communications Commission estimates that more than 60 million people lack the digital literacy skills they need. Libraries can be at the forefront of closing that significant gap and preparing our library users at all levels to meet those employment demands. This was affirmed when President Obama and Congress recognized this fact by including libraries in the Workforce Innovation and Opportunity Act.

It has never been more important than now to embrace our leadership role in libraries and in our communities.
Your leadership has an impact locally: when you host How-To Festivals. When you host financial literacy workshops for high school and college students. When you defend the right to read by building a diverse collection. You have a tremendous and profound impact on your community.

The work you do is also important to the profession: when you share your ideas, successes, and failures at local, regional, state, national, international, and virtual conferences, your peers are inspired and have new ideas for community outreach, therefore continuing a dialogue that strengthens those relationships focused on engagement and the fulfillment of aspirations. You provide compelling stories for me to talk about with the media - and it's your stories journalists, bloggers, decision makers in government or administration at all levels are interested in; you provide an answer to the question "Why libraries".

It has never been more important than now to embrace our leadership role in libraries and in our communities. We provide resources needed to live, learn, work, and govern. Libraries empower individuals, strengthen communities, and foster participation in the larger society at the local and national level by providing access to information, by supporting use of networks and social media, and by advocating for users' rights to information.

At the same time our leadership in this profession also strengthens that role. Your participation in this conference reflects the essential role of all types of libraries in meeting our society's education, literacy (and by literacy I mean in the broadest sense, its evolving application beyond the ability to read the written word), and access needs. Your commitment to supporting your associations allows them to keep the important work of libraries in the minds of decision makers at all levels.

Libraries serve as places to connect the community with expertise within the organization, throughout the community, and world. As librarians, library staff, library school students, LIS faculty, and library advocates, we know the value of libraries and what that value means for our communities. In addition to providing desired and inspiring resources and services, there is a need for even greater external engagement by all of us with community partners, all levels of government, and even commercial entities - to articulate that value. Libraries are our great information equalizers - the only place people of all ages and backgrounds can locate and use print and non-print materials, with the expert guidance of librarians and staff. Our missions call on us to be leaders, and we are leading by being essential in meeting the needs of a changing $21^{\text {st }}$ century citizen.

ALA is the voice of America's libraries and the millions of people who depend on them. Its goal is to see that all who use these libraries have the information they need to live, learn and work. Through the support of school, public, academic, and special libraries that build the collections, provide services, and develop and maintain facilities toward that goal, libraries remain one of America's most democratic institutions. And no matter how they change, libraries will still be committed to open access for all in a community gathering place.

Thank you for your leadership in your community, the state of North Carolina, and this profession. The work all of you do is so inspiring, and I thank you for continuing our profession's tradition of leadership. 


\section{1st Biennial Conference: Biennium Reports}

\section{Youth Services Section}

Looking back on my tenure as chair, I can only say that it was a time of transition. One of the first things I focused on was setting clear expectations for conducting our business meetings and setting guidelines to foster productivity during these meetings. I also detailed the role and responsibility of each board member position. For example, our two director positions became Director of Membership and Director of Public Relations. These positions continue to evolve to stay relevant and focused on the needs of the membership and the organization as a whole.

Speaking of evolving and staying relevant, the board worked diligently this past biennium to enhance member engagement throughout the section. We developed the U in Youth Services, which is a monthly email to spotlight one YSS member. We organized a special projects committee to work on the LEGO Initiative, sponsored by LEGO and the State Library. We created an application process and selected 14 counties around the state to receive LEGO kits to support and enrich kids programming. We introduced a scholarship opportunity for the Leadership Institute and selected two candidates to sponsor. We plan to continue and grow scholarship opportunities and have added an ad hoc position to the board for a Scholarships Chair.

A standing tradition of YSS has been to host an off-year fall retreat. Our past retreat brought in record numbers and received amazingly positive feedback. In the hope of an even greater success for 2016, we have secured space at Black Mountain. This facility will provide more flexibility and space

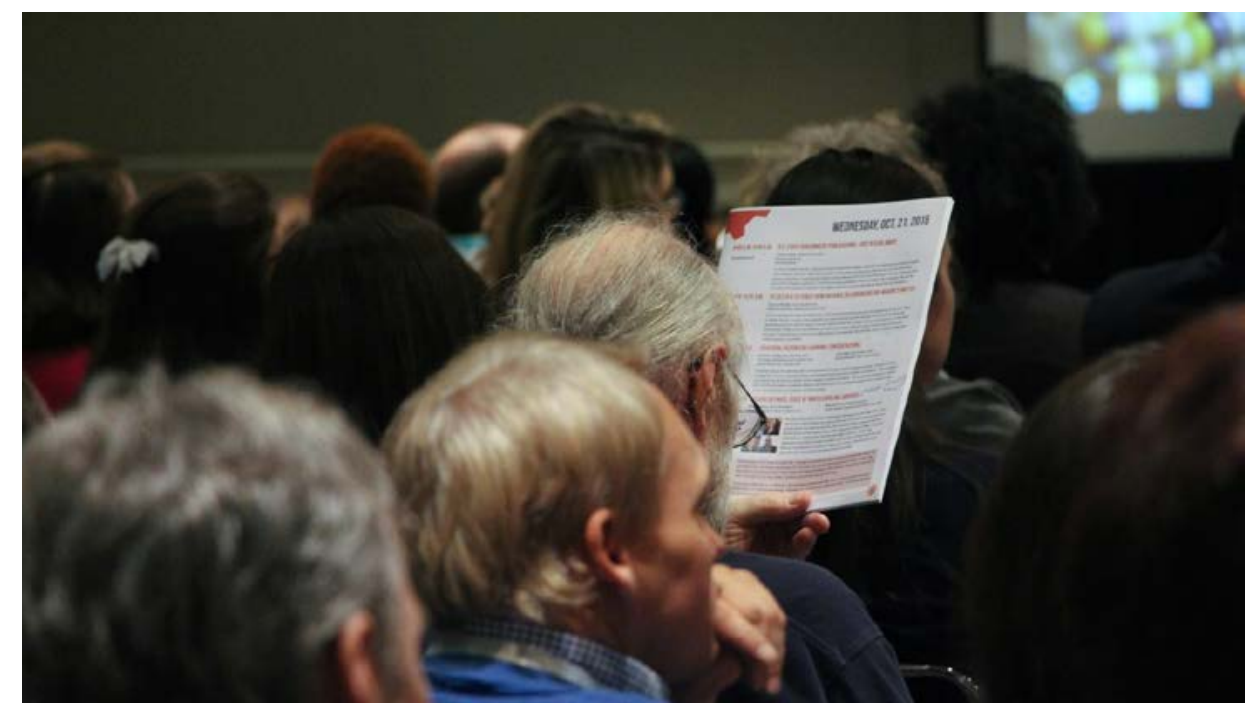

during the retreat for presenters and breakout sessions and also provide better accommodations for larger attendance.

We also continued our tradition of a jointly sponsored luncheon with PLS at the conference last year. Brian Sturm, a dynamic storyteller and professor at UNC, offered an inspirational presentation followed by a hands on storytelling program. Other YSS sponsored events included Storytime Tips, Tricks to incorporate ECRR, and a forum to share the importance of Summer Reading data. Incoming chair, Tanika Martin, was also involved in the launch of Librarians Build Community. This widely popular event is continuing to grow and develop into a team of librarians who have a passion and desire to reach out and meet the needs of their community.

One of my last tasks as chair was to nominate a new slate of candidates for the upcoming biennium. I am very excited that we welcomed five brand new board members that I know will bring new energy and fresh ideas to the section. The board will continue to work on marketing and promotion of the section and NCLA, partnerships among other sections and within the community, and member engagement. It is our hope that our combined efforts will continue to grow our membership as more and more people learn the value of joining and being involved with NCLA.

\section{Debbie Shreve (past chair)}

\section{NCLA Public Library Section}

The Public Library Section had a successful and productive biennium, fulfilling its mission of uniting NCLA members who have a particular interest in public libraries. Opportunities were created for sharing and learning new skills and for discussing issues of importance to all public libraries in North Carolina while fulfilling the goals of NCLA . Programs in both the non-conference and conference years helped us meet these goals

The Public Library Section's Executive Board:

- Chair: Billy King

- Vice Chair: Jason Rogers

- Secretary: Arthur Erickson

- Director: Laura Highfill

- Director: Lindsey Shuford 
Planning Council:

- Sandra Lovely: Chair, Adult Services Committee

- Tammy Baggett, Chair, Awards Committee

- Decca Slaughter, Chair, Branch Services Committee

- Cathy Rudelich, Chair, Collection Management Committee

- Jennifer Daugherty, Chair, Genealogy \& Local History Committee

- Don Dwiggins and Sarah McGough, Co-Chairs, Marketing Committee

- Joan Sherif, Youth Services Section Liaison

- Martha Sink, Webmaster

- Pam Jaskot, Past Chair

\section{Conference}

Winston-Salem, NC

The Public Library Section's premier event was the author luncheon and business meeting featuring best selling mystery authors Charles and Caroline Todd. At this event, the William Roberts Public Library Distinguished Service Award was presented to Lisa Flanigan, Youth Services Specialist at Watauga County Library. She and her library each received an award of $\$ 500.00$. The Section also co-sponsored a luncheon with the Youth Services Section featuring author Allan Wolf. The Section also provided eight programs sponsored by its various committees.

\section{Leadership Institute}

The Public Library Section provided scholarships to two librarians to attend the 2014 Leadership Institute. The recipients were Karen Feeney from Forsyth County Public Library and Amy Wyckoff from Charlotte- Mecklenburg Library.

\section{Fabulous Fridays}

For the third time PLS organized and hosted three mini-conferences across the state to promote conversation and continuing education opportunities for public library staff. The sessions were held on three consecutive Fridays in October in Asheville, Charlotte and Fayetteville. PLS committees created, organized and presented programs of interest. State Librarian Cal Shepard and NCLA president Dale Cousins provided keynote speeches for the sessions.

2015 Conference, Greensboro, NC The section hosted a wine and cheese reception for bestselling author Diane Chamberlain and presented the William Roberts Public Library Distinguished Service Award to Meryle Leonard, Library Outreach Service Manager for Charlotte-Mecklenburg Library. The Section's committees presented eight programs during the conference on topics ranging from genealogy triage and circulation issues to a fiction fans' readers advisory and starting a makerspace with very little money.

Incoming Public Library Section Executive Board:

- Chair: Decca Slaughter

- Vice Chair: Sandra Lovely

- Secretary: Arthur Erickson

- Director: Laura Highfill

- Director: Lindsey Shuford

\section{Billy King}

\section{Development Committee}

The chair of development worked with the Marketing Committee to develop a campaign to make the NCLA Endowment fund more visible to the membership. Two avenues of support were developed to encourage members to donate to the endowment fund: Every member $\$ 10.00$ every year and the $\$ 500$ Pin Club. As individuals become new members or renew membership, we ask that the $\$ 10$ box be checked on the membership form to add $\$ 10$ or more for the endowment. Presently there are four Pin Club members. To receive the special club pin, a member will donate $\$ 500$ during the biennial.

\section{Make NCLA Your Favorite Charity}

At the Biennial conference in Greensboro, three activities raised approximately $\$ 3000$ for the endowment: the endowment dinner, the pub crawl and the sandwich-board walk around.

To let the membership know how their gifts are used a list of activities supported are as follows:

- Special Project (Board Projects)

- Advocacy

- Intellectual Freedom

- Leadership Development (Barbara Beebe Fund)

- Leadership Institute

- Library Grants

- Scholarships

Fund Balance as of June 302015 $\$ 168,314.00$. Please help NCLA reach the next endowment benchmark of $\$ 200,00.00$

Harry L Cooke

\section{Technology and Trends Round Table}

The members of the 2013-2015

TNT Executive Board were as follows:

- Chair: Kathy Shields, High Point University

- Vice Chair/ChairElect:

- Jenny Dale,UNC Greensboro

- Secretary/Treasurer: Julie Raynor, High Point Public Library

- Director: Chad Haefele, UNC Chapel Hill

- Director: Suvanida Duangdom, Wake Tech Community College

Since the 2011-2013 board was not put in place until late 2012, the membership approved the reelection of all 
positions to another two-year term, so that we could continue the work we began in the previous biennium.

The TNT board met virtually throughout the biennium to plan webinars and other activities for our membership and the general NCLA membership.

\section{Highlights of the 2013-2015 Biennium}

Our biggest event was in March 2014, when we coordinated with the State Library of North Carolina to bring Jason Griffey, a well-known library technologist, to four locations around the state: Appalachian State, High Point Public, Wake Tech, and ECU. For each location, members of the board served as or recruited volunteers and helped coordinate lunch and a special "Lunch with Jason" event for TNT members.

We also hosted 11 webinars on a variety of topics, including RFID, social media, website usability, and library technology for people with disabilities.

In summer 2015, we received approval from the NCLA Executive Board and our membership to update the TNT Bylaws to allow for electronic voting by members for elections. We also updated board positions to reflect current practice. We then held our first electronic vote for new officers in advance of the 2015 Conference.

\section{3-2015 Activities}

\section{Webinars}

On February 25, 2014, we hosted a webinar on RFID in libraries with Christee Pascale (Associate Head, Acquisitions \& Discovery) and Mara Mathews (University Library Technician, User Experience) from NCSU Libraries.

On April 29, 2014, we hosted a webinar on Social Media Creation and Management for Libraries, presented by Katie O’Connor (UNCG MLIS grad).

On May 22, 2014, we hosted a webinar on Library Technology for People with Disabilities led by Holly Mabry (NCKNOWS).

On June 19, 2014, Marc Bess (UNCC) presented a webinar on Creating Digital Objects for Library Instruction Using Adobe Captivate.

On July 9, Kate McNamara (Chapel Hill Public Library) presented on Becoming a Tumblarian.

On September 12, 2014, we held a webinar on Google Analytics, which was presented by Laura Wiegand of UNCW.

On December 18, 2014, we held a webinar on Community Readers' Advisory, which was presented by Suzanne Moore and Suzanne Spanburgh of Ashe County Public Library.

On January 14, 2015, we held a webinar on Teaching and Training with Google Drive presented by Jenny Dale and Amy Harris Houk of UNCG.

On February 26, 2015, TNT held a webinar, "The Top 10 Things I Wish I Had Known Before RFID (or How to Stay Sane Dealing with Summer Volunteers)," which was led by Megan Bowers, a library associate at High Point Public Library.

On March 26, 2015, Aislynn Denny, Media Specialist at Guilford Middle School, led a webinar on "Cybersafety and Digital Citizenship," which focused on techniques to help students be smarter about their online lives.

On April 22, 2015, Chae Haefele, Emerging Technologies Librarian at UNC Chapel Hill, will be leading a webinar on web usability, "Assess Your Website With Free Usability Testing Tools."

\section{Member Outreach}

We added a members-only section to our NCLA website that has a list of
TNT-approved tools, including mobile applications, software, and websites. We advertised this to our members as a special perk of membership.

Julie Raynor created a calendar of technology-related events for us that we shared with our members.

We also sent out a survey to solicit feedback from our members on what topics they would like to see from our webinars and upcoming conference programming. We used these to help inform our webinars and conference programming.

\section{Conference Activities}

TNT was extremely active at the 2015 Biennial Conference, held in Greensboro. We had a table in the registration area, where we had a prize wheel and gave away TNT-branded items, such as a cord keeper, headphones, smartphone stand, and stylus pens.

We sponsored a preconference on Tuesday, October 20, on "Social Media Hacks: Tips and Conversation for Enhancing Social Media Use in Libraries" presented by Stephanie Willen Brown (UNCCH), Matthew Clobridge (Durham County Library), and Jennifer Lohmann (Durham County Library).

On Wednesday, we sponsored a poster by Megan Bowers, a library associate at High Point Public Library, on "The Top 10 Things I Wish I Had Known Before RFID; A Public Library's View on RFID."

We also sponsored several programs on Wednesday:

"Academic Library Websites as Information Gateways: Prioritizing User Needs in Website Evaluation and (Re) Design" by Terry Brandsma (UNCG)

"Reaching Digital Readers Where They Are" by Julie Raynor (High Point PL)

“tl;dr: Enhancing Students' Online Research, Reading, and Writing Practices with ProQuest Flow" by Kathy 
Shields and Allison Walker (High Point University)

We also cosponsored a panel with WILR on "Women in Technology in Libraries: A Panel Discussion," which featured librarians from different areas who shared about their experience in technology positions in libraries.

On Thursday, we presented "Top Tech Trends 2015," which featured three librarians who shared some of their top tools from the past year.

We also held a business meeting on Thursday, where we opened the floor for any final nominations for officer positions and welcomed our new board members.

\section{New TNT Board for 2015-2017}

- Chair: Jenny Dale, UNCG

- ViceChair/ChairElect: Julie Raynor, High Point Public Library

- Treasurer/Secretary: Kate Hill, UNCG

- Director: Suvanida Duangdom, Wake Tech

- Director: Sarah Arnold, UNCCH

- Past Chair: Kathy Shields, High Point University

I look forward to seeing what the next board does. We received some thanks at our business meeting at the conference for the rejuvenation of this group, and I know that the next board will continue the tradition of providing great opportunities for professional development and the spirit of collaboration that we have sought over the past biennium.

\section{Kathy Shields, Past Chair}

\section{College \& University Section}

With the help of some amazing volunteers, the College and University Section (CUS) put on a one-day miniconference in 2014. "Academic Libraries: Present and Future" took place on Friday, December $5^{\text {th }}$, at the

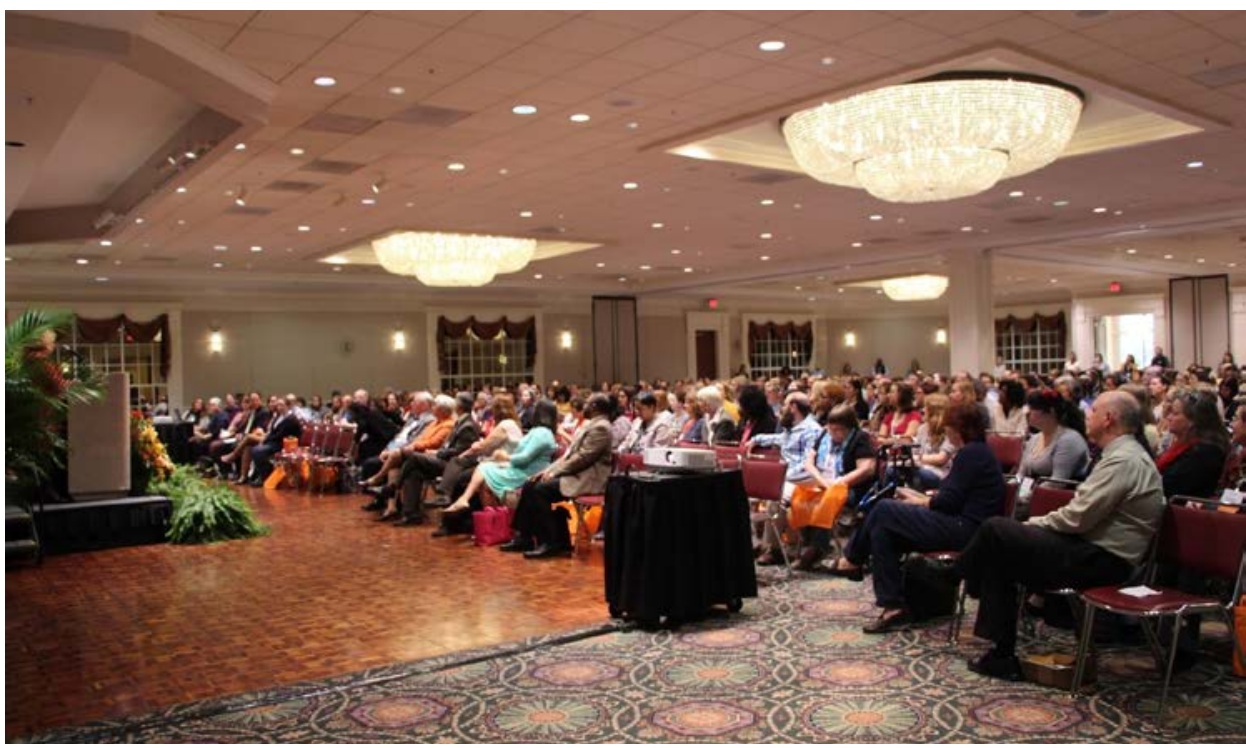

UNC-Charlotte Center City Campus. The keynote speaker was Patrick Deaton, Associate Director for Learning Spaces and Capital Management at North Carolina State University, who oversaw the design, construction and furnishing of the award-winning James B. Hunt Jr. Library. Breakout sessions were organized around three tracks: the physical library, the virtual library, and the professional marketplace.

During NCLA's 61st Biennial Conference, CUS sponsored an "Unconference" during its luncheon on October 22, 2015, at the Koury Convention Center in Greensboro. This brainstorming session was attended by CUS members as well as others interested in academic libraries. Attendees contributed ideas about activities and events they would like to see from CUS in future. The ideas and suggestions will be used by the new CUS Executive Board to plan activities for the 20152017 biennium, with the goal of generating enthusiasm and increasing membership in CUS.

\section{Randall H. Bowman}

\section{Library Administration and Management Section}

The Mission of the Library Administration and Management Section of NCLA:

- To focus on improving the practice of library administration

- To foster the development of administrative skills in areas such as budgeting, personnel training, buildings and equipment, and public and governmental relations.

Goals for the 2014-2015 Biennium:

- Establish programming around the state, using experienced local managers to encourage career development for LAMS members.

- Make LAMS page of NCLA website more interactive and use it to solicit articles for LAMS Letters.

- Work with NCLA to offer an exciting and interesting Leadership Institute for the association. Schedule October 30, 2014 November 2, 2014

- Establish LAMS Letters as a monthly publication

- Update LAMS Bylaws: Lorrie Russell to head committee

2014 - 2015 Library Administration and Management Section Officers

- Chair, Laurence Gavin, Cumberland County Public Library 
- Vice-Chair/Chair Elect, Mark Sanders, UNC East Carolina

- Acting Secretary/Treasurer, Siobhan Loendorf, Catawba County Public Library

- Director, Ruth Ann Copley, Davidson County Public Library System

- Director, Brandy Hamilton, Wake County Public Libraries

- Director, Joan Sherif, Northwest Regional Public Library

- Immediate Past Chair, Lorrie Russell / High Point Public Libary

- Publicity Committee Director, Michael Crumpton, University of North Carolina, Greensboro

- Committee Member, Elizabeth Novicki, Salem Academy \& College

- Committee Member, MaryAnne Sommer, Cumberland County Public Library

- Committee Member, Megan Smith, Cumberland County Public Library

- Committee Member, Mary DiRisio, Cumberland County Public Library

\section{Summary of Accomplishments}

In collaboration with New Members Roundtable, LAMS conducted a one-day conference entitled "Marketing Yourself: Career Advancement at any Stage" with the theme, "Reaching Your Career Potential." The program was conducted at the Concord Public Library in Cabarrus County. The keynote speaker was Chapel Hill Library Director Susan Brown. Breakout sessions included: Marketing Yourself with Social Media; Personal Branding- putting your best foot forward; Cover letter and resume workshop; Speed Interviewing; PublishingGetting Started, Finding Time; Getting Involved- National, State and Local associations; Presenting- Finding Opportunities, Best Practices; and Developing Career Soft Skills.

LAMS also conducted an Experienced Managers Discussion Panel at the Cumberland County Public Library during which six library leaders in academic and public libraries shared insight with library school students, as well as new and experienced library managers on developing strategies to guide the communities they serve through change.

Catawba County Public Library Assistant Director Siobhan Loendorf was the recipient of the LAMS scholarship to the 2014 NCLA Leadership Institute. Siobhan was thankful for the interactive learning opportunity to develop leadership skills, change management and emotional intelligence. She states that she will be able "...to use the experience to look at myself and my role as a leader through a different lens. Self-reflection and mindfulness are a couple of the tools that I will continue to use to make myself a better leader, co-worker, wife and parent."

Partnering with the State Library of North Carolina, LAMS cosponsored "Knowing You, Knowing Them: Success Secrets for New Supervisors at the Henderson, Cabarrus, and Cumberland County Public Libraries," presented by trainer \& consultant, Linda Bruno, participants were encouraged to reflect on the human side of supervising, emotional intelligence, as well as creating a positive and motivating work environment.

A committee to amend the LAMS bylaws, led by Immediate Past Chair Lorrie Russell, completed its task with a vote of approval from the Executive Board in July 2015 and a membership vote conducted from $7 / 30 / 15$ to $8 / 28 / 15$ in which $100 \%$ of respondents accepted the changes. The revised bylaws were uploaded to the NCLA LAMS webpage on 9/25/2015 by Vice Chair/Chair-elect Mark Sanders.

In a survey conducted by the Executive Committee to determine the effectiveness of the LAMS Letters newsletter $96 \%$ of respondents stated the newsletter was useful and $76 \%$ of respondents stated it was very useful. The goal of LAMS Letters as a monthly publication was to establish more regular communication between the Executive Committee and the membership. In this biennium LAMS Letters facilitated conversations with new and experienced library leaders, conducted LAMS business, and engaged the membership.

Work began in 2015 on developing the Partnering with a Professional mentoring program targeting library science students taking management courses at the 5 accredited universities across North Carolina. At this time, professors teaching management courses at each of the 5 universities have been contacted and are receptive to the idea of promoting the program. Registration forms have been created for both mentors and mentees and a list of volunteer mentors has been established. At the October 2015 Executive Board Meeting, the New Members Round Table chair Sarah Lyon expressed an interest in collaborating with LAMS. Moving forward, the Executive Committee will integrate the missions of LAMS and NMRT to establish a common goal reflected on the mentor and mentee registration forms along with a clear message to be used by all committee members to detail a unified message about how the program will work as we visit each of the target universities.

At the $61^{\text {st }}$ Biennial Conference 2015 "Make it Matter," LAMS presented the following:

- "Lite Project Management for Librarians" featuring Kathy Bradshaw, Human Resource Librarian at UNC Greensboro.

- "Managing Change: Your Role in Strategic HR Initiatives" with Michael Crumpton, Asst. Dean for Administrative Services at UNC Greensboro 
- “Grant Writing 101” presented by Kelly O'Brien, Director of Strategy and Innovation at UNC-CH School of Government.

- LAMS Business meeting

- LAMS also prepared a basket for the raffle to raise funds for the section and the association at conference.

\section{Elections}

We held our elections in September of 2015 using LAMS Newsletter to provide the membership with biographies of the candidates and a link to a survey monkey survey to cast their votes. The link to the survey was also sent to the LAMS membership via email. Candidates were informed of the election results on October 9, 2015, and the NCLA membership was informed of the new slate of officers via email listserv on October 26, 2015.

\section{6-2017 Section Officers}

- Chair - Mark Sanders / East Carolina University

- Vice Chair/Chair Elect - Elizabeth Novicki / Salem Academy \& College

- Secretary/Treasurer - Siobhan Loendorf / Catawba County Public Library

- Director - Brandy Hamilton / Wake County Public Libraries

- Director - Lorrie Russell / High Point Public Library

- Director - Kelly Vadney / Sandhills Regional Library System

- Immediate Past Chair - Laurence Gavin / Cumberland County Public Library

- Publicity Committee Director Michael Crumpton, University of North Carolina, Greensboro

Laurence Gavin, Chair 2014-2015

\section{Closing Session}

Following the October 2013 conference, the Executive Board of the North Carolina Library Association approached the new biennium Stronger Together!

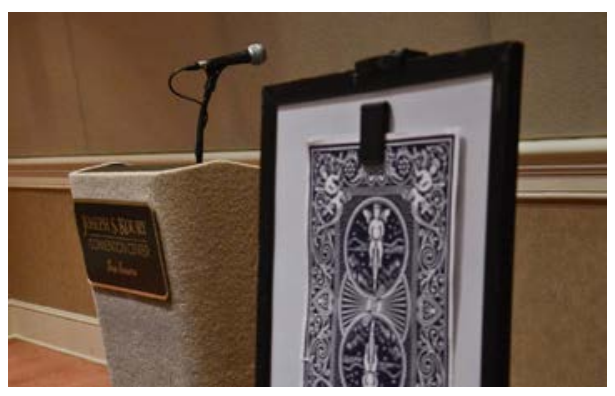

The new board held its initial meeting in January 2014 which was also a planning retreat. A strategic plan was developed for the biennium, facilitated by Dr. Anthony Chow from UNC-Greensboro's School of Education. In addition, every section, roundtable, and committee was charged with revising, updating and focusing its bylaws and operational procedures. Most sections have since accomplished this. The management of our finances will be transitioned to Quickbooks software over the biennium with multiple people (Treasurer, Treasurer-Elect, Executive Assistant and Finance Committee Chair) being trained on the use of the software. Early in calendar year 2016, an external auditor will conduct a full review of NCLA finances. The goal, in addition to updating our financial records, is that every section, roundtable, and committee will receive reports that are current, accurate and simplified for maximum understanding.

Rather than report, item by item, on the Strategic Plan, I have elected to report on the accomplishments and various activities from the biennium using the organization's new tag line; Inform, Connect, Support.

The North Carolina Library Association has informed its members by

- Beginning the biennium with a new logo, tag line, and a marketing strategy

- Launching a new webpage
- Refreshed Facebook page as a nonprofit organization page

- Encouraging expanded use of the listserve by members

- Scheduling quarterly meetings of the Executive Board in geographically diverse locations of the State for the biennium

In addition:

- The initial Board meeting/retreat examined the effectiveness and efficiency of Board operations. I asked Lorrie Russell to lead a committee to examine this topic and the committee returned with recommendations for improvements and a "best practices" summary for expectations of a successful section, roundtable, and/or NCLA committee.

- Electronic newsletters were distributed to section members of WILR and LAMS

- The Government Resources Section has, to date, provided over 50 webinars for continued learning. Lynda Kellam of that section received a grant to purchase software to archive the webinars for future expanded use by the NCLA membership. Ms. Kellam volunteered to load the webinars using the software.

- PLS continued its popular Fabulous Fridays series across the State and BLINC continued to offer ongoing CE sessions for its imbedded librarian members.

- The Executive Board voted to dissolve the School Library Media Section, noting that the section is fully engaged with an independent organization of its own. In its place, a liaison to NCSLMA organization now has a seat at the NCLA board table. To date, a representative has been present to report at NCLA Board meetings and has participated in National Legislative Day activities.

- Finally, the Make It Matter! conference has informed all of its attendees. 
The North Carolina Library Association has connected its members by

- An expansion of social media, beginning with this 2015 conference and henceforth.

- Continued networking events hosted by NMRT and NCLPA.

- Representation on the ALA Council by Dana Eure. Note: Letters from the President, in collaboration with ALA, were written in response to book challenges in both Orange and Forsyth Counties.

- Representation on the SELA Board from Wanda Brown. Note: Wanda has led conversations with SELA about a combined Leadership Institute for 2016.

- Both the President and PresidentElect have attended regularly scheduled State Library Commission meetings to represent NCLA.

- NCLA, in collaboration with international nonprofit Contextos, opened a library for children in a school in El Salvador with a contribution of $\$ 5000$.

- NCLA has been represented routinely in North Carolina Public Library Directors Association meetings and with the work of the North Carolina Community College Learning Resources Association.

- NCLA's Continuing Education Committee was dissolved, creating instead a liaison seat on the State Library's Continuing Education Committee. Thanks to Brandy Hamilton for representing NCLA.

- And Make it Matter! has connected established and new members of the Association.

The North Carolina Library Association has supported its members by

- Workshops, seminars, webinars and retreats have been offered by nearly every section of the Association over the biennium.
- The Leadership Institute with its 23 graduates was coordinated by Mike Crumpton. Kudos to the contribution of this group and the mentors at conference and thank you to Mike who has committed to leading the event again in 2016.

- National Legislative Day, coordinated with ALA by Dr. Anthony Chow and LaJuan Pringle.

- Support of the NC Public Library Directors Association's "Day in the District" as a state advocacy project.

- A rename and refocus for the Endowment Committee to be the Development Committee with financial management falling to the Finance Committee; Thanks to Harry Cooke and Tamara Rhodes for the new marketing strategy for raising Endowment funds (that is $\$ 10.00$ every year from every NCLA member!)

- Mentoring events hosted by LAMS and NMRT.

- A generous bequest from Wake County School Librarian Mary Ruth Duncan for $\$ 23,000$.

- Celebrating our own; ALA's recognition of Gerald Holmes for his career-long work on diversity; LJ Paralibrarian of the Year, Tamara Faulkner; NC Heritage Award to Sylvia Sprinkle Hamlin; UNC-G Alumni Award to Rodney Lippard.

- The Past Presidents Council was created to advise the President. Of the 14 living Past Presidents, 6 were in attendance at various points of the conference.

- Unlimited praise for the greatest supporter of NCLA and its members goes to Executive Assistant, Kim Parrott. Kim is a critical component for any success seen by the Conference, the Leadership Institute, National Legislative Day, the Executive Board, the President and any activity of the Association and its affiliates. Thank you to Kim.

- And Finally, Make It Matter! has supported all of us all week.
The challenge for the future for the North Carolina Library Association is to remain relevant, vibrant and vital to its membership. NCLA is a volunteer professional association that provides a forum for expanding the views of libraries. Through being involved with NCLA, members can learn about libraries of all types and library services throughout our State. Members can grow personally and professionally.

Members can share ideas, projects and even frustrations and challenges with understanding peers. NCLA provides a network of colleagues and friends that will last throughout a career. So, I encourage you to become involved. NCLA is only as strong as its membership and it is membership that keeps the organization going and growing. Become engaged and bring a colleague!

Dale Cousins, President 2014-2015

\section{NCLPA Two-Year Review}

A quick rundown of the events of NCLPA as we have now reached the end of the current 2-year term of office for the 2013-2015 elected individuals. While we seemed to have had a slow start in 2014, behind the scenes members of the Executive Board were working to make modifications and updates to our printed literature and online available information. Discussions were held regarding possible change of design for our logo, as well as consideration of our group description. Board members asked, "Are we still comfortable with description 'paraprofessional,' or should we change to 'support staff' or perhaps 'paralibrarian?”" These possible changes were tabled for further discussion among the board members and well as input from the membership. This is something we all need to consider and provide input. 
In the spring of 2014, the Triad Academic Library System of the Piedmont (TALA) held its first annual conference where our Chair, Harry Frank, provided a speech on "Rise of the Niche" And Nita Williams also gave a presentation on "Student Workers."

In May after the Executive Board meeting and the evening prior to the annual Joyner Library Paraprofessional Conference, NCLPA sponsored a Meet \& Greet at the Mellow Mushroom in Greenville. This event was well attended; food and fellowship with old and new friends was tremendous.

The next day, NCLPA provided information about our organization at the Joyner Paraprofessional Conference which was as always a wonderful event.

At the August of 2014 meeting, it was decided to offer partial scholarship for a paraprofessional to participant in the NCLA Leadership Institute. We were very proud to provide this financial support to Juli Moore of Iredell County who was selected to participate in the 2014 class. And as we congratulated Juli, we ask all members to please accept our encouragement to pursue your passion for your library and your patrons and apply to attend the 2016 LI. The application process will begin in January 2016.

In the September of 2014, NCLPA was very proud to play a small part in the African-American Author Festival held at the Greensboro Public Library by serving refreshments to participating authors and their assistants at the festival. The festival was hugely successful with many individuals attending and taking part in the presentations by authors throughout the day. The event was sponsored by Book Clubs United for African American Literacy with 11 featured authors, presentations, books signings, arts, and prizes. Weather was perfect and the event was enjoyed by all, including and especially the NCLPA members in attendance.

In November 2014 after the Executive Board meeting, our first "Snack and Chat" was held at the Alamance County Public Libraries in Burlington NC with all surrounding library staff invited as well as any library staff from any location wishing to attend. We were very pleased with the attendance and decided to make this an event once a quarter to be tied in with our quarterly executive board meeting. We were much honored to have as one of our attendees, Dale Cousins, then current President of NCLA, and at subsequent NCLA Executive Board meeting we were extended several invitations to hold such events at other library locations.

In February 2015, our plans for Executive Board meeting and to hold a Snack and Chat in Fayetteville at the Cumberland County Public Libraries met with bad weather, not just in our areas of travel, but in the destination of Fayetteville, quite a surprise for all, and our plans were canceled.

Later in February, our Chair Harry Frank, tendered his resignation to the Executive Board. Harry was a wonderful leader, but due to a change in his career, he felt he could no longer make the commitment of time he would prefer to our organization. His resignation was accepted and best wishes for his continued success in his new professional endeavor were offered.

It was at this time that according the NCLPA bylaws, Cathy Wright as Vice-Chair moved to the role of Chair, and Beth Lyles graciously accepted the role of Interim Vice-Chair.

In March, we received notification of tremendous news! Our own Tamera Faulkner was named the 2015 Library Journal Paralibrarian of the Year!!! Front cover of magazine and all! Since that time Tamara has been a very busy celebrity!
In March, the second annual TALA Conference was held in High Point with Tamara Faulkner as the keynote speaker.

And then May 2015 rolled around, and that is the signal for the wonderfully popular and well organized ECU Joyner Library Paraprofessional Conference. The Executive Board met at the Sheppard Memorial Library in Greenville and once again held a Snack and Chat. While the event was not as heavily attended as we had hoped, we were pleased with the opportunity to chat with several individuals that day. It seems in hindsight that perhaps our time slot was a little too early for those arriving in town for the conference and for those working at libraries in the area. Lesson noted.

The next day, we were pleased to set up our information table at the Joyner Library Paraprofessional Conference. There we had the opportunity to see old friends and make a few new friends. We offered information and candy, we were pleased with our endeavor. We also took the opportunity to attend several of the sessions and experience the wonderful day-long conference. For anyone considering the value of this conference, we offer our recommendation to make the effort to attend, you will not be disappointed!

In June, 2015, the call was issued to all members of NCLA and NCLPA for applications for our Meralyn G. Meadows Conference Scholarship. This was the first step for NCLPA as planning for the biennial conference had begun.

\section{Conference Planning}

At our August Executive Board meeting, it was now time to turn our focus to conference preparation and select the Conference Scholarship winner. We were given guidelines from NCLA that each round table or section would be allowed to sponsor three 
presentations at the conference. Many ideas surfaced for great presentations and the following selections were made: 1) "Make deselection matter; the dark half of collection development"; 2) "Community Outreach and Partnerships"; and 3) "Core Competencies? Continuing Education? Professional Development? Oh my!” We also tossed around several ideas for lunch programs, and the decision was made to provide entertainment in the form of non-library related for all to take a break from the wonderful world of library for just a while and just simply be entertained. It was also decided by the board members to create a "Gift Card Tree" to be raffled at the NCLA Conference.

Our proposals were submitted to NCLA and we were very pleased to receive the news that all were accepted. We hope you were present at the NCLA Conference and had the opportunity to attend all 3 NCLPA Sponsored events.

Also, a huge decision for the Executive Board was suggested to purchase a tablecloth to use at events such as our Snack and Chats, information tables at various workshops and conferences, and specifically the initial use at the 2015 Biennial NCLA Conference. After discussion, a motion was made, seconded, and approved to purchase a royal blue 8' tablecloth with the NCLPA logo in gold from JanWay. The debut was indeed at the conference in Greensboro and was well received by all, a great purchase for our Round Table!

\section{Scholarship}

At the Conference Luncheon Meeting, Cathy Wright recognized and offered our thanks to Amy Whitmer, Chair of the Scholarship Committee and one of her committee members, the 2013 recipient Juli Moore. We were very fortunate to have such wonderful applicants, and it was a hard task to select just one winner. Our thanks to all applicants and a sincere invitation to accept active roles in NCLPA was extended.

Cathy Wright then presented the 2015 Meralyn Meadows Conference Scholarship Certificate and check to Laura Chapman of the Jackson County Public Library System in Sylva NC. We all congratulated Laura and look forward to her continued participation in NCLPA.

\section{New Officers}

Also at the Conference Luncheon Meeting, the announcement and introduction of your newly elected members of the NCLPA Executive Board took place, with the new members taking office at the conclusion of the meeting. Region Director, Brandon Stilley of Joyner Library in Greenville NC; Treasurer, Nita Williams of High Point University in High Point, NC; Secretary, Tamara Faulkner of Hickory Public Library in Hickory, NC; Vice-Chair, Beth Lyles of Perry Memorial Library in Henderson, NC; and your Chair, Cathy Wright of Alamance County Public Libraries in Burlington, NC. Congratulations were offered and an invitation extended to anyone interested in a position of Region Director, or Committee member. Please do not hesitate to contact Cathy Wright or any member of the Executive Board. We would love to see everyone enjoy active membership in the NCLPA, where together we can do great things! Or perhaps better stated, "Make it Matter"!!

\section{Thank You to Friends of the Library} And before turning our luncheon program over to Tamara for her introduction of our entertainment, Cathy Wright offered our thanks and recognized our most generous Friends for their financial support in bringing the program to those in attendance. The Alamance County Friends of the Library, the Hickory FOL, and the Friends of the Western Watauga Public Library. We do have great Friends!

\section{Conference Entertainment}

Ronn Winters, Mentalists and Magician, then was introduced by Tamara Faulkner, and the crowd of 65 in attendance were amazed at his abilities and thoroughly enjoyed the event.

\section{Post Conference Biennium Finale}

Soon after the conference ended, we were very pleased and fortunate to add Laura Chapman to the NCLPA Executive Board as our newly appointed Region 4 Director. Laura works with the Jackson County Public Library in Sylva, NC.

This now brings an end to the 20132015 term for NCLPA. It has been a great two years and we all look forward to even better things in 2015 - 2017 with all members enjoying active participation. The Executive Board welcomes all comments and/or suggestions and hope to see each of you in the coming months.

\section{Thank You!}

\section{Cathy Wright, NCLPA Chair}

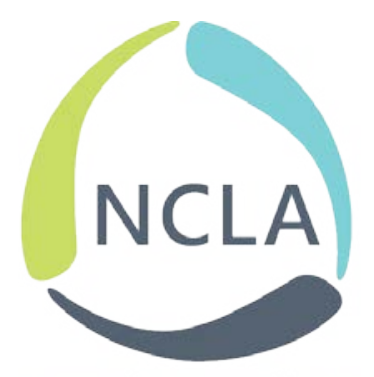

North Carolina Library Association 


\section{UNC-CH Library School Master's Paper Abstracts Summer 2014 - Spring 2016}

\section{Summer 2014}

Brittany Hayes. Detecting Lexically Cohesive \& Temporally Bounded Tweet Sessions on Twitter Timelines. A Master's paper for the M.S. in I.S. degree. April, 2014. 59 pages. Advisor: Stephanie W. Haas

This exploratory study examines the concept of the "tweet session"-instances where a user of the microblogging site Twitter posts two or more related tweets in a short period of time. The study outlines a set of characteristics that aid in the detection of topically cohesive units. Four of these properties are external to the tweet text: a 24-hour time frame, inclusion of at least two tweets, inclusion of originally authored tweets and the exclusion of replies. Four additional properties were derived from the natural language processing and information retrieval literature: lexical cohesion based on unigram and character bigram feature representations, conjunction use, signals of continuation, and anaphora resolution.

A sample of 220 user timelines was analyzed to detect series of tweets meeting the definition of a session as conceptualized in the study. $93.6 \%$ of timelines included at least one technical tweet session. Lexical cohesion as determined by cosine similarity retrieved the most sessions: 815 technical sessions when unigrams were used as the unit of tokenization, and 1391 technical sessions when character bigrams were used. The majority of users engaged in tweet sessions exceeding 140 characters (the Twitterimposed limit for a single tweet); however, when unigrams were used in the feature representation approximately $47 \%$ of timelines had tweet sessions of less than 140 characters on average. This research shows that tweet sessions exist and can be detected by computational means.

Erin L. Carter. Library and Information Science Students' Ethics Training and Attitudes about Intellectual Property Rights: An Exploratory Study. A Master's Paper for the M.S. in I.S degree. April, 2014. 75 pages. Advisor: Anne Klinefelter

The purpose of this research is to gain a greater understanding of the factors that influence library and information science (LIS) students' views on intellectual property rights, specifically illegal reuse of content on the web. The study utilizes interviews and surveys to explore attitudes toward illegal downloading of digital content in general, extent of ethics education in LIS classes, disciplinary differences between information and library science, and these variables' influence on attitudes towards illegal reuse of copyrighted content analyzed for correlation. The end result of this study is an exploration of the attitudes about intellectual property rights in the next generation of librarians to determine future areas of improvement (e.g., required ethics trainings for future librarians and information science workers; specific ways LIS programs can emphasize intellectual property concerns).

Joseph T. Gilmore. The Use of University of North Carolina Library Materials on Internet Archive. A Master's Paper for the M.S. in L.S degree. May, 2013. 32 pages. Advisor: Dr. Richard Marciano

An examination of rates of use of digitized materials uploaded to Internet Archive by UNC Libraries. Suggestions for improvement to the organization of those materials.

Kathleen Hill. Usage of Social Media in the University of North Carolina at Chapel Hill Health Science Library: A Case Study. A Master's Paper for the Masters of L.S. degree. July, 2014. 32 pages. Advisor: Mary Grace Flaherty

This paper examines the efforts one health science library puts into outreach and marketing through social media platforms. It focuses specifically on a case study of the University of North Carolina at Chapel Hill Health Science Library. There is a strong correlation between the content of social media posts and the number of patron interactions with said post. Visual content in posts boosts interactions, but creating posts with only links does not. The data gathered from the study will allow for the library to target its postings in the future, which in turn could garner more followers and interactions with patrons.

Madeeha Khan. Using User-Centered Design Methodologies to Redesign the Office of International Student and Scholar Services Website. A Master's paper for the M.S. in I.S. degree. July, 2014. 73 pages. Advisor: Ronald E. Bergquist

The Office of International Student and Scholar Services (ISSS), is the administrative office that serves international students, research scholars, and visiting professors 
at the University of North Carolina at Chapel Hill. ISSS spent the fall 2013 - spring 2014 academic school year redesigning their website using user-centered design methodologies with the assistance of a SILS graduate student. User-centered design is an approach where the needs and requirements of the users are put in focus throughout each stage of the design process. This study describes how usercentered design principles were incorporated into the final design of the website.

In addition, this study examines to see if incorporating user-centered design methodologies in the redesign of the website can allow for international students to successfully complete common tasks on the website at an above average user task completion rate of $80 \%$ or above. The study tested the task completion rate by conducting a series of user-testing sessions on the redesigned ISSS website with eight UNC international students.

Virginia L. Ferris. Beyond "Showing What We Have": Exploring Linked Data for Archival Description. A Master's Paper for the M.S. in L.S degree. July, 2014. 76 pages. Advisor: Timothy Shearer

Research explores current professional attitudes, applications, and potential impact of linked data in archival repositories, through eight structured interviews with archivists and early adopters of linked data and semantic web practices within the archival community. Interviews evaluate current archival practitioners' perceptions of the benefits and challenges of applying linked data practices to archival description, to examine the current barriers and potential solutions in integrating linked data with archival description. Analysis investigates ways in which linked data and the semantic web may impact archival descriptive practices and user experience in accessing archival materials, and ways to facilitate greater engagement with linked data within the archival community.

Adrian T. Ogletree. Metadata Workflows Across Research Domains: Challenges and Opportunities for Supporting the DFC Cyberinfrastructure. A Master's Paper for the M.S. in I.S. degree. August, 2014. 52 pages. Advisor: Jane Greenberg

Metadata is necessary for finding, using, and properly managing scientific data. This master's paper presents results from a survey studying metadata workflows. A metadata workflow is a workflow that generates metadata for a data collection. A questionnaire was distributed to DataNet Federation Consortium researchers and collaborators. There were fourteen participants representing the following domains: hydrology, biology, climatology, ecology, library sciences, computer science, engineering, social sciences, and information sciences. Data management best practices recommend that data documentation, including metadata planning, occur prior to the data collection activity. However, the results of this survey indicate that in the scientific domains explored, more metadata is created during and after the data collection process than when the activity commences. Results also show that few researchers take advantage of automated metadata generation workflows. In addition, $9 \%$ of respondents did not know whether or not a standardized metadata scheme is used in their institution, and $20 \%$ did not know whether or not they provide metadata along with their data to repositories. Lastly, impediments to research data sharing and reproducibility were explored, including the need for highly specialized knowledge, software, or equipment. Data curators, librarians, and archivists, along with automated systems, can assist researchers by intervening earlier in the data life cycle in order to produce higher-quality metadata and ensure longterm data preservation.

Joshua G Rice. Improving Conversion Rates at 80 Percent Solutions. A Master's Paper for the M.S. in I.S degree. August, 2014. 44 pages. Advisor: Paul Jones

This experiment used A/B testing to attempt to improve three tracked conversion goals-- "Engagement", "Paypal Submission", and "Purchase Clicks" --on 80 Percent Solution's product website www.MacFreedom.com. The participants for this study were web users from any location or device who visited www.MacFreedom.com during the testing period.

Three randomized controlled experiments were executed using Visual Website Optimizer to test for statistical significance of the conversion goals. The results of these experiments showed that:

- Changing the site's tagline demonstrated significant success.

- Changes to landing page call-to-action buttons exhibited negative statistical significance.

- Variations of the purchase page call-to-action buttons demonstrated significant success.

Maria Terrien. Revistinha: A Brazilian Online magazine for Kids. A Master's Project for the M.S. in I.S degree. April, 2014. 27 pages. Advisor: Brian Sturm

This project is the first phase of a new online magazine, a resource for young kids presenting topics related to the Brazilian culture. The magazine's goals are to improve knowledge of Brazilian culture, provide fun, and improve reading literacy. Magazines for kids are very popular in 
Brazil. The magazines are bought on the streets in a newsstand and they are in a comic format. As a result, today Brazilians have a comic book culture. For Brazilians living outside Brazil, magazines are the cheapest and easiest product from Brazil to transfer Brazilian culture to their kids. Not all of them can afford travels or shipping magazines. Many of these families do not speak Portuguese at home and the cultural withdrawal is worsened by the lack of pedagogic material. Revistinha wants to fill this market with a magazine in a comic format presenting topics related to the Brazilian culture.

Jody Seim Timmins. Using Comics to Promote Literacy in the K-8 Classroom. A Master's Paper for the M.S. in L.S degree. July, 2014. 44 pages. Advisor: Sandra Hughes-Hassell

Students, publishers, and educators have embraced comics for their engaging format and high-interest storylines. Comics are not just popular choices for independent reading, however. Comics can be used in the classroom to support literacy instruction. Comics have been found to foster multimodal literacy, support English language learning, and motivate reluctant readers. The layout of comics makes visible the meaning-making strategies deployed by proficient readers. These strategies include sustained comprehension, visualization, and making inferences. Comics also provide opportunities for readers to explore literacy concepts such as setting and characterization, and literary devices such as foreshadowing, point of view, and flashback. This paper provides a framework for educators to select high-quality comics that can be used to scaffold these and other literacy lessons for K-8 learners. It includes an annotated bibliography of print and digital curriculum guides to integrate comics in the classroom.

Haley M. Walton. ORCID Integration Among Publishing and Funding Organizations: An Examination of Process and Rationale. A Master's Paper for the M.S. in L.S. degree. July 2014. 57 pages. Advisor: Kevin L. Smith.

This study examines how a sample of scholarly publishers and granting organizations have integrated the Open Researcher and Contributor ID (ORCID) into their grant application and manuscript submission workflows. The study was conducted to discover what benefits these organizations gain from using the ORCID unique author identifiers and how effective they are at introducing scholars to ORCID as a service.

The data was collected through interviews of representatives from a sample of publishing and funding organizations: the National Institutes of Health, the U.S.
Department of Energy's Office of Science and Technical Information, the Wellcome Trust, Autism Speaks, Elsevier, and Oxford University Press. A representative from eJournalPress, a software company that provides manuscript management tools was also interviewed. The result is an analysis of best practices for ORCID integration at these types of organizations and suggestions for improvement. The conclusions drawn are generalizable to other institutions seeking to adopt ORCID themselves.

\section{Zachery P Whitaker. Moving With the Crowd: Gauging} the Prevalence and Execution of Crowdsourcing in Archives. A Master's Paper for the M.S. in L.S. degree. July, 2014. 50 pages. Advisor: Denise Anthony

This study describes an online survey sent to the Society of American Archivists' Archives and Archivists listserv to illicit responses from archivists regarding the use of crowdsourcing in archives. The survey was conducted to determine the prevalence of crowdsourcing in the archives profession. In addition, the survey sought to gain insight into the level of interest in crowdsourcing among archivists as well as the methods by which archivists have executed crowdsourcing projects.

Slightly over half of archivists surveyed indicated they have either engaged in, are currently engaging in, or have plans to engage in crowdsourcing, while seventy-nine percent of archivists who identified as having no plans to engage in crowdsourcing indicated they were slightly to very interested in the subject. In addition, the survey found that archivists execute crowdsourcing in myriad ways and often employ several technologies and competencies simultaneously.

\section{Winter 2014}

Kristen L. Bowen. UNC-Chapel Hill North Carolina Collection Fiction from 2000-2014. A Master's Paper for the M.S. in L.S degree. November, 2014. 45 pages. Advisor: Dr. Claudia J. Gollop

This study investigated how North Carolina fiction set in North Carolina has developed over the time period of 2000-2014. The North Carolina fiction studied was fiction held in the North Carolina Collection at UNC-Chapel Hill that had been published in the years 2000-2014 and was blogged on the Read North Carolina Novels blog. Seventy-five books were included in the study, and the genres, settings, and authors of these books were examined.

Based on the results of the study, the data revealed that the two most popular genres for the years of 2000-2014 were mystery and romance/relationship. These two genres 
contain different subgenres and are adaptable to appeal to a wide range of users and also to authors because of their marketability. However, the lack of science fiction/fantasy novels from these years demonstrates the importance of studying North Carolina fiction to determine what is actually occurring within this market.

\section{Lindsay J. Conway. Content Analysis of a Choir's Score} Annotations: Characterizing Annotations and Assessing a Coding Scheme. A Master's Paper for the M.S. in Library Science degree. November, 2014. 66 pages. Advisor: Ericka Patillo

Previous research has found that annotations Western classical musicians create in their sheet music during ensemble rehearsal play a key role in fostering group coordination during music performance. Despite their important role in musicians' information interactions with sheet music and with each other, a dearth of research exists regarding musicians' annotations. This study conducted a content analysis of annotations that singers in a 100 -voice choir created in 158 copies of music while rehearsing two pieces. More than 2,600 annotations were identified and classified according to a coding scheme previously developed by the most extensive study of musicians' score annotations to date. This study characterized choristers' annotations using the coding scheme. This paper offers an assessment of the coding scheme, suggestions for an improved research design, and ideas for future research of musicians' score annotations.

Vida Djaghouri. Gender, personality, and their effects on avatar customization for on-line video game environments. A Master's Paper for the M.S. in I.S. degree. November, 2014. 54 pages. Advisor: Richard J. Marciano

In light of the recent Gamergate controversy, the tension between male and female video game players is as discernable as ever. It behooves behavioral scientists, information scientists, and game developers to investigate the differences between men and women in video game environments, particularly in the ways in which they choose to physically represent themselves for online interaction. Several previous studies observed gender differences in avatar selection and customization, which typically only included human avatars as options to participants. Some of these studies also identified correlations between gender, Big Five personality traits, self-esteem, and avatar selection. The current study sought to improve upon these past studies by presenting other non-human races as additional avatar options. The results of the current study reflected similarities in men and women's avatar selection choices and corresponding personality traits to previous studies in terms of avatar-participant discrepancies in light of the additional non-human race options.

Caroline M. Eckardt. Meeting the Information Needs of Studio Art Students in the Academic Library: A Survey Conducted at the University of North Carolina-Chapel Hill. A Master's Paper for the M.S. in L.S. degree. November 2014. 32 pages. Advisor: Barbara B. Moran.

This study looks at the information-seeking behaviors of students enrolled in studio art courses at the University of North Carolina-Chapel Hill and the students' perceptions of the effectiveness of the library instruction session within their art courses. In an effort to contribute new findings to the established discourse on this topic, surveys were distributed to graduate and undergraduate students to determine similarities and differences in behaviors and perceptions. The results of the survey echo the findings of earlier literature on the information-seeking behaviors of studio art students, reinforcing the idea that this population seeks creative inspiration for their works from a variety of sources. Survey results also reveal that a majority of responders have attended library instruction sessions as part of a studio art course and have found these sessions useful in various ways when conducting research for art-based projects.

Barrye O. Brown. A Case Study on the Diversity Initiatives at the School of Information and Library Science at the University of North Carolina at Chapel Hill. A Master's Paper for the M.S. in L.S. degree. November, 2014. 40 pages. Advisor: Dr. Claudia Gollop

This study examined the diversity initiatives at the School of Information and Library Science at the University of North Carolina at Chapel Hill (UNC-SILS), as they pertain to the recruitment and retention of students and faculty from historically underrepresented groups. The case study method was used to gauge the extent to which "diversity" as a core value of the Information and Library Science profession has been embraced and implemented within the context of an Information and Library Science (ILS) school. As such, this study addresses the following questions: 1. What is the history of the UNC-SILS diversity initiative? 2. How have the objectives of the diversity initiative at UNC-SILS been identified? 3. What major steps have been taken to promote diversity at UNC-SILS? 4. What steps are being taken to assess the success of the short and long term effects of the diversity initiative? What measures will be used? 
Stacy R. Gilbert. As seen on TV and in the archive: A comparison of television shows in the Library of Congress Online Catalog, YouTube, and the Internet Archive. A Master's Paper for the M.S. in LS degree. November, 2014. 50 pages. Advisor: Ryan Shaw

The objective of this study is to compare the comprehensiveness of the television collections of a traditional archive, the Library of Congress Online Catalog, and video-sharing websites, YouTube and the Internet Archive. Content analysis was used to compare the collections and descriptions of U.S. television episodes. The collections were compared based on the comprehensiveness of genres and time, as well as the type and degree of descriptions. This study will build upon other research that compared YouTube to traditional archives. It will also provide further information on the similarities and differences between video-sharing websites and traditional archives by comparing three collections that have not been empirically studied before.

Hillary Hollinger. Preserving history in motion: using oral history to preserve and enhance the memory of a National Hockey League team and of the individual players. A Master's paper for the M.S. in L.S. degree. November, 2014. 31 pages. Advisor: Denise Anthony

This study describes a questionnaire survey of the Carolina Hurricanes fan base. The survey was conducted to establish fan interest in oral histories of the Carolina Hurricanes team and staff. 167 responses were received and analyzed. Participants answered three multiple-choice questions and two free-response questions offering opinions about the current state of the identity and team memory of the Carolina Hurricanes. It was determined that fans want more than what is being currently documented and presented as the history of the team. Desired types of information include greater fan recognition and inclusion, team history, and celebration of existence in a non-traditional market, all of which can be effectively captured by oral histories.

Joshua V. Leto. The Preservation, Curation, and Accessing of SILS Course Material Using the LifeTime Library. A Master's Paper for the M.S. in L.S. degree. October, 2014. 45 pages. Advisor: Arcot Rajasekar

Since the accretion of knowledge is a cumulative endeavor, it is a problem that all course materials used by students in UNC's School of Information and Library Science disappears after the completion of each semester. To remedy this problem I propose using the LifeTime Library to archive the course materials for each class offered at SILS and make the archive available for students. By creating an easy to use template, adding metadata and rules, students can find information about classes they are interested in taking, as well as access old syllabi, PowerPoint slides, class lectures, assignments, and notes.

Christine F Mayo. The Location of the Citation: Practice vs. Recommendations in Data Citation. A Master's Paper for the M.S. in L.S degree. November, 2014. 32 pages. Advisor: Todd Vision

Over the last decade, citation of archived scientific data have been the focus of intense debate. However, much of the work on data citation has centered around proposing specific formats for references. In the meantime, scientists have been creating and citing archived data sets, and we thus far lack a deep body of evidence to map the emerging best practices onto actual usage of data references.

This study sketches out some of those connections by examining references to data from the Dryad Digital Repository as appearing in articles collected in PMC Europe. I collected examples of references that appear in works cited lists and intratextually, and analyzed the occurrence of references over time, both by themselves and in conjunction with several other factors. This paper offers preliminary insights into current data citation practices, which hopefully can be used to help inform the discussion surrounding data citation.

Mary Mellon. "The Use of Cyrillic Metadata for Enhancing Discovery of Russian Digital Collection Items: A Case Study of the Bowman Gray World War I Postcards Digital Collection." A Master's paper for the M.S. in I.S. degree. November, 2014. 35 pages. Advisor: Denise Anthony.

This paper examines the online discoverability of multilingual digital collections, focusing on the effectiveness of romanized and original script metadata for providing access to materials in non-roman script languages. Using the World War I Postcards from the Bowman Gray Collection digital collection at the University of North Carolina at Chapel Hill as a case study, the dynamics of Russianlanguage user access to postcards with and without Cyrillic description were compared with those of other major language user groups accessing the collection.

While limited on a dependence on Google's system of determining user language, the results suggest that the nature of the Cyrillic metadata included in postcard records, limited to title, publisher, and other information transcribed from the resource in a bibliographic cataloging context, did not enhance the discoverability of the postcards. Moreover, every language group was at a distinct disadvantage 
compared to English-language users in terms of numbers of items discovered. In conclusion, I discuss various factors that may have affected these results, as well as implications for cultural heritage institutions with multilingual and multi-script collections.

Meredith McClure-Scott. Trainers, Shorten Thy Training! An experiment to predict the effectiveness of a high-quality, interactive electronic LC shelving training tool. A Master's Paper for the M.S. in L.S degree. November, 2014. 32 pages. Advisor: Robert M. Losee

Training students to work in academic libraries is important work. It is also constant, given the nature of student turnover. Therefore, library managers and trainers should seek efficiencies in training without sacrificing quality. One part of training to examine for efficiencies is LC (Library of Congress) shelving training. This study examines which characteristics the best interactive electronic LC shelving games share per a literature review. Then it compares the performance of twenty shelvers who trained with a high quality interactive electronic LC shelving training tool versus the performance of twenty shelvers who trained with an excellent static guide. The interactive electronic group scored higher on average and experienced fewer low scores on the LC shelving test. More significantly, the interactive group members pinpointed where they made errors, which suggests that library employees trained with interactive shelving tutorials would need less remediation than employees who were trained using static shelving guides.

Valerie A. Moore. Public Perception of the Differences Between Printed and Electronic Books: A Content Analysis. A Master's Paper for the M.S. in L.S degree. November, 2014. 77 pages. Advisor: Denise Anthony

This study investigated user perceptions of the differences between print and electronic books. Using Marshall McLuhan and others' contention that media are not neutral conduits of information but rather shape the information they convey according to their own affordances and biases, this study focused upon the fundamental differences that are based on each medium's essential nature. Seven such differences were drawn from the literature and were used to categorize comments posted to online discussion boards and blogs using qualitative content analysis. Comparisons on all seven dimensions were identified, with tangibility discussed most and the direction of information flow discussed least. Two additional dimensions emerged during the coding process which may form an additional category. The list of fundamental differences may help cultural institutions prioritize what to digitize and inform the discussion as to why these media may be different and suited to different uses.

Megan Proctor. The Chronically Ill Child: A Content Analysis Assessing The Realistic Portrayal of the "Illness Experience" for Child Characters in 21st Century Children's Picture Books. A Master's Paper for the M.S. in L.S. degree. November, 2014.90 pages. Advisor: Brian Sturm

The growing realism that has emerged in children's literature in the past several decades has made it possible for more complicated topics such as chronic illness to be considered. Despite the growing presence of illness in children's literature, chronically ill characters are still vastly underrepresented and are often portrayed negatively or only partially. This remains true even as more children are diagnosed yearly with a chronic condition.

Research suggests that for children's literature featuring chronically ill characters to be valuable to its young readers, it must be reflective of the realistic emotions and behaviors chronically ill people experience. The "illness experience" has been defined in this paper by medical, social, and emotional factors. The following content analysis considers whether twenty children's picture books published since 2000 realistically present the illness experience of childhood chronic illness.

Jody D. Smith. Deficiencies in the Collection of American Indian Children's Literature in North Carolina's Public Libraries. A Master's Paper for the M.S. in L.S degree. December, 2014. 72 pages. Advisor: Sandra Hughes-Hassell

North Carolina is home to the largest population of American Indians east of the Mississippi River, and the state with the seventh largest Indian population overall. Likewise, the nationwide Indian population is growing at a rate almost twice as fast as the U.S. average. Anticipating the needs of a growing population, it is important that public libraries in North Carolina provide Indian youth with books which provide culturally-affirming representations of Indian peoples, traditions, and histories.

For this study, the nine counties in North Carolina with the largest Indian populations were isolated using 2013 U.S. Census estimates. Then, utilizing the online public access catalogs of the public libraries serving those counties, bibliographic searches were conducted for a selection of 206 books recommended by professional reviewing authorities. The data indicate that less than a quarter of the selected titles have been collected by a majority of libraries in the subset. 
Jayasurya Somasunder. Designing and Creating a Database for Effective Storage and Retrieval of Pediatric Drugs. A Master's paper for the M.S. in I.S. degree. December, 2014. 46 pages. Advisor: Brad Hemminger

This paper discusses the creation of databases specially designed for pediatric drugs. There are many medical drugs databases available currently for adults but there is no database for pediatric drugs that can benefit end users who are looking for information specific to drugs for children. So the Division of Pediatric Hematology Oncology in UNC, Chapel Hill wants to have a repository to store and organize information about pediatric drugs in order to provide this information in a structured and easily accessible format that will benefit end users. This database will also be used to provide information to end-users especially consumers about drug repurposing i.e. using the same pediatric drug for more than one purpose.

Tana W. Stewart. Identifying Criteria Predictive of Successful and Unsuccessful Process Automation Projects. A Master's Paper for the M.S. in I.S degree. 12, 2014. 91 pages. Advisor: Stephanie W. Haas

The purpose of this study is to discover criteria that can be used to predict the type of candidate a process is for automation; good, or poor. Although automation has become the natural solution for organizations to enhance work processes, not all process are best improved by automation. Risks of changing a system with automation were identified in a literature review. Data about process automation projects, collected from IT professionals at a single organization, were analyzed in association with these risks. This study found that a process may be a good candidate for automation if risks to stakeholder interactions, risks in planning and stakeholder interactions, and risks in implementation and stakeholder interactions can be sufficiently managed, whereas a process may be a poor candidate for automation if the risks in planning, risks to stakeholder interactions, and risks in planning and stakeholder interactions cannot be sufficiently managed.

Luke A. Williamson. Exploring Mobile Knowledge Workers' Technological Barriers and Adoptive Strategies. A Master's Paper for the M.S. in I.S. degree. December, 2014. 48 pages. Advisor: Mohammad Jarrahi

This paper focuses on the technological barriers mobile knowledge workers contend with in their professional activities. In conducting an exploratory study of a small group, themes emerged regarding their technological barriers that eroded their capacity for mobility, which included interacting with associates remotely, incorporating mobile technologies into the suite of professional tools, and building a portfolio of applications and services that prioritized their efficiency. My analysis is developed from concepts in Ubiquitous Computing and sociotechnical theory. By analyzing their barriers and adoptive strategies, I suggest a framework that aims to identify barriers and associate them with solutions.

Christine J. Cherney. The Contemplative Space: How Theological Libraries Can be Hospitable to Their Patrons' Process of Reflection. A Master's Paper for the M.S. in L.S degree. December, 2014. 37 pages. Advisor: Brian Sturm

This paper answers the modern movement of library design toward group spaces and computer workstations, sometimes to the cost of quiet spaces needed for contemplation. The study and observation of places created to inspire contemplation will yield a sampling of common characteristics that will be gathered into a rubric, and which can then be applied to today's theological libraries, helping them remain hospitable to the process of reflection. Not an argument against modern trends, this is a call for the defense of the quiet, the solitude, and the beauty that were once defining hallmarks of every library.

Marli Johnston. Autism Spectrum Disorder Representation in Young Adult Literature: A Content Analysis. A Master's Paper for the M.S. in I/L.S degree. December, 2014. 49 pages. Advisor: Sandra Hughes-Hassell.

This study examines the representation of protagonists with Autism Spectrum Disorders (ASDs) in young adult literature. A sample of 11 books were analyzed in an attempt to determine the most common way this group of young adults were represented and what types of stereotypes may be perpetuated. The results of this study found that most characters were relatively realistic and overall were accurately represented.

Laura Vepraskas. An Evidence-Based Study of Social Media Use by Small Businesses. A Master's paper for the M.S. in I.S. degree. January, 2015. 135 pages. Advisor: Stephanie W. Haas

Over the past decade, social media networking has become increasingly valuable to individuals and other entities, such as small businesses for promotional means. Developed as a tool to help individuals interact, communicate, and exchange information, social media use can yield positive outcomes for small businesses as evident through financial gain and increased customer communication. 
Using Evidence-Based Practice (EBP) principles, this study evaluates the current body of literature regarding small business use of social media. Thirty articles were evaluated using a criteria checklist to develop recommended principles of how small businesses may best use social media in their future marking strategies.

\section{Spring 2015}

Lisa D. Becksford. What Do Composition Faculty Want Their Students to Learn? Examining Source Evaluation. A Master's Paper for the M.S. in L.S degree. April, 2015. 47 pages. Advisor: Claudia Gollop

Over the last 25 years, library instruction has come to include not only teaching students how to find sources, but also how to critically evaluate information. A common place for such instruction is the composition classroom, but little research has been done to learn about the attitudes of composition faculty in regards to teaching students these skills. Through interviews with composition instructors in North Carolina State University's first-year writing program (FYWP), this study sought to learn about the attitudes of composition instructors towards teaching students to evaluate sources, including what students should learn and who should teach them. Participants' responses indicate that composition instructors want their students to be able to distinguish between reliable and unreliable sources and develop a basic understanding of the context of scholarly communication. In addition, most participants believed that some form of collaboration with the library was the best way to teach source evaluation.

Faith A. Burns. The Library as an Intervention in Children's Health: An Assessment of How Five Public Libraries in North Carolina are Collecting and Circulating Children's Books that Promote Physical Activity.

A Master's Paper for the M.S. in L.S degree. April, 2015. 63 pages. Advisor: Dr. Mary Grace Flaherty Childhood obesity is a concern in the United States, with over onethird of children being overweight or obese. Obesity increases children's risks for chronic conditions, premature disability and death. Bibliotherapy is an intervention that encourages individuals to cope with life and health challenges through reading. It has been used to help children deal with issues and can be guided by a trained professional. Because of their professional skills, and the collection of materials in the library, librarians are at a unique position to use bibliotherapy to help children. With the growing emphasis on fighting obesity, many libraries have implemented initiatives and programs that encourage healthy lifestyle choices. This paper examines the extent to which five public libraries in North Carolina collect and circulate children's books promoting physical activity. The paper uses the data collected to assert that the studied libraries have a unique opportunity to help fight childhood obesity.

Alison Blaine. A Survey of How Organizations Address the Information Needs of Farmworkers and Considerations for Mobile Solutions. A Master's paper for the M.S. in I.S. degree. April, 2015. 47 pages. Advisor: Cliff Missen

This study describes results from a survey of organizations that deliver information to farmworkers and three semi-structured interviews related to mobile technology projects that address farmworker information needs. The survey was conducted to determine how organizations currently meet farmworker information needs and explore whether mobile technology is part of their information solutions. The interviews were conducted to provide examples of mobile solutions and offer considerations for organizations interested in exploring mobile options.

Brian M Burns. Physical Versus Digital Museums: The User Experience. A Master's Paper for the M.S. in LS degree. April, 2015. 26 pages. Advisor: Brad Hemminger

The purpose of this study is to distinguish the way people interact with artifacts in a physical environment versus a digital environment. As technology advances, we are getting closer and closer to having a more 'realistic' experience within digital museums. A literature review looks at the pros and cons of these advancements, and discusses what they mean for the future of museums. A study is conducted and concludes that while digital museums are a fantastic resource, they do not perfectly capture the experience one has within a physical museum.

Kelsey C.H. Chandler. Virtual Spaces and Physical Places: Analyzing Patron use of Digital and Physical Collections at the Louis Round Wilson Library, University of North Carolina, Chapel Hill. A Master's Paper for the M.S. in L.S degree. April. 2015. Year. 89 pages. Advisor: Dr. Denise Anthony

This study describes a multi-modal use assessment of the digital collections and corresponding special collections materials at Wilson Library, the University of North Carolina at Chapel Hill. The study includes: a study of Google Analytics data relating to specific digital collections, an analysis of physical collections use based on metadata provided by the Aeon request system, and a survey-based exploration of current user experiences and expectations 
regarding materials in Wilson Library's Special Collections.

Collections that data indicated were more popular had a higher bounce rate and a lower depth of exploration by patrons than collections with a smaller user population, the use of which suggested an in-depth, purposeful exploration of the collections. Subjects indicated interest as the most likely reason to use physical collection materials or visit a physical exhibit incorporating said materials, but also privileged accessibility and outreach as key components in use decisions. The study indicated an interest, among subjects, in more visible outreach and advertising regarding programming at Wilson Library and a need for greater awareness regarding the accessibility of special collections materials at Wilson Library.

Brett D. Currier. Comparing Dyslexia and Visual Impairments under W3C's WCAG: A Legal Standard for Web Design? A Paper for the M.S. in L.S degree: April, 2015. 51 pages: Advisor Amelia Gibson.

W3C's Web Content Accessibility Guidelines (WCAG) has become the de facto legal standard for web design based on recent settlement agreements. The Department of Justice has even tried to make WCAG the actual law. This paper examines the most common plaintiffs in successful Americans with Disabilities Act (ADA) litigation against colleges and universities (individuals with visual impairments) and compares these plaintiffs to individuals with dyslexia, as both populations are covered under the ADA, as both populations have the same affected major life activity: reading. After identifying the 15 overlapping Success Criteria, this review then uses a systematic review methodology to determine when designing for individuals with dyslexia, then it also creates accessible webpages for individuals with visual impairments and when they do not.

Kai Ewing. LGBTQ Center Resource Library Access: A Case Study. A Master's Paper for the M.S. in L.S degree. April, 2015.60 pages. Advisor: Sandra Hughes-Hassell.

This case study discusses why LGBTIQ collections are important, LGBTIQ people and their needs, a brief history of UNC and the LGBTQ Center, and work done at the LGBTQ Center's Resource Library. This included inventorying and cataloging the collection as well as working on the Resource Library webpage. Finally, the study addresses results of the reorganization process, limitations faced in this particular setting, and lists recommendations for other LGBTIQ groups, organizations, offices, and centers looking to increase the visibility of their collections.

By conducting and writing the results of this case study, I hope to contribute to the literature on how LGBTIQ organizations on college and university campuses develop and promote their collections. In particular, I hope to create a template LGBTIQ-focused organizations, centers, and offices can employ to build representative collections and represent their existing resource library in their institution's online catalog.

Gergana Dimitrova. Correlating Twitter Sentiment with Basketball Game Events and Characteristics. A Master's Paper for the M.S. in I.S degree. April, 2015. 75 pages. Advisor: Stephanie Haas.

This study performed sentiment analysis on Tweets created during 30 basketball games. 14,440 Tweets were collected using the Twitter Streaming API, parsed by a script and analyzed using the program SentiStrength. There was significant strong positive correlation between game sentiment of fan Tweets and the outcome of the game. Significant correlation was also found between fourth quarter sentiment of fan Tweets and the outcome of the game. Findings suggest that fans participate in live-Tweeting game events as a way to interact with the game and other fans. This study proposes that improvements can be made to sentiment analysis through domain-specific approaches such as improved domain dictionaries and lexicons.

Neda E. Defibaugh. Librarian Perceptions of Problematic Adult Behavior in the Teen Space. A Master's Paper for the M.S. in L.S degree. April, 2015. 43 pages. Advisor: Sandra Hughes-Hassell

This study investigated problematic adult behavior in the teen spaces of public libraries in North Carolina. Data was gathered through surveys and interviews, recruiting participants through the state listserv for children and youth services library staff. The results of this study found that problematic behavior commonly included adult use of space, invasion of teen privacy, predatory behavior, disregard of library policies or signage, and acting as authority figures towards teens within the space. This study concludes libraries should consider the role the physical library layout plays in problematic incidents, as well as foster cooperation among staff outside of youth or teen services in addressing problematic behavior in addition to current strategies for handling problematic adult behavior.

Kelly M Fullerton. Popular Reading Collections in Academic Libraries: Are they worth it? A Master's Paper for the M.S. in L.S degree. April, 2015. 43 pages. Advisor: Mary Grace Flaherty

Academic libraries, though situated within universities, are not purely for academic purposes and have made efforts 
to provide services that support the overall university life of students. These efforts include providing recreational reading materials to patrons. This paper is a case study of one particular leased recreational reading collection at a southeastern university that looks at how these collections are utilized by patrons and perceived by librarians. Circulation statistics for the collection were analyzed and interviews with librarians involved with the collection development and maintenance of the materials were conducted to consider how these collections fit within academia. Additionally, this paper includes a survey of 12 universities with similar collections to determine if the results from one university are broadly applicable to others. Research determined that popular reading collections have a demonstrated use for various patron groups and are valuable to both patrons and librarians.

Landon J Grindheim. Data Visualization Service: SQL vs. NoSQL. A Master's Paper for the M.S. in I.S degree. April, 2015. 36 pages. Advisor: Arcot Rajasekar

This paper compares the performance of a relational database (PostgreSQL) and NoSQL database (MongoDB) in retrieving sets of IP intelligence data for information visualization. After an overview of the history of the two database paradigms, a study reporting the performance of an instance of each is described. Also described is database performance in conjunction with visualization software. Results are compared and discussed. Finally, limitations of the study are discussed and areas of future research are introduced.

Paul D Farrell. Automating Author Gender Identification from Blogs. A Master's Paper for the M.S. in IS degree. April, 2015. 27 pages. Advisor: Stephanie Haas

The rapid growth of public blogging on the Internet has opened up a vast trove of information that can be text mined for potential insights. This study explores the potential of automating blog author gender based on differences in lexical expressions. The results of this study were mixed, and further refinement is needed.

Courtney Fenters. Evaluation of a Training Method for Library Cataloguing Volunteers. A Master's paper for the M.S. in L.S. degree. April, 2015. 46 pages. Advisor: Ericka Patillo

This paper describes a project conducted in conjunction with the library at the LGBT Center of Raleigh. Five volunteers were instructed to create catalog records for the same ten books, following only the instructions in a set of procedures called the cataloguing manual. Their work was then briefly discussed. The effectiveness of the manual was evaluated by comparing the participants' records with librarian-created "perfect" records for the same books. Participants' qualitative feedback was then incorporated into the final draft of the manual.

Charles S Fultineer. A Case Study and Literature Review: How Effective IT Governance is the Key to Successful Enterprise Resource Planning Deployments. A Master's Paper for the M.S. in IS degree. April, 2015. 43 pages. Advisor: Lew Hassell

Deploying an Enterprise Resource Planning (ERP) solution is a complex and risk laden program of work that not every company is successful in delivering. In this study, the author (an IT leader at a large pharmaceutical company) presents a case study where he draws upon his experiences and learnings from leading two ERP implementations, as well as a literature review examining whether the author's hypothesis that IT Governance is the critical success factor in ERP deployments is supported amongst IT industry researchers, analysts, and strategists. The study goes was able show a strong correlation between companies who have strong IT Governance presence on ERP deployments and their ability to deliver the program of work successfully.

Catherine Field. A window opened on the library: An analysis of public library marketing. Master's paper for the M.S. in L.S. degree. April, 2015. 48 pages. Advisor: Mary Grace Flaherty

This study performed content analysis on nine library websites, which were deemed to be leading libraries by The Library Journal's Star Index. The content analysis was conducted to determine what America's leading public libraries were doing to market their services. First the cycle of marketing was divided into four necessary steps: analysis, planning, implementation, and evaluation. Twelve indicators were developed to represent the different steps in the marketing process. The websites were searched for evidence of these twelve indicators, and the results varied greatly from library to library. Four of the indicators were found on every library's website, showing that public libraries are currently placing importance on library logos and branding, social media accounts, online resources, and patron contact forms. Overall the findings suggest that libraries are doing some steps in the marketing process, but they lack cohesion and connection.

Halley L. Hair. Investigating the information needs of interdisciplinary research centers: A content analysis. 
A Master's paper for the M.S. in L.S. degree. April, 2015. 32 pages. Advisor: Rebecca Vargha

This study describes a content analysis of the websites of interdisciplinary research centers co-located on and associated with university campuses. The purpose of the study was two-fold; first, to determine whether the information needs of interdisciplinary research centers were indicated on their websites, and second, whether these needs appear to be met by current academic library partnerships or services. Little evidence was observed of services or partnerships between academic libraries and interdisciplinary research centers. This analysis fills a gap in the literature, as research on the relationships between interdisciplinary research centers and academic libraries has been limited. The study uses a small sample of twenty-five websites in order to develop themes and categories upon which later research might be based.

Michael E. Head. Change Blindness in Web Applications. A Master's Paper for the M.S. in I.S degree. April, 2015. 52 pages. Advisor: Todd Barlow

Design practitioners have long believed that web interfaces are at a disadvantage compared to desktop interfaces because the web page model may cause change blindness more than non-page based interfaces. To evaluate this concern, a within-subjects experiment was set up to test various change types in a mock web application. User performance was better when a page loaded as normal and when elements changed instantly on screen compared to a half-second flicker change type. However, change detection rates were only $5 \%$ greater and response times only 0.1 second faster for the instant change compared to page loading. This shows that there is some change blindness effect due to the Web's page-by-page architecture, but it is not nearly as disconcerting as practitioners have long believed. Furthermore, single page applications that minimize full-page refreshes may help reduce the incidence of change blindness on the web.

Elizabeth M. Huessy. Change Makers: An Annotated Bibliography of Social Action in Children's and Young Adult Literature. A Master's Paper for the M.S. in L.S degree. April, 2015. 54 pages. Advisor: Sandra HughesHassell

A recent focus in education on the importance of teaching social justice issues necessitates the creation of resources to support teachers and librarians in this work. This annotated bibliography recommends a selection of children's and young adult literature that features social action and social justice in the areas of human and civil rights, labor and community organizing, and the environment and animal welfare. This resource is not comprehensive, rather it highlights a selection of high-quality literature published in the last twenty years that through the genres of realistic fiction, historical fiction, narrative non-fiction and biography, provides models of social action for young people. Through identification with the literary role models in these works, children and teens can begin to understand the myriad forms that social justice can take and be empowered to make change in their own lives. This, then, is a collection of works for exploring the lives of historical change makers, imagining fictional ones, and identifying with the unsung heroes in our midst today.

\section{Joy E. Jones. We share what we are: user contributions} and annotations in digital contributory archives. A Master's Paper for the M.S. in L.S. degree. April, 2015. 45 pages. Advisor: Ryan Shaw

A contributory archive is one in which individual users may interact with materials through activities like commenting, tagging and sharing, but more importantly they may add content to the collection through uploading items like photos or videos and adding stories and text. This paper examines the community-led contributory archives listed at the website for the UK Community Archives and Heritage Group (www.communityarchives.org.uk), an umbrella organization that provides a central location for community archives, as a case study for expanding our knowledge of user participation in digital archives. This study examines user-generated content in digital community archives including annotations and contributions, the type and frequency of content created, and technical specifications as insight into amateur digital preservation of heritage materials. The information gleaned from this study can be used to assess the effectiveness of communityled projects as a possibility for cultural heritage centers to expand their mission in a participatory platform.

Lynne E. Jones. Graduate Education in Cataloging: What Courses and Competencies Are Being Taught?. A Master's Paper for the M.S. in L.S degree. April, 2015. 41 pages. Advisor: Wanda Gunther

This study has, through crafting a list of competencies for catalogers, analyzing course offerings, and conducting a content analysis of syllabi, attempted to describe the current state of cataloging education in ALA accredited graduate programs for library and information science. A review of the literature has yielded a list of seventeen basic competencies in several different topical areas. Analyzing course offerings has shown that of the fourteen selected 
schools, all have at least two courses that contained cataloging content. The analysis of syllabi revealed that adequately addressed competencies include cataloging and classification standards, general knowledge of theory and tools, subject analysis, and the theory behind and format of authority records. However, courses do not properly address competencies in the areas of bibliographic utilities, understanding of library catalogs and integrated library systems, practical skills for authority work, an understanding of cooperative programs and groups in the field, and metadata instruction.

Evgeniia Kazymova. Carolina Health Informatics Program website overhaul to improve usability and information access. A Master's Paper for the M.S. in I.S. degree. April, 2015. 42 pages. Advisor: Javed Mostafa

The Carolina Health Informatics Program (CHIP) is a new program at the University of North Carolina at Chapel Hill that conducts research and training in health sciences by applying informatics approaches. The CHIP "Faculty, Scholars and Researchers" webpage (http://chip.unc.edu/ faculty-scholars-researchers/) provides information about the CHIP faculty and researchers. The goal of this project is to enhance the webpage by adding dynamically updatable information about each member's current research. The goal was achieved by retrieving the information from Google Scholar and PubMed databases by executing the client-side and server-side code written in JavaScript/JQuery, PHP, CCS, and Ajax. A usability study was performed to assess the enhanced webpage. Based on the usability study findings, the prototype system was improved and further suggestions for improvements were proposed. The usability study demonstrated that the developed prototype greatly enhanced the usefulness of the website and helped to achieve CHIP's goal to provide easy access to the current research information for each faculty member.

Anna B. Loewenthal. Comparing Representations of Race in Finding Aids Over Time. A Master's Paper for the M.S. in L.S. degree. April, 2015. 42 pages. Advisor: Denise Anthony

This study compares two sets of finding aids about the same set of collections, written in the early 1990s and updated in 2011, in UNC's Southern Historical Collection. Instances of race terms, particularly as relating to black people, were compared between the finding aids to discover how representations of race have changed over time. The study revealed a decrease in the use of "negro" with an increase in the use of "African American." The word "slave" in both sets of finding aids most often identified the presence of black people in the collections. Archivists updated their race terms, but there were ultimately fewer instances of race words, which in some instances lead to a loss of representation.

Ashleigh N. Lumpkin Stevens. Sheet Music Cover Art: A Case Study in Institutions' Guidelines and Practices. A Master's Paper for the M.S. in L.S degree. April, 2015. 40 pages. Advisor: Ericka Patillo

Sheet music cover art is a seldom studied point of access for users in the modern library. While research is beginning to recognize that users desire greater discoverability via cover art, it is not known how this is being handled currently in music institutions' collections. In this study three institution's collections are studied to establish the community's guidelines and practices for describing cover art. Through comparative case studies, the study found that the process and practice of description for cover art is a complex mixture of standards, research, and institutional limitations. This amalgam, while based in standards, was found to be overall ineffective in presenting cover art for users. Issues of definition, transparency, and aging were identified to compound this.

McAdams, Jessica. Portrayals and Presence of Adult Female Characters in Children's Picture Books: A Content Analysis of Bestsellers from the Past Five Years. A Master's paper for the M.S. in L.S. degree. April, 2015. 55 pages. Advisor: Brian W. Sturm.

This paper presents a content analysis of thirty-one bestselling picture books from the years 2010 - 2014 in order to reveal how women are portrayed to children. The purpose of the study was to discover whether or not young readers are receiving stereotypical gender representations through picture books that can affect their view of gender roles in society. The analysis explores professional roles adult female characters held in these books as well as what they were performing, where they were physically located, and what they were wearing.

The results of the content analysis revealed that women are more frequently present in children's picture books than men. These female characters however, are not representative of the abundance of job opportunities available to women today; rather they are predominately depicted as mothers with their primary responsibility being caring for children and other household duties. These results suggest that there has been progress towards gender equality in picture books but there is still more work to be done to ensure that the breadth of male and female gender roles is showcased. 
Elizabeth J. McGlynn. Information Literacy by Design: Creating a Teaching \& Training Template for Developing Library Instructors. A Master's Paper for the M.S. in L.S degree. April, 2015. 47 pages. Advisor: Jonathan McMichael

To meet increased demand for library instruction, many academic research and instruction departments rely on pre- and paraprofessional librarians to teach classes. However, due to the general lack of teaching experience these staff members tend to possess at the time of their hire, they often have to receive extra training. This paper documents the process of creating a framework for developing instructors at the University of North Carolina's Undergraduate Library, entitled Information Literacy by Design (ILbD). Based on Wiggins and McTighe's Understanding by Design, this framework acts as supplemental training for new and developing instructors, equips them with a template for creating lesson plans, and provides a web-based outlet for them to share their work.

Grant L McLendon. Talking Back: How Congress Engages With the Public on Twitter. A Master's Paper for the M.S. in IS degree. April, 2015. 27 pages. Advisor: Jaime Arguello

This paper examines political social media interaction between Members of the United States Congress and the general public on Twitter. Specifically it attempts to gain a better understanding of what motivates a Member of Congress to reply to a tweet by building a model to predict which tweets Members of Congress will reply to. Predicting social media interaction of elected Members of Congress is a challenging machine learning task. MOCs reply more often to positive tweets based on personal interactions they have had and positive feedback. The distribution of reply to non-reply tweets makes predicting responses very error prone. In this process a several methods of predicting rare events in text were attempted with inconclusive results.

Shelby L. Merritt. Describing Historical Objects for Users with Subject Knowledge: Lessons from the Charles Kuralt Learning Center. A Master's Paper for the M.S. in L.S degree. April, 2015. 45 pages. Advisor: Denise Anthony

The research on improving the accessibility of descriptive records for cultural objects is extensive. Such studies, ranging from indexing and subject access to experiments with social tagging, have historically focused primarily on art objects to the neglect of other cultural objects, however. Utilizing the Charles Kuralt Learning Center, a collection of historical objects at the University of North Carolina-Chapel
Hill, this study explores the needs of a specific user groupresearchers with relevant subject knowledge-when using descriptive object records for research. Three major themes emerged during the data analysis process: the contextualization of objects; the relationships between object records; and an interest in confirmation, validation, and authenticity.

Katherine L. Meyer. Towards a Definition of Minimalism: Principles of Minimal Visual Design in Web Interfaces. A Master's Paper for the M.S. in I.S degree. March, 2015. 58 pages. Advisor: Dr. Ronald Bergquist

"Minimalist" has grown into more than just a buzzword amongst Web designers. In the past ten years, a minimalist design aesthetic has rapidly gained popularity and respect in mainstream Web audiences. Most Web design experts agree that minimalist Web designers approach their work with a 'less-is-more' philosophy: only absolutely necessary graphic and content elements should be included. However, Web design experts differ in the details, and each has a slightly different argument about what characteristics qualify as minimalist.

This study surveys the writings of several prominent Web design experts to tease out a working definition of what constitutes a minimalist Web interface. The study then codes a sample of minimalist interfaces based on the most important characteristics of minimalism, as determined by the working definition. The results suggest that visual focus on primary content, flat graphic design, and restricted color palettes are important features of minimalist websites.

Hillary K. Miller. Securing Text and Data Mining Rights for Researchers in Academic Libraries. A Master's Paper for the M.S. in L.S degree. April, 2015. 50 pages. Advisor: Anne Klinefelter

This study describes the results of an online survey of librarians involved in license negotiations at academic institutions in the United States. The survey sought to discover the approaches taken by academic librarians to secure text and data mining rights through licensing of electronic resources.

Kathleen A. Monahan. “can i h31p u?”: Analyzing Chat Reference Questions in a Special Collections Library. A Master's Paper for the M.S. in L.S degree. May 2015. 49 pages. Advisor: Claudia Gollop.

This study examines the types of questions asked via chat reference in a special collections library at a public university. Examining a year of chat transcripts (115 
transcripts in total), this study categorized questions as research, ready reference, directional, policy and procedural, holdings/do you own, and reproduction requests. It also examined whether questions asked via chat were answered entirely within the chat conversation or if the staff referred the patron to email in order to answer the question at a later time. The study found that $36.7 \%$ of total questions were research questions and that $45 \%$ of questions were answered completely in chat while $55 \%$ were referred to email.

Sarah E. Morris. Evaluating the Impact of the StudentAthlete Library Liaison Program at the University of North Carolina- Chapel Hill. A Master's Paper for the M.S. in L.S degree. April, 2015. 46 pages. Advisor: Ericka Patillo

This plan was created to assess the impact of the StudentAthlete Library Liaison Program on student-athletes' selfefficacy when approaching library resources. The program is an initiative of the library to ensure it is meeting studentathletes' information needs. The program uses an embedded model where library tutors hold drop-in hours at the athletic center at UNC. The evaluation action plan includes pre- and post-intervention surveys developed to measure self-efficacy and the impact of immediacy and location on student-athletes' comfort with the library resources. The assessment plan can be implemented by tutors during and after sessions, and this paper discusses potential setbacks and opportunities when libraries evaluate programs involving student-athletes.

David O'Ferrell. Introducing an Enterprise Project Management Tool into an Agile Development Environment: Fit and Performance Impact. A Master's Paper for the M.S. in I.S. degree. May, 2015. 68 pages. Advisor: Barbara Wildemuth

The principles of Agile software development promote interactions over tools, but practical application of Agile can demand a considerable amount of structure from software development teams. Vendor software solutions specifically designed for Agile work offer an alternative for many organizations still using manual methods or ill-fitted tools. In this study, we examined task-tool fit between functionality provided by a vetted Agile software solution, and tasks needing to be accomplished by software development teams practicing Agile Scrum methods. A high level of task-tool fit was determined for tasks within several Scrum summary activities. Also evaluated was task-tool fit impact on actual performance of Scrum teams. Quantitative metrics demonstrated an average overall increase in performance after tool implementation for accomplishment of tasks within two Scrum summary activities being measured (Sprint Planning and Sprint Execution). It is suggested this performance improvement can be generally attributed to the determined high level of task-tool fit.

\section{John O'Connor. Towards a Profile of Open Government} Data Users. A Master's Paper for the M.S. in I.S. degree. April, 2015. 65 pages. Advisor: Prof. Paul Jones

This paper studies the user bases of two large open data initiatives in the United States in order to determine a profile of the users of open data services. Survey data from Open Raleigh (Raleigh, NC) and DataSF (San Francisco, CA) are used in combination to determine demographics of open data users. Discussion includes implications of demographics on the future of open data initiatives and whether the demographics as they exist today are acceptable for programs funded by the public at large.

Jamie A. Patrick-Burns. History and Genealogy: A Study of the Relationship between Genealogical Research and Interest in History. A Master's Paper for the M.S. in L.S degree. April, 2015. 50 pages. Advisor: Helen Tibbo

Genealogists make up an important segment of libraries' and archives' user population. This study explores the connection between genealogical research and interest in history to better understand user interests and needs. A survey of three North Carolina genealogical societies was compared to the answers of graduate students at the University of North Carolina - Chapel Hill. The results indicate that genealogists tended to be more interested in history in general than the students and revealed some common motivations for genealogical research between the two groups. Both groups enjoyed learning the context of ancestors' lives, exploring the continuity of family traits, and building a narrative. Distinct from the students, genealogists also tended to like community, the learning process, and problem-solving. These findings can help information professionals develop more effective resources for and provide better service to their genealogist patrons.

Elizabeth I. Peele. Forming Your Terrorist Network: ISIS, Twitter, and the Terrorist Propaganda Campaign. A Master's Paper for the M.S. in IS degree. April, 2015. 77 pages. Advisor: Mohammad Hossein Jarrahi

Since the founding of the Caliphate in June 2014, the Islamic State of Iraq and Syria has gained worldwide media attention for its campaign of violence across Iraq and Syria. Social media, particularly Twitter, has become a main aspect of ISIS's media campaign. It has been used to spread 
propagandistic images and videos of ISIS into the Twittersphere. This propaganda is important to ISIS because it spreads their message far past its occupied borders and helps to gain support from a wider audience. Using social media analysis and Twitter's own APIs, this research focused on ISIS's Twitter propaganda campaign and sought to discover the underlying network structure. The resulting network structure - scale-free - is then analyzed to see how it affects ISIS's dissemination of propaganda on Twitter. Ultimately, this research hopes to start a conversation on how network structure can be used to stop terrorist organizations from spreading their message online.

Mary E. Peterson. Not-so Social Media: Citizen-Legislator Communications in the Digital Age. A Master's Paper for the M.S. in I.S. degree. April, 2015. 48 pages. Advisor: Jaime Arguello

This exploratory analysis investigates how constituents talk to their members of Congress via the popular microblogging site, Twitter. An analysis was performed on roughly 3500 tweets sent to members of Congress over a 6-week period by developing a novel categorization system and then applying the categories both with human annotators and machine learning.

Jonathan L. Pulliza. An Analysis of Speculative Language in SEC 10-K Filings. A Master's Paper for the M.S. in I.S degree. May 201536 pages. Advisor: Stephanie W. Haas

This study applies sentiment analysis techniques to model the usage of speculation within a collection of financial documents. The model is trained on the MPQA corpus to extract features that correlate with speculative sentences and applied to a collection of SEC 10-K documents from a five year period. The documents with the highest amount of speculation contained a different concentration of terms compared to the entire collection, and the sentences mostly consisted of explaining potential risks concerning projects, taxes, and pensions.

Michael Schaffer. Law School Mission Statements and Librarians' Perceptions: An Analysis of Law School Library Practices. A Master's Paper for the M.S. in I.S. degree. April 2015. 43 pages. Advisor: William Cross

This study examines the mission statements of three different law schools and compares those stated missions to the actual practices of the affiliated law school library. In an attempt to better understand the purpose of law school libraries and what influences their practices, librarians at three law schools with differing missions were interviewed regarding the practices, policies and priorities of the library and the results from those interviews were compared to the content of the libraries' related law school's mission statement. The findings in this study prove that the mission of a law school has a great influence on the practices of the school's library, and the practices of those libraries play a significant role in assisting the school in carrying out its mission. In addition, the findings of this study highlights ways in which law school library practices can both differ and be similar.

Oak Ritchie. Platform Algorithms and Their Effect on Civic and Political Arenas. A Master's Paper for the M.S. in IS degree. April, 2015. 66 pages. Advisor: Dr. Zeynep Tufekci

The purpose of this research was to analyze the ways that social media platform algorithms affect user experience and thus, civic and political arenas. This paper analyzes literature on the topic that will illuminate specific ways that algorithms dictate to the user what is visible or invisible, considered "fresh" or "irrelevant" and the implications of such digital curating.

C. Allison Sills. Library Services for the Homebound: You Can Afford It. A Master's Paper for the M.S. in L.S. degree. April 2015. 38 pages. Advisor: Mary Grace Flaherty

Homebound patrons are an often-overlooked population, though their needs like their size are growing. This paper examines literature about the population, their needs and the methods used to reach them. Included is research about several North Carolina public library homebound programs that show real world examples of different delivery methods. Different delivery methods include home delivery and mail delivery. Examination of those methods can be used to determine, from a variety of different methods, which method may be financially feasible for a library seeking to add homebound service in their community.

Lindsey J. Smith. Users and Special Collections: Access and Outreach Awareness at the University of North Carolina's Wilson Library. A Master's Paper for the M.S. in L.S degree. April, 2015. 53 pages. Advisor: Denise Anthony

This study examines the experiences of a sample of users of the Wilson Library Special Collections. Issues of accessibility, outreach effectiveness, and user satisfaction are addressed, including access to digitized collections, user awareness of outreach activities, and patron experiences 
with the spaces and resources available for their use. Survey results are discussed and suggest that, from this small sample, user priorities and those of archivists may differ in their scope. When developing collections, outreach programs, collection websites, and other user tools and spaces, special collections professionals should take into account their desired audience and examine their needs as objectively as possible to make such activities as successful as possible.

Kyle J. Shaffer. Predicting Speech Acts in MOOC Forum Posts Using Conditional Random Fields. A Master's Paper for the M.S. in I.S degree. April, 2015. 54 pages. Advisor: Jaime Arguello

Massive Open Online Courses (MOOCs) have emerged as a way to reach large numbers of students by providing course materials as free online resources. The popularity of these courses has been reflected in high enrollment numbers, however it is unclear how successful MOOCs are at educating their students given their high attrition rates. One cause for this may be due to instructors' inability to manage the large number of students that enroll. While discussion forums are available for students to seek help, instructors are unable to monitor the large number of posts written in these forums. This study investigates the effectiveness of using machine learning models to classify posts into speech acts as a way to help instructors monitor these discussion forums. Speech acts describe the purpose of a post and may be indicative of common functions such as asking questions or raising issues. A linear classifier is compared against a conditional random field (CRF) classifier, which is able to leverage contextual information about the forum in order to make predictions. The results of this study find that CRFs outperform a simpler linear classifier, and this suggests that casting this prediction problem as a sequence labeling task is fruitful for predicting these speech acts, and automatically identifying posts of interest.

Anna M. Snyder. Stages of E-Government Service in North Carolina Counties: Examining the Inventory. A Master's Paper for the M.S.in L.S degree. March 2015. 101 pages. Advisor: Evelyn Daniel.

This study examines the use of e-government services by North Carolina county governments. The study was conducted to investigate at what stage of e-government North Carolina counties have reached. Three variables were examined to determine which, if any, could explain the e-government stage where the counties are the three variables were region, economic development tier level, and broadband access. Methods employed over the course of the study included sending a survey to county IT directors and managers, and examining county websites in the case of non-response. Zero counties were found to be at the Presence stage, while 13\% were found to be at the Interactive stage, and $87 \%$ are at the Transactional stage — which was divided into Early and Advanced Transactional stages for closer inspection. Though the variables individually can impact Internet or e-government uses, none of them completely explain the e-government stage of North Carolina counties.

\section{Rebecca Solomon. Personal Digital Photograph Man- agement and the Impact of Social Media. A Master's paper for the M.S. in I.S. degree. April, 2015. 53 pages. Advisor: Robert Capra}

This study describes eight one-on-one interviews of UNC-Chapel Hill undergraduate students about their digital photograph collection. Analysis of the interviews explores how participants manage their personal digital photographs and the influence of social media on their collection management. The participants discussed why they post photographs to social media, why they delete photographs from their devices and social media, and how they transfer photographs between their multiple devices. They also discussed their photograph management through the lifecycle of a photograph, from capturing, editing, sharing, and storing an image on their devices. The social media sites used by the participants included Facebook, Instagram, Twitter, Google+, and Picasa.

Caroline A. Simpson. Nonprofit Use of Information Visualization. A Master's Paper for the M.S. in L.S. degree. April, 2015. 47 pages. Advisor: David Gotz

This study explores how nonprofit organizations implement information visualization in their operations. Nine nonprofit employees were interviewed to better understand how these organizations use information visualizations to make decisions, plan for the future, and communicate information insights to stakeholders.

Expertise and use of information visualization in nonprofits seems to be growing. Interestingly, some nonprofits create information visualizations and tools that foster relationships with stakeholders and spread the use of data to different levels of the organization and various partner organizations. Most nonprofits interviewed use information visualizations on some level in both internal and external organizational activities although many lack standards for creating visualizations and methods for evaluating the effectiveness of the visuals they create. 
Margaret Southwell. "I Don't Care What Color You Are": The Depiction of Adolescent Interracial Romances in Young Adult Novels. A Master's paper for the M.S. in L.S. degree. April, 2015. 65 pages. Advisor: Brian Sturm.

This study used qualitative content analysis to examine the way in which adolescent interracial romances are portrayed in Young Adult novels. The purpose of the study was not only to identify the consistent, overarching themes in the novels but also to compare their depiction of adolescent interracial romances to the research on the reality of the experience of these relationships. Seven realistic fiction, YA novels in which the protagonists date interracially were selected for the study, and analyzed in depth using several guiding questions based on the literature, emergent coding, and the constant comparative method. Overall, the study found that the portrayal of adolescent interracial romances in these novels was positive, encouraging the hope for a more tolerant, integrated society in the future. Surprisingly, race was not the focus of most of the novels, and the difference in race was often only a secondary obstacle to the relationships.

Emily D. Spunaugle. Books Unre(a)d : The Institutional Logics of Soviet Book Procurement in the Wake of the Foreign Agents Registration Act. A Master's Paper for the M.S.L.S degree. April, 2015. 76 pages. Advisor: Stewart Varner.

The Foreign Agents Registration Act (FARA) of 1938 was instrumental in detaining or destroying solicited and unsolicited mail from the Soviet Union bound for American addressees, including libraries and research centers, until the 1960s. FARA appears briefly in library literature, but no in-depth examination of its mechanisms and effects has been hazarded. This study posits a model for representing the importation and circulation of materials using Roger Friedland and Robert R. Alford's (1991) concept of institutional logics, highlighting the tension created through the competing interpretations of FARA of the Soviet export house, Department of Justice, Department of State, Post Office Department, Customs Bureau, booksellers, and research libraries. FARA's perniciousness coincided with the library's fundamental shift in institutional ethics, as the profession became politicized amid the coalescence of contemporary notions of intellectual freedom.

Julie N. Stivers. The Graphic Novel Gap: Collection Strength and School Librarian Understandings of Graphic Novel Benefits. A Master's Paper for the M.S. in L.S degree. April, 2015. 43 pages. Advisor: Sandra Hughes-Hassell
Educators and researchers advocate for including graphic novels in both the school library and curriculum, as a wide range of literacy benefits have been identified for both specific groups of youth — and students as a whole. Despite this professional advice however, school librarians differ in the extent and manner in which they collect and promote these materials. This research examined school librarian attitudes, behaviors, and collection habits regarding graphic novels to better understand the reasoning behind collection choices and how these factors were affected by librarians' knowledge of graphic novel benefits. Interview data and collection analyses comparing libraries with study-specified strong and weak collections showed that expressed belief in the importance of graphic novels did not always translate into accompanying levels of use. Those libraries with the strongest collections, however, promoted the format heavily in their own libraries and advocated graphic novel use throughout their schools.

Sarah D. Thornton. Factors Influencing Changes in Public Library Adult Programming: A Look at Program Practices in Two North Carolina Public Libraries. A Master's Paper for the M.S. in L.S degree. April, 2015. 44 pages. Advisor: Mary Grace Flaherty

This study describes an examination of the history and current practices of adult programming in two North Carolina public libraries. The examination was conducted to determine the current state of adult programming in public libraries, as well as the factors that have influenced its changes.

Public libraries have begun to offer more diverse types of adult programming for their patrons. For example, some categories of programming being offered that have recently grown in prevalence are Entertainment, Arts/Crafts, and Health. This is due to a combination of many factors, and reasons vary between communities. The most significant factor affecting the planning of adult programs is the preferences of an individual community. Librarians must take into account what their communities need and desire from the library in order to have successful programs.

Rachel D. Walton. Looking for Answers: A Usability Study of Online Finding Aid Navigation. A Master's Paper for the M.S. in L.S degree. April, 2015. 76 pages. Advisor: Helen Tibbo

In an effort to move towards a practical and user-centered model for online finding aid navigation, this usability study asks -- what kind of navigational features are effective, efficient, and user-valued components within an academic archive's online finding aid? Using Princeton University's 
Finding Aid website as a prototype, the researcher collected quantitative as well as qualitative data from ten relatively inexperienced online finding aid users as they interacted with and reacted to the finding aid interface in question. The results of the study suggest major navigational difficulties experienced by users included ambiguous and/or unintuitive labeling, unclear relationships between tabs, and insufficient visual cues for certain navigational features. In contrast, uservalued navigation aids included centralized hyperlinked content, nested and hierarchical content tabs, and a collection-level search bar. The paper concludes with ten pragmatic guidelines for archival professionals trying to solve the ongoing puzzle of online archival finding aid usability.

Mari EA Warren. The Value of the Stone Center Library in the African-American Undergraduate Experience. A Master's Paper for the M.S. in L.S degree. April, 2015. 33 pages. Advisor: Amelia Gibson

This study describes how African-American students use and perceive the library within the Sonja Haynes Stone Center for Black Culture and its impact on their undergraduate experience. On the campus of the University of North Carolina at Chapel Hill, six interviews were done with undergraduate students ranging in ages from 18-22 and across classifications.

Students generally found the library as an important space, but there is some hesitancy as to whether it is an important part of the black experience as an undergraduate. They took value in the history and culture preserved in the space, and felt welcome when visiting. Students are also split when deciding whether they would be willing to fight to support the space and feel that it should be better utilized.

Emily A Yates. Exploring Local History through Primary Sources: Model Lesson Plans for High School Teachers and Librarians. A Master's Paper for the M.S. in L.S degree. April, 2015. 72 pages. Advisor: Sandra HughesHassell

This paper documents the process of creating lesson plans that use primary sources to teach about the movement toward civil rights in Durham, North Carolina. It also discusses the creation of a website designed to house the lesson plans and offers teachers and librarians resources on how to find and select primary sources. The lesson plans were created using backward design, and are grounded in elements of inquiry-based learning. The paper explores the benefits of teaching local history with primary sources, and supports this research by examining how primary sources can help diversify history instruction through critical race theory's concept of counter-storytelling. The website can be accessed at https://localhistorythroughprimarysources. wordpress.com/.

Katie G. Womble. Collaboration between Library Publishing Services and University Presses. A Master's Paper for the M.S. in I.S. degree. April, 2015.58 pages. Advisor: Amelia Gibson

The rapid pace of change in scholarly communication in the digital age has led many academic research libraries to adopt new roles as scholarly publishers, while university presses have also been in a state of changing roles. Qualitative research explores both the development of these library publishing services at responding libraries and how these services collaborate and relate to the university presses at their host institutions. Results demonstrate a variety of degrees of collaboration between library publishing services and university presses.

Karna Younger. The Politics of College Reading Programs in South Carolina: A case study of the College of Charleston and the University of South Carolina Upstate, 20132014. A Master's paper for the M.S. in L.S. degree. April 10, 2015. 124 pages. Advisor: Mary Grace Flaherty

This study analyzes the political response to and the resulting state budget cuts of the college reading programs at the College of Charleston and the University of South Carolina Upstate in the 2013-2014 academic year. Three participants in the events were interviewed: the directors of both reading programs and one state senator involved with the political debate. Coupled with an analysis of media reports, these interviews provided insight into why and how state politicians elected to cut the budgets for program and how these budget cuts affected the programs. Studying the South Carolina cases provides an example of how reading program directors can cope with political backlash, and how reading programs can simultaneously build and disrupt community.

Yonghao Yu. Research on Augmented Reality Technology and Build AR Application on Google Glass. A Master's Paper for the M.S. in I.S degree. April, 2015. 42 pages. Advisor: Brad Hemminger

This article introduces augmented reality technology, some current applications, and augmented reality technology for wearable devices. Then it introduces how to use NyARToolKit as a software library to build AR applications.

The article also introduces how to design an AR application in Google Glass. The application can recognize two different images through NyARToolKit build-in 
function. After find match pattern files, the application will draw different $3 \mathrm{D}$ graphics according to different input images.

Zekun Yu. Title. Web Design for Low Bandwidth Area. A Master's Paper for the M.S. in I.S degree. April, 2015. 30 pages. Advisor: Cliff Missen

This study gives an overview of the issues and solutions to develop Web sites for low bandwidth areas. It sheds lights on the fields in web design, cross-cultural environment, low bandwidth, and mobile web design. It provides some examples and potential solutions from the design and technique perspective to solve low bandwidth problems. And finally a demo project was created to prove the correctness of the analysis.

Chunxi Zhang. Usability Evaluation of A Clinical Knowledge Summary System. A Master's Paper for the M.S. in I.S degree. April, 2015. 36 pages. Advisor: Javed Mostafa

Physicians frequently raise questions during patient visits and around half of those questions are not even pursued due to various reasons. These unanswered questions represent huge knowledge gap and could lead to negative treatment outcomes. Internet technologies have been developing rapidly. On one hand, Internet provides us numerous information resources. On the other hand, Internet brings us voluminous increase in information and knowledge needs. To make medical information more easily accessible and to facilitate physicians' decision making process, we designed and developed a system that called the Clinical Knowledge Summaries (CKS) to automatically extract and synthesize relevant medical evidence from major resources including UpToDate and PubMed. We performed a usability study involving 10 physicians to evaluate the effectiveness, efficiency and satisfaction associated with the use of the system. Physicians in general found CKS intuitive to use and the information delivered valuable in adding in their knowledge gaps.

\section{Summer 2015}

Laura D. Ashcraft. Journal Access for Underserved Areas (JAFUA): Designing a Database for Underserved Countries for the WiderNet Project. A Master's Paper for the M.S. in I.S. degree. July, 2015. 65 pages. Advisor: Cliff Missen

The main job of a reference librarian is to know where to go for information resources needed by their clients and many of these resources are housed in databases.
Fortunately there are programs offering developing countries free or reduced cost access to their journals and books. However librarians in developing countries struggle with finding these organizations. The overarching problem is that they have to deal with a huge or total lack of Internet connection, and this is one of the biggest enablers to the digital divide that is currently and rapidly growing between first and developing countries. This project aims to connect journal providers who provide their content at free or reduced cost to underserved countries to librarians in these countries by means of a hybrid database called Journal Access for Underserved Areas JAFUA.

EunJeong Cheon. Information Practices of Young Users in the Context of Health Tracking Technologies. A Master's Paper for the M.S. in IS degree. July, 2015. 71 pages. Advisor: Mohammad Hossein Jarrahi

Use of health tracking devices by Digital Natives has drawn the attention of the health tracking technology industry. Despite that, it is not clear how those technologies really work for them in their life contexts, and more study is needed to understand how they interact with the large amount of information generated by these technologies. My study borrowed the Savolainen model of everyday information practice as a theoretical lens to focus on life contexts around the use of health tracking technologies. The data was collected qualitatively, through semi-structured interviews with nine college students. In the findings, information practices, personal life contextual factors, and technology enablement are identified. In evolving relationships among these factors, how information affordance was offered was discussed. Many information practices still relied on manual means, as reflected by life contexts.

Brendan D. Ferreri-Hanberry. Application of a POS Tagger to a Novel Chronological Division of Early Modern German Text. A Master's Paper for the M.S. in I.S. Degree. 106 pages. August, 2015. Advisor: Stephanie Haas.

This paper describes the application of a part-of-speech tagger to a particular configuration of historical German documents. Most natural language processing (NLP) is done on contemporary documents, and historical documents can present difficulties for these tools. I compared the performance of a single high-quality tagger on two stages of historical German (Early Modern German) materials. I used the TnT (Trigrams 'n' Tags) tagger, a probabilistic tagger developed by Thorsten Brants in a 2000 paper. I applied this tagger to two subcorpora which I derived from the University of Manchester's GerManC 
corpus, divided by date of creation of the original document, with each one used for both training and testing. I found that the earlier half, from a period with greater variability in the language, was significantly more difficult to tag correctly. The broader tag categories of punctuation and "other" were overrepresented in the errors.

James K. Geer. Tacit Knowledge in an Explicit World: An Exploration and Audit of Knowledge Management in an Organizational Context. A Master's Paper for the M.S. in I.S. degree. July, 2015. 50 pages. Advisor: Dr. Mohammad Jarrahi

This study is a qualitative survey and review of tacit and explicit knowledge management in an organizational context. It involves qualitative research and interview of fifteen employees and system designers in a medical malpractice insurance environment regarding their knowledge management habits and needs.

Traditionally, research has divided knowledge management into tacit and explicit knowledge. Models have emerged which state certain types of organizations should primarily focus of explicit knowledge management while others should focus on tacit in an 80/20 ratio. Further research intimated that $80 / 20$ as a strict guideline should be eschewed in favor of strategies that bridge the gap between the two.

In this organization, explicit knowledge needs rarely exist and primarily serve to orientate new employees, while tacit needs and opportunities continually exist regardless of employment duration.

Elizabeth Brooke Guthrie. Special Collections Instruction and the Undergraduate Student: A Study of the Wilson Special Collections Library's Collaboration with the Introductory English Program at the University of North Carolina at Chapel Hill. A Master's Paper for the M.S. in L.S degree. July, 2015. 68 pages. Advisor: Helen Tibbo.

This study presents the results of a survey distributed to first-year undergraduate students at the University of North Carolina at Chapel Hill. The survey examined instruction offered at the University of North Carolina at Chapel Hill's Louis Round Wilson Special Collections Library to undergraduate students during the spring semester of 2015. Focusing on first-year undergraduates enrolled in the University's required introductory English course, the survey collected information about the student experience in special collections instruction and the impact of instruction on the ability of undergraduates to conduct research at
Wilson Library. The survey produced thirty-five responses and revealed that students, while largely unfamiliar with special collections research, found the instruction session useful and relevant to their immediate needs. Survey responses also revealed a number of challenges faced by both students and library instructional staff and suggest that future instruction may benefit from changes in practice.

Caroline B. Hallam. The Definition and Roles of a Contemporary Undergraduate Library. A Master's Paper for the M.S. in L.S. degree. June, 2015. 108 pages. Advisor: Ronald E. Bergquist.

Though undergraduate libraries have changed since they were first conceived of and implemented more than half a century ago, the published definitions of undergraduate libraries have not. This paper explores proposed definitions of undergraduate libraries to determine if they are accepted by contemporary undergraduate librarians. Five librarians who work at Robert B. House Undergraduate Library at the University of North Carolina at Chapel Hill were interviewed using a card sorting task to determine which definitional criteria they considered most important, which criteria could be eliminated, and which additional criteria could be added. It was found that, though disagreement existed over which roles the Undergraduate Library should prioritize, the participants favored a simple definition that outlined the population served rather than listing the roles the Undergraduate Library should fill.

Rhonda D. Jones. Saving and Sustaining Community History One Block at a Time: A Case Study on the Marian Cheek Jackson Center and the Convergence of Public History, Community Informatics, and Digital Archives. A Master's Paper for the M.S. in L.S degree. July 2015. 48 pages. Advisor: Dr. Denise Anthony

Intertwining public memory, community archives, and technology, St. Joseph's C.M.E Church, the University of North Carolina's Southern Oral History Program (SOHP), and the Marian Cheek Jackson Center for Saving and Making History documented the legacy of the minority and working class voices within the Northside and Pine Knoll neighborhoods in Chapel Hill, North Carolina. Having preserved hundreds of oral interviews with a social justice orientation, the narratives were transformed into a physical and digital archive. This paper uses a case study approach to explore the Jackson Center's ethnographic framework and survey methodology used to entice community participation and examines 1) The application of oral and public history to document marginalized communities that may be underrepresented in traditional 
archival repositories 2) The definition of community archives 3) The role of Community Informatics in galvanizing support for the digital archives and 4) The implications of archival custody and the future for wider use.

Travis Jones. Giving 21st Century Researchers a Place in the Library: A Study of the Research Commons Planning Process at Duke University and the University of North Carolina at Chapel Hill. A Master's Paper for the M.S. in L.S degree. July, 2015. 43 pages. Advisor: Rebecca B. Vargha

Technology and other factors have radically altered the character of teaching, learning and research in higher education. In order to continue to meet the needs of their communities, academic libraries have introduced new spaces and services responding to these changes. Using semistructured interviews with key librarians and administrators, this study uses the research commons at Duke University and the University of North Carolina at Chapel Hill- The Edge and The Research Hub, respectively-as case studies, in order to better understand how libraries identify, plan and create new initiatives to serve their communities. The interviews demonstrate that both libraries exist in a complex research environment and that their ability innovate is dependent on understanding these environments in order to responsively position their spaces and services.

Xuxiang Mao. Oral history Topic Modeling using MALLET and Termite. A Master's Paper for the M.S. in I.S degree. July 6, 2015, 2015. 39 pages. Advisor: Ryan Shaw

This work aims to construct multiple topic models on a large corpus of oral history transcripts. In the paper, I explain the algorithm, toolkit and the process how to construct the topic model and make a preliminary analysis of the result.

Erin K. Moore. How does Cognitive Ability impact the use of Query Reformulation Moves? A Master's Paper for the M.S. in IS degree. August 2015. 27 pages. Advisor: Diane Kelly

People have different mental strengths and weakness, which can be measured according to cognitive ability. Learning about strengths and preferences in terms of search behavior, and looking for patterns between behaviors and cognitive abilities, creates the opportunity to make search tools and systems more effectively meet user needs and preferences. While we know that different cognitive abilities exist, and that people form and reform search queries in a variety of ways, we do not know how these two elements interact, or if the interaction is predictable or significant. This paper performs secondary analysis of data collected during a study of cognitive ability, adding in the element of query reformulation moves. It assesses the effect of these cognitive abilities on study participants' search formulation behaviors. Analysis showed that the most common search move was adding a concept to a query, followed by deleting concepts and manipulating search terms. Of the cognitive abilities, the only statistically significant differences between high and low groups were found in the visualization ability. Those in the high skill group made significantly more moves, and significantly more term manipulation moves, than their low skill counterparts.

Stefanie N. Protasowicki. Usability Study Methodologies of Electronic Health Record Systems: A Systematic Review. A Master's Paper for the M.S. in IS degree. July, 2015. 57 pages. Advisor: Javed Mostafa

This study is a systematic review of literature on electronic health record systems (EHRs) and the evaluation methods performed to study their usability. The purpose was to identify and review the extent of usability testing methods in their respective clinical environments. Full text review was completed for 121 of 753 titles intentionally identified, and 70 final articles were included.

The majority of methodologies reviewed were well established in HCI and the most common was the questionnaire. There was a wide range of study designs in terms of user populations (physicians, nurses, pharmacists, nurse practitioners, physical therapists and others), clinical settings (inpatient and outpatient, ambulatory, pediatric, intensive care units, and others), testing time (pre-implementation or post), and qualitative data analysis. Chosen methodologies and study designs closely depended on study goals, but all of them had large implications for the future of quality healthcare and how to achieve it.

Amanda B. Tickner. A Study of Users of the Liquid Galaxy Earth and Streetview Display at Davis Library. A Master's Paper for the M.S. in L.S degree. July. 2015. 29 pages. Advisor: Stewart Varner

This paper presents the results of a mixed method (survey and interview) qualitative study of users of the Liquid Galaxy Google Earth/Google Streetview immersive display in the Research Hub of Davis Library of the University of North Carolina Chapel Hill conducted in April of 2105. 25 users of the Liquid Galaxy responded to survey or interview questions about their user experience and their emotional response to the Liquid Galaxy. 
Jaci Paige Wilkinson. Low-Hanging Fruit and Pain Points: An Analysis of Change Implementation Resulting from Flash Usability Testing at Duke University Libraries. A Master's paper for the M.S in L.S. degree. July, 2015. 89 pages. Advisor: Ronald E. Bergquist

This paper describes a mixed method study of change implementation resulting from flash usability testing at Duke University Libraries. Flash usability testing, also known as guerilla or on-the-fly, is a method that allows researchers to collect large amounts of data in a short amount of time with quick, unplanned think-aloud tests in a high-traffic library space.

Data from usability reports was triangulated with data from interviews with members of Duke University Libraries' WebX team. WebX is a cross-departmental team that acts as "functional owner" of the libraries' web presence. It commissions flash usability tests and uses the data to implement changes or spur further research. Interviews incorporated a card sort of the recommendations from every flash usability test. The paper unearths myriad attitudes toward the libraries' web presence and perceptions of the role of usability testing in the academic library. Additionally, the paper details the subsequent effectiveness of change implementation.

\section{Winter 2015}

Elliot Maxwell Aronson. I Don't Get any Inspiration Sitting at my Desk: The Patterns of Flow Experiences in Expert Researchers. A Master's paper for the M.S. in L.S. degree. December, 2015. 41 pages. Advisor: Brian W. Sturm

This study describes the findings from coding the transcripts of personal interviews with associate and full professors within the University of North Carolina's School of Information and Library Science. The interviews were conducted to determine whether and how fully-present states of consciousness, known often as flow states in the literature, occurred in the research process.

A definite pattern was discovered wherein fully-present states of consciousness were occurring, but most often not during the active work of research, such as reading or writing. Rather, flow came to researchers when they would take a break from their work to do something less intellectually demanding. Here they would receive a personal insight on how to proceed with their work. Then the researchers would return to work to address the challenge of how to package what they had synthesized in their flow experience into language that could be understood and accepted by other researchers.
Rose M Combs. Searching for Unknown Allusions: A Need to be Filled. A Master's Paper for the M.S. in I.S. degree. November, 2015. 44 pages. Advisor: Jaime Arguello

In the growing world of technology, there are tools that have been developed to explore texts for those in the social sciences or humanities. These tools allow searching and analysis to occur that previously had to be done manually. While the tools that are available meet many needs, there is one need that is not being met. The ability to locate unknown allusions has not yet been addressed. This paper explains the benefits of having the ability to locate unknown allusions. In addition, it examines some of the tools that are available and what they are capable to producing. In conclusion, a description of the needed ability of a future tool is provided.

Madeline A. Coven. Toward a Visual Language for Abstract Ideas: Effect of Concepts on Perception of Symbols. A Master's Paper for the M.S. in I.S. degree. November, 2015. 22 pages. Advisor: Ryan Shaw

In our society, there is an ever-increasing demand for media, and the need, as much as ever, for ordinary people to think critically about ideas. This paper presents the first steps toward the creation of a visual language that might convey these ideas to an educational software or infographic audience. Since the problem I am trying to solve is one of agreement over abstract symbols, I conducted a paper questionnaire in which respondents selected shapes that they associated the most with a particular one-word concept. In most of the questionnaire categories (nature, order, significance, good, anti-, and divinity), most respondents chose one symbol over the other. Future work is needed to reproduce these results, but the results point to the possibility that we can indeed design a universal visual language of ideas with "dialects" for different cultures.

Patrick Dollar. Users' Perceptions on Searching, Locating, and Accessing Dispersed Materials in Archival Institutions. A Master's paper for the M.S. in L.S. degree. December, 2015. 33 pages. Advisor: Denise Anthony

This study describes a semi-structured interviews of professional researchers located in the North Carolina area. This study evaluates the personal experiences and information seeking behaviors of researchers working with materials dispersed across multiple physical and digital locations. The survey was conducted to determine the strategies researchers use to identify and access all material relevant to their research questions, even if the materials are dispersed across different archival institutions. 
Olivia D Dorsey. A Visual Analysis of Phases of Police Brutality Against Unarmed African Americans from 1979 to 2014. A Master's Project for the M.S. in I.S. degree. November, 2015. 31 pages. Advisor: David Gotz

This report describes the process used to create an online resource that compiles a sample dataset regarding police brutality incidents against African Americans between 1979 to the present and also analyzes the similarity between these incidents by contextualizing them into "phases of police brutality." However, this dataset is only a small sample of the total population and may not be entirely representative of that population. Data regarding these incidents were collected from various news sources including crowdsourced database efforts, local news websites, and national news websites.

Ebony S. McDonald. The Only One in the Room: Professional Identity and Black Male Librarians in North Carolina. A Master's Paper for the M.S. in L.S degree. Dec, 2015. 66 pages. Advisor: Claudia Gollop

A qualitative study was conducted using semi-str

uctured interviews to describe how seven black male librarians' dual minority status within the profession influences the construction of their professional identities. Recently, successful professional identity construction has become an important theme in career literature because it has often been associated with career success. However, career literature fails to link the influence social identities have on the construction of professional identity, particularly if those identities are in some way marginalized within that profession and/or stigmatized within the society at large. Black male librarians hold both a marginalized and stigmatized identity in their profession and American society through their race and gender. Yet, in Library and Information Science (LIS) literature, there is little focus on the intersection between professional and stigmatized social identities, particularly when it comes to race and gender. This study addresses the knowledge gap in LIS literature.

Bendte L. Fagge. Usability Study of Request Functionality in Website User Interfaces at Duke University Libraries. A Master's Paper for the M.S. in I.S. degree. November, 2015. 109 pages. Advisor: Robert Capra

This paper presents the results of a usability study on request functionality conducted using web page interface mock-ups of Duke University Libraries' website. The study focused on account logins as well as single- and multipleitem requests. In addition, participants had to select delivery locations and assess the clarity of confirmation status for the requests. Results of this study identify areas where these interfaces can be improved, particularly around account login for users who have Library Card accounts and for requesting multiple items at one time.

Sierra K. Johnson. Access to Legal Information by Public Patrons in Varying Types of Law Libraries: A Case Study. A Master's Paper for the M.S. in L.S degree. July, 2015. 52 pages. Advisor: Hollie White.

This paper describes a case study conducted in three different varieties of law library in North Carolina. Public, private, and hybrid libraries were studied to determine if any meaningful difference existed between the types as to the level of legal materials and services available to members of the general public. Although much research has been conducted on why people file pro se, little research has been done on how they, and other public patrons, are able to access legal information once they determine that they need it. The results of this study indicate that two libraries showed no major observable difference, despite being different library types, while one library stood out as being much less helpful in allowing public patrons to access legal information. Results of this research may be of interest to public service attorneys, members of the public conducting research, law librarians, and anyone determining funding for law libraries.

\section{Sreenivasula R Gajjala. Longitudinal Analysis of Re-} admission Risk Using Machine Learning. A Master's Project for the M.S. in I.S. degree. November, 2015. 30 pages. Advisor: David Gotz

Unnecessary hospital readmissions are a major problem impacting millions of patients and costing billions of dollars per year. Unfortunately, accurate assessment of readmission risk remains an open problem. In this study, several methods and tools for readmission prediction were developed using UNC hospital data available from April 1, 2014 to November 1,2014 . This study investigated the change in readmission risk for patients over time to explore at which times high-risk patients can be most effectively identified. Toward this goal, multiple Machine Learning models of hospital readmission using patient history prior to admission and comparing them with baseline model which uses data during hospitalization were developed. The results of this study find that patients history did not produce better predictive performance than the baseline model that considered just hospitalization data. However, the dataset considered is small and results may not generalize to large data sets over longer period of time. 
Amanda Gresham. Portrayal of Gifted Children in Children's Chapter Books. A Master's Paper for the M.S. in L.S. degree. December, 2015. 42 pages. Advisor: Brian Sturm.

This paper is a content analysis of seventeen chapter books geared towards upper elementary and middle school aged children that feature twenty-three intellectually gifted child characters. The books were analyzed for the presence of themes mentioned in literature on the subject (isolation and resulting desire for acceptance, normalcy, and belonging) as well as gifted stereotypes often seen in media. The overall portrayal in the books of the gifted population's abilities was then compared to the real distribution of cognitive abilities in the population. Themes were largely handled well, with positive resolution for most characters, and stereotypes were mostly avoided. There was, however, an overrepresentation of profoundly intellectually gifted characters.

Sierra Moore. A Mobile Security Document Collection. A Master's Paper for The M.S. in I.S. degree. November 18, 2015. 45 pages. Advisor: Robert Capra

Mobile security refers to the safeguarding of a device's (often a smartphone) data against potential viral threats resulting in a user invasion of privacy. As part of this Master's paper, a Mobile Security document collection and an accompanying Wordpress website were created. The intent of this project is to make it easier for smartphone users to learn about security issues. The collection is composed of documents categorized as: academic, best practices, consumer, corporate, government document, how-to, magazine and product review. Each category is associated with key term subject tags.

Wickliffe W. Shreve II. CrowdTrusting: Case Studies in Crowdsourcing Projects. A Master's Paper for the M.S. in L.S degree. November, 2015. 48 pages. Advisor: Denise Anthony

Crowdsourcing has gained popularity over the past few years as a way for library and archive professionals to supplement and enhance the description of their collections. This paper provides case studies of four community archiving projects, focusing on crowdsourcing techniques they used to describe or enlarge their collections. The studies were conducted to determine the kinds of techniques used in community archives, and the potential benefits and barriers they faced in developing and using the techniques. Analysis of the projects indicated that the up-front investment in developing crowdsourcing tools may be prohibitive for community archiving projects. However, the results also indicated that digitization projects were still of value.
Lauren W. Turpin. Vertical Search Behavior and Preference of Users with Different Visual Memory and Perceptual Speed Abilities. A Master's Paper for the M.S. in I.S. degree. November 2015. 43 pages. Advisors: Diane Kelly and Jaime Arguello

Vertical search in Information Retrieval (IR) represents display opportunities for searcher interaction in the form of blended and non-blended results. Search behavior and preference in interacting with these results can be influenced by both design and personal, cognitive abilities. This study evaluates the relationship between cognitive ability and vertical search behavior and preference.

In this lab study cognitive tests measuring perceptual speed and visual memory were administered to sixteen participants who subsequently performed four search tasks on two search engines, one with a blended display and one with a non-blended display. Cognitive tests, search logs and participant questionnaires were used to evaluate vertical search behavior and preference in cognitively high and low performers. The findings suggest that cognitive ability influences vertical search engagement and preference. The value in this research is its ability to contribute to issues of result merging, display, and interaction at a personal level in vertical search.

Latia L. Ward. A Content Analysis of Major Themes in Young Adult and Middle Grades Novels Published Between 2006 to 2015 That Feature Young Undocumented Immigrants as Protagonists. A Master's Paper for the M.S. in L.S degree. October 2015. 98 pages. Advisor: Sandra Hughes-Hassell

This paper presents a study of common themes in young adult (YA) and middle grades novels published between 2006 and 2015 that feature young, undocumented immigrant protagonists who live in the United States. The themes found in the novels include the realistic yet sometimes sanitized portrayal of the violent experiences of undocumented immigrants, the protagonists' perilous journeys to the United States, their silence over their status as undocumented immigrants, their refusal to be victims which corresponds with a demonstration of agency, their desire for and assistance in getting an education, and their development or display of a hybrid identity. Overall, the novels have happy endings even in situations in which the protagonists do not obtain United States citizenship. Although the prevalence of happy endings may not be entirely trueto-life, reading the novels may be a starting point for exploring issues relevant to undocumented immigration. 
Megan Williams. The Changing Face of Cultural Heritage and Art Archives: The Challenge and Promise of Online, Digital Repositories. A Master's Paper for the M.S. in L.S. degree. August, 2014. 42 pages. Advisor: Heather Gendron

Cultural heritage and art archives that exist exclusively online are becoming increasingly popular, however little has been written about their particularities. This paper presents an exploratory study of four different online cultural heritage archives: the African American Performance art Archive, Documents of 20th - century Latin American and Latino Art, Public Art Archive and Europeana. Through website analysis, each project was surveyed with respect to their mission, producer, collection development, collection materials and online presence. A synthesis of that information compares the online archives to one another and to traditional, physical archives and argues that although online archives represent a challenge to certain archival principles and practices, they also embody the monumental changes in archival science brought forth by postmodern theory and the internet. These projects raise important questions about what an archive is and what it can achieve, and should therefore be included in wider discussions about the future of the field.

\section{Spring 2016}

Emma C. Boettcher. Predicting the Difficulty of Trivia Questions Using Text Features. A Master's Paper for the M.S. in I.S. degree. April, 2016. 70 pages. Advisor: Stephanie W. Haas

In numerous contexts, including community question answering systems, school exams, and trivia competitions, a need to assess the difficulty of questions arises. This study examines what features predict difficulty in the realm of trivia questions, considering features related to readability and the question's topic as potential contributors. Using clues from the game show Jeopardy!, the study finds that features relating to a trivia question's length, the inclusion of audiovisual media, and its constituent noun and verb phrases have a significant impact on the clue's difficulty. Based on these findings, this study proposes that finding more nuanced ways to depict the amount of information in a trivia question would lead to further advancements.

Erin E Baucom. Do Archival Finding Aids Describe LGBT Individuals the Same Way They Would Describe Themselves? A Master's Paper for the M.S. in L.S degree. April, 2016. 42 pages. Advisor: Denise Anthony
This study compares the terms used by the LGBT community to describe themselves to those terms used in institutional archives' finding aids. An archive and LGBT history project website from each region in the United States and one region of Canada was chosen in an effort to examine differences in language uses. The history project websites were examined to find a list of terms used by the LGBT community to describe core identities. These terms were then searched for in the archival finding aids. It was determined that the archival descriptions were often only using general, politically correct terms to describe LGBT collections. There was also evidence that some archivists were describing materials incorrectly.

Harika Boya. Finding similarity using metadata of clinical trials using Natural Language Processing in DataBridge. A Master's Paper for the M.S. in I.S degree. April, 2016. 40 pages. Advisor: Arcot Rajasekar

Information explosion in every field in this age creates one big challenge - how to extract meaningful information from massive amounts of data. Currently there are millions of datasets available as a result of research by various scientists. It is necessary to find the hidden potential of this data and identify different ways data can be related to each other. The purpose of the project is to identify the level of similarity between the metadata of any two clinical trials that have been completed in Databridge application. The dataset being considered is the entire metadata of all the concluded clinical trials as updated on clinicaltrials.gov. Only the trials which have been completed and have results updated are being considered. This paper discusses four different techniques employed for finding similarity between any two particular clinical trials and their corresponding results.

Jiaoling Chen. A Study to Explore How Differences in the Amount of Details in Visualization Impact Decision-making. A Master's Paper for the M.S. in I.S degree. April, 2016. 41 pages. Advisor: David Gotz

This study explores how differences in the amount of details in visualization impact the decision-making process. Everyday decisions like buying a used car are the focus of the study. A visualization tool that is able to show different number of attributes was designed and developed using JavaScript library d3. Twenty users participated in the user study and were asked to make car-buying decisions based on the observation of different levels of details of car information presented in the developed visualization tool.

Two patterns of the decision-making process were summarized. The increasing number of details in information 
visualization does not always influence participants' decisionmaking, while the value range and the level of importance of the newly added attributes turned out to be more influential on participants' decision-making processes. A weak correlation between level of confidence and the number of details in information visualization is found.

Maria E. Chiochios. The Tweets Heard Around the World: Ferguson Municipal Public Library's Twitter Use Around the 2014 Civil Unrest and its Role in Supporting Community Disaster Resilience. A Master's Paper for the M.S. in L.S degree. April 2016. 102 pages. Advisor: Ericka Patillo

In 2014, Ferguson, Missouri experienced multiple waves of civil unrest in response to the fatal shooting of Michael Brown and the grand jury decision not to indict Darren Wilson, the police officer responsible for the shooting. During this time, the Ferguson Municipal Public Library served a crucial role in responding to this community crisis. The actions of this library supported Ferguson's community resilience by limiting the impact and helping residents respond, recover, and heal from the civil unrest. A content analysis of the library's tweets reveals how the library used Twitter to communicate with the public and support its resilience around both waves of civil unrest. This case study highlights the importance of library disaster planning, roles libraries can play in helping communities plan, respond, and recover from crises, and explores how a library can employ social media to communicate with patrons and support community resilience.

Aurora L. Cobb. Supporting Victims, Striving Against Violence: How Public Libraries Can Serve the Information Needs of Sexually Assaulted Women. A Master's Paper for the M.S. in L.S. degree. April, 2016. 71 pages. Advisor: Mary Grace Flaherty.

Every year in the United States millions of women are victims of rape, sexual assault, and other forms of sexual violence. In order to determine what might be done in public libraries to extend support to victimized women and prevent sexual violence, this study sought to identify the information needs of sexually assaulted women. Interviews were conducted with three "companions," or victim advocates, responsible for assisting callers to the Orange County Rape Crisis Center's 24-Hour Help Line. The interviews revealed key areas of information need among victims of sexual violence, including information related to reporting crimes of sexual violence, interacting with law enforcement, the procedures of the sexual assault forensic exam, and facts about sexual violence against women. These findings were applied in the development of recommendations for public libraries and librarians seeking to address sexual violence against women in the communities they serve.

David A Cowhig. End-user System for Generating SoundExchange Reports. A Master's Paper for the M.S. in I.S. degree. April, 2016. 42 pages. Advisor: Paul Jones

This paper describes the design, implementation, and testing of an information system built to generate streaming radio reports for ibiblio and the open-source Icecast streaming media server. This new system allows end-users to generate reports on demand, in either standard Icecast format or the SoundExchange 2013 reporting format. The system was designed to help aid community radio stations in complying with government reporting and regulations. In addition, a plan to increase system availability for ibiblio radio streaming is discussed.

Matthew B Cresson. Consistency in Reference Systems A Master's Paper for the M.S. in L.S. degree. April, 2016. 30 pages. Advisor: Denise Anthony

This study was created to determine the differences or similarities between different locations of the National Archives and Records Administration in how they receive and maintain researcher data.

Nahali R. Croft. Keep It or Toss It? Legislative Records Retention Practices in the U.S. House of Representatives. A Master's Paper for the M.S. in L.S degree. April 2016. 51 pages. Advisor: Christopher A. Lee

Because the records of individual Members of the House of Representatives are considered personal property, what happens to those records once a Member leaves office is up to him or her. Legislative records, particularly files and reports used to develop policy and draft bills, have historical value and are one of the types of files most used in current Congressional collections, as they point toward legislative intent. The House Records Management Manual for Members suggests that offices permanently maintain these types of files. This study reveals to what extent House offices are preserving records that provide future researchers with legislative intent, finding that while congressional staffs are not largely aware of the manual, they do attempt to preserve differing types of legislative background materials. There is a general awareness that their practices have room for improvement, but with no requirements to implement a retention schedule, there is little incentive for congressional staffs to develop better records management procedures. 
Melissa A. Denby. A Descriptive Study of IT Spending at Library and Information Science Programs. A Master's Paper for the M.S. in I.S degree. April, 2016. 49 pages. Advisor: Aaron Brubaker

This study examines and compares how decentralized IT departments serving Library and Information Science (ILS) programs operate. An online survey was sent to 47 American Library Association (ALA) accredited ILS IT departments in the United States. Survey questions focused on demographics, budget, and current and future operations of the IT departments, along with perceptions of the respondents. Two programs emerged within the survey, those with an internal IT department within the ILS school and those with a hybrid mix of an internal IT department and support from central IT. The hybrid IT respondents were more macro focused and served several colleges within the university. The internal IT respondents served larger populations, had more employees and student workers, and higher budgets in comparison to the hybrid IT respondents. Both groups had similar revenue sources and spending trends. Priorities and day-to-day operations differed among all respondents as each department had unique IT solutions.

Colleen E. Daw. Fan Materials from a Galaxy Far, Far Away: A Study of the Potential Use of Fan Materials in Archives. A Master's Paper for the M.S. in L.S degree. April, 2015. 60 pages. Advisor: Steve Weiss

This paper addresses a need for further collection development in the archives community. As more and more items from popular culture are archived (i.e. movies, music, television, etc.) so should the accompanying fan materials. These fan materials provide important contextual information for their source materials, as well as evidence of the rich cultural history surrounding these materials. To get an understanding of these fan communities, this paper focuses on the large and active Star Wars community. In order to explore the potential archival value of the materials produced by these communities, a qualitative content analysis was conducted of a Star Wars fan fiction, fan podcast, and fan news site. They were analyzed using a contextual entity model designed by Christopher Lee for digital objects, in order to see how the fan materials contextualized and informed on the source materials or Star Wars films. By doing this study, we hope to encourage archives to expand their collections and consider this new type of material that expands the overall cultural history.

Laura K Dimmit. Building a Community of Practice Around Information Literacy by Design: A Case Study at UNC-Chapel Hill's Undergraduate Library. A
Master's Paper for the M.S. in Library Science degree. April, 2016. 62 pages. Advisor: Jonathan McMichael

A gap currently exists between the level of instructional training needed for public service librarians to succeed, and the level being provided by employers and LIS programs. Communities of practice (CoPs), as described by Lave and Wenger, provide a sustainable, practice-centered model for instructors of all experience and skill levels to grow individually while supporting each other. This paper documents the analysis of redesigned instructional training for the instruction team at UNC-Chapel Hill's Undergraduate Library (UL), centered around Information Literacy by Design (ILbD). Interviews with instruction team members are coded to track indicators of CoPs, which reveal key trends involving peer relationships, self-efficacy, and ways of learning. The redesigned training is revealed to have influenced the development of a community of practice among the UL instruction team.

Jessica D. Dixon. Measles on Main Street, USA: How Public Health Events Affect Public Library Policy. A Master's Paper for the M.S. in L.S degree. April, 2016. 65 pages. Advisor: Mary Grace Flaherty

This study describes a questionnaire survey of library directors, county librarians, and city librarians representing eighty-three of California's one-hundred and seventy-nine total public library districts. The study was conducted to determine the effects, if any, of the 2015 Disneyland measles outbreak and California Senate Bill Number 277 on public library policy in California.

One library district changed an existing policy following the Disneyland outbreak, and another district changed an existing policy in response to the Senate Bill. No library districts added, eliminated, plan to change, plan to add, or plan to eliminate policies owing to either event. Three districts anticipate that these events will likely impact policies in the future. Although the events have yet to elicit many policy changes, public libraries should consider implementing such policies to strengthen the health of the communities they serve before governing bodies place pressure on them to do so.

Erin M. Enos. Generation Speaking: A Perspective of Genealogy Captured Through the Lens of the Millennial Generation. A Master's Paper for the M.S. in L.S degree. April 2016. 77 pages. Advisor: Denise Anthony

Within the last 20 to 30 years, researchers have conducted studies of the genealogy community. Unfortunately, these studies have not recognized the millennial generation, as an active group of the genealogical 
community. Millennials have overtaken the Baby Boomer generation as the largest age group in America. Regarding the generation's population size, why haven't millennials been widely studied in the genealogy community? Few studies about millennials and genealogy leave numerous questions left to be answered: How much is known about the millennial generation in genealogy studies? What thoughts do millennials have in regards to genealogy? What factors drive their feelings? The researcher conducted a genealogy-based survey with millennials at the University of North Carolina at Chapel Hill in hopes of uncovering answers about this generation. The findings of this study will help institutions to better understand millennials as recognized members within the genealogical community.

Abigail K Flanigan. Digital Humanities Collaborations in the Library: A Case Study of Project Beta. A Master's Paper for the M.S. in L.S degree. April, 2016. 44pages. Advisor: Stewart Varner.

This paper investigates the libraries' role in collaborative digital humanities projects through an anonymized case study of Project Beta. Digital humanities collaborations are becoming increasingly common in libraries, but there is a dearth of scholarly literature articulating the experiences of and challenges faced by people actually doing this work. This study aims to contribute to a shared knowledge about how libraries can effectively partner with scholars to create innovate digital scholarship. Semi-structured interviews were conducted with key stakeholders on Project Beta, which illuminate the institutional, social, and technical challenges associated with creating and sustaining a digital humanities project in the library. Recommendations for addressing the identified challenge areas are made based on the holistic picture provided by interviewees.

Laura A. Fogarty. Measuring Trends and Efficacy: An Analysis of the British Museum's Facebook. A Master's Paper for the M.S. in L.S degree. April, 2016.39 pages. Advisor: Denise Anthony

There is a distinct lack of current and specific guidance on the creation of content for social media in cultural heritage institutions. This study aims to remedy that lack of specificity by examining user responses to social media strategies employed by cultural heritage institutions and in so doing, identify and evaluate emerging trends in social media content generation. In order to accomplish this task, the researcher conducted an analysis of the British Museum's Facebook page. This consisted of evaluating posts according to a coding schema and recording the level of user response to each post. This method allowed the researcher to identify past, present, and emerging trends as well as the efficacy of each trend in terms of user interaction.

Julia R. Glauberman. Academic Integrity Policies: Content, Context, and Implications for Academic Librarians. A Master's Paper for the M.S. in L.S degree. April, 2016. 45 pages. Advisor: Paul Jones

Instruction librarians are often expected to promote academic integrity. However, the content and implementation of institutional academic integrity policies may vary greatly from one university to another. This study employed a mixed methods approach, combining content analysis of policies and a survey of librarians involved with instruction. The policies analyzed and the librarians surveyed were from UNC and its fifteen peer institutions. The results of the document analysis identified at least three distinct types of policies defined by their length, use of legal language, and overall purpose. The survey results suggest that although academic librarians understand and are cognizant of their universities' academic integrity policies, they are not strongly influenced by these documents. This study contributes to the existing literature on academic integrity policies while also beginning to bridge the gap between that body of literature and our understanding of the roles played by librarians in supporting academic integrity.

Rachel C Goatley. Documenting Tragedy: Collection Development, Material Culture, and Collective Memory (A Case Study of the Virginia Tech April 16, 2007, Condolence Archives). A Master's Paper for the M.S. in L.S degree. April, 2016. 99 pages. Advisor: Denise Anthony

In the present era, archivists are increasingly tasked with documenting the aftermaths of tragic events. This paper explores the development of the April 16, 2007, Condolence Archives at Virginia Tech, following a mass-shooting at the university in 2007. It covers topics such as the objective and scope of the collection, archival appraisal, and exhibition of materials. It also examines examples of items in the collection, as well as the personal experiences of staff involved. Finally, this paper analyzes this collection in regards to general archival collection development, material culture and memorialization, and the development of collective memory.

Meredith L. Hale. Searching for Art Records: A Log Analysis of the Ackland Art Museum's Collection Search System. A Master's Paper for the M.S. in I.S. degree. August, 2015.88 pages. Advisor: Diane Kelly.

Search log data from the Ackland Art Museum's online 
collection search system was analyzed in order to determine the search categories most frequently employed by users of the system. The data consisted of a total of 16,729 actions and 3,459 search sessions. It covered a three-month time period from February 19 to May 19, 2015. Analysis of actions associated with the Ackland's advanced search feature suggest that the department, classification, and artist fields have the highest usage while searchers rarely submit queries relating to a work's particular medium (2.55\%). Review of the most common queries submitted by users reveals that search terms most commonly relate to representational subjects visually presented in a work of art rather than formal titles. Investigation into how users alter the queries they submit throughout a search session indicates that users often do not change categories during a search session, but primarily make parallel changes $(68.11 \%)$.

Rachel J Hinrichs. Perceptions and Knowledge of Privacy Risks in Mobile Apps. A Master's Paper for the M.S. in L.S degree. April, 2016. 43 pages. Advisor: Brad Hemminger

Consumers often have little knowledge about the extent of privacy risks taken when using mobile applications (apps) on their smartphones, and are unlikely to be informed by federal regulations or privacy certifications. A survey was distributed to smartphone users to determine their perceptions and knowledge of privacy risks in mobile apps, and if these perceptions vary in different contexts (i.e., a health app vs. flashlight app). This study found that people appear to see privacy in mobile apps as contingent and contextdependent. While smartphone users were found to have a good understanding of privacy risks, they considered user rating and price to be more important factors to consider than privacy when selecting a mobile app. Presentation, clarity, and context all influence people's decisions to install and use mobile apps. This study has important implications for how privacy permissions and ratings can be presented to best inform consumer decisions.

Wei Hu. Medical Data Signature Extraction Using Modified TF-IDF in DataBridge Project. A Master's Paper for the M.S. in I.S degree. April, 2016. 40 pages. Advisor: Arcot Rajasekar

This project is a part of the DataBridge project, where we try to find similar datasets among a large number of medical datasets stored in the DataBridge server using key words extraction and similarity algorithms. In this project, a sample of 1,000 datasets were randomly chosen from the 18,000 datasets corpus. Modified TF-IDF was used in the sample data to generate key words for the 1,000 datasets and similarity analysis was followed. According to the results, we find that the key words extraction works fine in calculating similarities between different datasets.

Alex S. Japha. Digital Preservation and Access of Three Dimensional (3D) Resources in Cultural Heritage Organizations. A Master's Paper for the M.S. in L.S degree. April, 2016. 58 pages. Advisor: Helen Tibbo

This study describes a series of interviews with individuals at seven cultural heritage organizations that work with 3D digital objects. It examines the resources, preservation policies, storage, file formats, software, metadata, and access methods employed by these virtual heritage organizations.

William W. Knauth. 3D Digital Imaging \& Cultural Heritage Institutions: An Examination of Utility and Practices. A Master's Paper for the M.S. In L.S. Degree. April, 2016. 63 pages. Advisor: Dr. Ronald E. Bergquist

$3 \mathrm{D}$ digital imaging is becoming a more and more approachable technology for cultural heritage professions. A variety of institutions have enacted projects making use of the unique affordances and opportunities presented by this technology. These include preservation, outreach \& access, and research. This research seeks to examine the nature and potential value of $3 \mathrm{D}$ digital imaging in this context. This piece will seek to determine practical and effective approaches to 3D digitization programs centered on cultural heritage. This has been accomplished through interviews with domain specific professionals synthesized with data from academic literature and salient $3 \mathrm{D}$ projects. The result will form a resource for understanding and demonstrating the usefulness of this technology and it possibilities.

\section{Sharon L Kolling-Perin. What It Means To Use Gender} to Guide Readers' Advisory. A Master's Paper for the M.S. in L.S. degree. March, 2016. 60 pages. Advisor: Sandra Hughes-Hassell

Readers' advisory is a central job of librarians who work with youth, and it is especially critical for youth who are struggling or reluctant readers. Readers' advisory is often conducted based on gender, partially due to the fact that boys are more often seen as reluctant readers, and score lower on reading measures. As there is growing awareness that not all youth fit into the classic definition of a gender binary, librarians must reconcile the needs of reluctant readers and the needs of gender non-conforming youth.

This study examined what youth librarians in school and public libraries understand about using gender in 
readers' advisory. The study consisted of four semi-structured interviews with youth librarians, exploring the issues of readers' advisory, gender, and gender non-conformity.

Bailey A. Jones. Exploring Salient Thumbnail Generation for Archival Collections Online. A Master's Paper for the M.S. in I.S. degree. April, 2016. 67 pages. Advisor: Robert Capra

This study developed and evaluated a method for generating thumbnails for archival documents utilizing open source image saliency software. Salient thumbnails were evaluated against a baseline by running a lab study that assessed the thumbnails' usefulness during finding and re-finding tasks. Results did not find any significant difference in time, user confidence, or user preference of salient thumbnails compared to the baseline. However, salient thumbnails resulted in improved accuracy during refinding tasks, suggesting that they may offer some advantage for representing archival correspondence.

Justin P. Kreft. Measuring the Impact of Body Worn Cameras (BWC) on Data Management and Record Retention for Law Enforcement Agencies. A Master's Paper for the M.S. in I.S degree. April, 2016. 78 pages. Advisor: Cal Lee

This study examines the rates of data production for US law enforcement agencies deploying Body Worn Camera and DashCam systems. Analysis estimates that local law enforcement agencies can reasonably expect to produce 33.9 individual video files, totaling 11.1 hours of video, and (depending on the video capture quality) requiring between 10-20 gigabytes of storage space per officer, per month. The study also demonstrates that video file production rates from existing DashCam systems can be an effective benchmark when considering the implementation of a Body Worn Camera system. Finally, the study finds that of all implementation policies examined, only two policies demonstrated significant positive impact on video capture rates: 1) if officers were required to inform citizen of camera in operation, and 2) if officers were allowed to view footage prior to making a shift report.

Jyotsna Krishna Sastrula. Analysis and Visualization Methods for Data-Driven Longitudinal Patient Summary. A Master's paper for the M.S. in I.S. degree. May, 2016. 35 pages. Advisor: David Gotz

Digitization of health records has opened avenues for intensive research in the fields of health informatics. Power of machine learning, statistical analysis and visual analytics could be utilized to make optimal use of this information.
The proposed project is to develop an interactive visualization tool that summarizes a patient's medical history, highlighting all his/her important events based on the knowledge of similar patients. Given a set of patients with common conditions, statistical analysis can be used to develop models that prioritize features based on associations between features and condition-specific outcome measures.

This manuscript in particular describes the model developed to prioritize a patient's events from his medical history. The model is trained with the population of patients and their events. Their correlations with the outcome variable are calculated to identify the important events in a specific cohort. This correlation score can be used to prioritize the events associated with an individual patient. This model is one of the models that will be used to summarize an individual patient's medical data via interactive visualization methods.

\section{Rita Kundu. Visual Analytics System Implementation} in ICISS environment. A Master's Paper for the M.S. in IS degree. April 2016. 45 pages. Advisor: David Gotz

The paper describes the process involved in implementation and evaluation of an existing visual analytics tool on Integrated Cancer Information and Surveillance System environment. Dataset from the system contains information about breast cancer patients of North Carolina, which includes age, demographics, Medicare, and procedure reports of patients. The tool will enable researchers to compare different aspects of data thus minimizing the effort spent on getting sample data for their study. User feedback has been analyzed to understand the pros and cons of the tool and if it is suitable for the new dataset.

David Y. Lee. A Case Study of Workforce Development Programs in the Cumberland County Public Library System. A Master's Paper for the M.S. in I.S. degree. April, 2016. 56 pages. Advisor: Mary Grace Flaherty

This paper examines the workforce development programs implemented at the Cumberland County Public Library. The case study focuses on the specific initiatives and evaluation methods implemented by the library for workforce development programs. Analysis indicates that the efforts and initiative of library personnel is a key factor in successful implementation and evaluation of workforce development programs in addition to in-depth research and innovative approaches to data collection. Funding plays an important but supplementary role in supporting initiatives. Finally, job fairs are key workforce development initiatives which illustrate the findings in the paper. 
Stephen L Levin. Evaluating clinics' use and adaptation of technology to the unique barriers faced by atrisk, HIV-positive individuals in the development of medication adherence plans. A Master's Paper for the M.S. in I.S. degree. 04, 2016. 48 pages. Advisor: Mary Grace Flaherty

This research reports on a case study of Whitman-Walker Health, an urban clinic that serves at-risk patients who are HIV positive. Interviews were conducted with administrators and clinicians to gain insight into the medication adherence barriers faced by their patients, and also study the methods and technological adaptations the clinic employs to help overcome the barriers faced by their patients. The study found a welldeveloped workflow and adept use of technology to create and keep patients on a path of medication adherence.

Mingyu Li. The Implementation and Evaluation of a Simple Online Reservation System

for Local Sports Game Meet-ups. A Master's Paper for the M.S. in I.S degree. May,

2016. 48 pages. Advisor: Hemminger, Bradley $M$

Scheduling and coordinating a sport game with multiple participants is increasingly complicated. It is particularly difficult to account for participant's travel schedules, and to accommodate those participants from different places to go to the same event. A simple online reservation system that allows people to sign up for recurring sports events is in demand. This project implemented a high-efficiency and user-friendly online reservation system for local sports game met-ups. The features included creating events, joining existing events, search events, cancelling events, and communicating between group members. We conducted a usability study to test the system and concluded that the system is helpful in improving user experience.

Dong Liang. Predicting Stock Price Changes with Earnings Call Transcripts. A Master's Paper for the M.S. in I.S degree. April, 2016. 43 pages. Advisor: Arcot Rajasekar

This paper adopts sentiment analysis approaches to predict stock price changes of 14 major U.S. airlines, using 325 earnings call transcripts from year 2007 to 2015 . We combined machine learning classification techniques with Loughran and McDonald Sentiment Word Lists (Master Dictionary), and built the Python program from scratch. Text transcripts as well as stock prices were captured online. Transcripts were labeled according to sentiment scores defined by us. After a three-way data split, all six algorithms failed to result in an ideal accuracy. The results suggest that earnings call transcripts are not informative enough to predict stock price changes.

Huiying Ma. Implementation of An Event-based Business Document Indexing and Retrieving System. A Master's Paper for the M.S. in I.S degree. April, 2016. 40 pages. Advisor: Ryan Shaw

This paper presents a business event-based indexing and retrieval system that enables searching for business articles and journals based on not only their full texts but also business events detected through natural language processing(NLP). The system was implemented using Apache Solr as the indexing and searching platform, on top of which I built my own algorithms and methods for document indexing and retrieving. The development of this system involved source document collection and tagging, indexing algorithm design and implementation, and system evaluation. Progress to date has shown that both precision and recall have been improved when searching using event-relevant key words and this also provide a way to retrieve entities combine with events.

\section{Alexandria C Mesa. Forms of Patient Empowerment in an Anxiety Discussion Forum. A Master's Paper for the M.S. in L.S degree. April, 2016. 72 pages. Advisor: Dr. Barbara Wildemuth}

The U.S. Department of Health and Human Services defines health literacy as "the degree to which individuals have the capacity to obtain, process, and understand basic health information and services needed to make appropriate health decisions". One of the antecedents of health literacy, patient empowerment, has seen an increase from the participation of patients in online health communities. In this study, 4367 group forum posts from 215 users of Anxiety Connect, a moderated online health community, were analyzed using the patient empowerment processes and outcomes of Bartlett and Coulson. Patient empowerment was evident in the forum posts. Every post contained evidence of at least one empowerment process; $\mathrm{X} \%$ of the posts contained evidence of at least one empowerment outcome. The empowerment process most prominent in the Anxiety Connect forum was sharing experiences, included in $57.6 \%$ of Total Posts. The empowerment outcome most prominent was increased acceptance, included in $5.1 \%$ of Total Posts, closely followed by optimism and hope for the future and increased social well-being, included int $4.5 \%$ and $4.7 \%$ of the Total Posts respectively. These findings have implications for the design of moderated online health communities. 
Jonathan B. Moore. Evaluating the spectral clustering segmentation algorithm for describing diverse music collections. A Master's Paper for the M.S. in L.S degree. May, 2016. 104 pages. Advisor: Stephanie Haas

This paper presents an evaluation of the spectral clustering segmentation algorithm used for automating the description of musical structure within a song. This study differs from the standard evaluation in that it accounts for variability in genre, class, tempo, song duration, and time signature on the results of evaluation metrics. The study uses standard metrics for segment boundary placement accuracy and labeling accuracy against these song metadata. It reveals that song duration, tempo, class, and genre have a significant effect on evaluation scores. This study demonstrates how the algorithm may be evaluated to predict its performance for a given collection where these variables are known. The possible causes and implications of these effects on evaluation scores are explored based on the construction of the spectral clustering algorithm and its potential for use in describing diverse music collections.

Jennifer B. Parks. Learning in Middle School Library Makerspaces: A Makerspace Collaboration Guide for School Librarians. A Master's Paper for the M.S. in L.S degree. April 11, 2016. 99 pages. Advisor: Dr. Sandra Hughes-Hassell

This paper establishes an argument for the beneficial roles makerspaces can provide in school library programs. It builds a bridge between formal and informal education by grounding it in current accepted educational theories and frameworks including constructivism, constructionism, inquiry-based learning, and Backward Design. The paper stresses the importance of understanding adolescents and how they learn in a school library makerspace. It also addresses the role of school librarians as collaborators and their responsibility to conduct evidence-based practice. The final product resulting from this work is a makerspace collaboration guide intended for use by school librarians. It provides tools for facilitating productive collaborations between the school librarian, teachers, students, and community members. A version of this collaboration guide is available for download and modification at jennythelibrarian.wordpress.com.

Sara C. Paschal. "No Enjoyment Like Reading!” Pride and Prejudice Fan Fiction as Resources for Libraries and Readers. A Master's Paper for the M.S. in L.S. degree. April, 2016. 68 pages. Advisor: Melanie Feinberg

This paper introduces the concept of fan fiction and identifies distinctions between professionally published fan fiction, self-published fan fiction and online fan fiction as a way of presenting online fan fiction as a useful tool for reader's advisory and creative writing education. Using a sample of five texts for each of these three categories, this paper analyzes the works' contents for characters, settings, plots and themes from the original novel on which they are based, Jane Austen's Pride and Prejudice, as well as the type of sequel and genre. The findings describe what distinctions are found in the samples as respect these concepts and support the use of online fan fiction as resources for readers and writers.

Hannah L. Pope. Make-ing the Difference: Makerspace Instruction and the Student Perspective. A Master's Paper for the M.S. in L.S degree. April, 2016. 44 pages. Advisor: Chad Haefele.

This study describes the perceptions of students who have attended makerspace workshops at the Kenan Science Library Makerspace at UNC-Chapel Hill. Interviews were conducted with undergraduate students to determine the instructional and technological impact of the makerspace.

A group of five undergraduates who had attended a library session were interviewed. Instruction in the Kenan Science Library Makerspace covers emerging technologies such as $3 \mathrm{D}$ printing, 3D scanning, Introduction to Arduino, and Introduction to Tinkercad. The makerspace and its instruction sessions was found to be beneficial to students, increasing their knowledge of emerging technologies.

Daniel J. Pshock. Usability Heuristic Evaluation of 80 North Carolina Public Library Websites. A Master's Paper for the M.S. in I.S. degree. April, 2016. 52 pages. Advisor: Ronald E. Bergquist

This study discusses the results of a heuristic evaluation of 80 public library websites in the state of North Carolina. Each public library website (PLW) was evaluated using a usability heuristic questionnaire, with questions covering criteria taken from humancomputer interaction literature. Development of this questionnaire allowed a broad evaluation of 80 North Carolina PLWs to be conducted. The purpose of the study is to understand the extent to which PLWs in North Carolina meet basic usability heuristics. Developing a method of evaluation that can cover many PLWs of a specific locale allows librarians to use shared governance in future opportunities for investigation and improvement of websites in North Carolina public libraries. Results show that North Carolina PLWs meet some usability heuristics but not others, and that most North Carolina PLWs are more usable than they are unusable. 
Mark T Riddle. 'Do they look different?' An exploratory eye tracking study of whether the scanpaths of Novice and Familiar readers of graphic novels differ on the dominant/inset page. A Master's Paper for the M.S. in L.S degree. April, 2016. 81 pages. Advisor: Brian Sturm

Graphic novels, a large and growing part of the popular culture, are found across society from private homes to University Libraries. They have been found to be of benefit to early and reluctant readers and are also used for other tasks in the private and business sphere. As graphic novels become more popular, new forms of page layout are appearing. This exploratory study examined how university undergraduate's eyes traveled across specific 'dominant/ inset' page layouts. Participants' eye tracking data were collected using a Tobii Pro X2-30 Eye Tracker. Participants' scanpaths were analyzed using visual analysis techniques to determine how closely they corresponded to the Chronological Sequence Path set by creators. This study found that readers more familiar with graphic novels read these pages in a smoother fashion and were less likely to revisit text than novices.

Joseph Sanders. Audiobook Collection Development in North Carolina Public Libraries. A Master's paper for the M.S. in L.S. degree. April, 2016. 40 pages. Advisor: Ericka Patillo.

This study describes a questionnaire survey of librarians responsible for audiobook selection in the public libraries of North Carolina. The survey was conducted to determine the selection criteria employed by those librarians for audiobook selection, how they differed from print, and how technological change affected the process. The criteria used by public libraries to select audiobooks vary, but are largely similar to that of print materials. Responses show that patron demand is the most influential factor in audiobook selection, and that budgetary restrictions heavily shape the collection. The trend towards digital media has had a significant effect on the way that libraries build their collections, but a consensus on providing digital audiobooks in public libraries has not been reached. Currently, audiobook selection is based primarily around popularity.

Rachel C. Sanders. Hispanic and Latino Students and Their Library Experiences and Attitudes at a University in the Southeast. A Master's Paper for the M.S. in L.S degree. April, 2016. 52 pages. Advisor: Claudia Gollop.

This study describes a survey of Hispanic and Latino students at a major research university in North Carolina.
The purpose of the survey was to determine students' satisfaction with and use of the university's libraries. The study also included six interviews with students, which discussed more in-depth their attitudes toward library use at their university and their research processes.

Hispanic and Latino students are at a higher risk for dropping out of college during their first few years than many of their counterparts. There are a number of factors which influence this dropout rate; among them is a lack of support on campus. When students do not identify with their librarians they become less likely to approach librarians for assistance with coursework. The interviewees' feedback supports the literature which claims that Hispanic and Latino students are hesitant to approach librarians and are not necessarily confident in their research abilities.

Bess P. Schrader. Cross-Language Citation Analysis of Traditional and Open Access Journals. A Master's Paper for the M.S. in I.S degree. April, 2016. 43 pages. Advisor: Bradley Hemminger

This study examines the differences in the proportion of non-English language citations given to English language articles published in open access and traditional library and information science journals. It compares the average percentage of foreign language citations to total citations between 207 open access articles and 196 traditional articles published between 2011 and 2012. An independent, two-tailed t-test found no statistically significant difference between the foreign language citation percentages of open access and traditional articles. An analysis of variance also found no significant difference in the proportion of citations given by each non-English language according to journal type.

Elizabeth F. Shulman. An Exploratory Study on Undergraduate Archival Searching Behaviors. A Master's Paper for the M.S. in L.S degree. April 2016. 59 pages. Advisor: Helen Tibbo.

The purpose of this paper is to explore whether students with experience using archives search finding aids differently than students no experience. A usability study was conducted using four different finding aids from four institution with eleven undergraduate students from the University of North Carolina at Chapel Hill. The participants were recorded completing the tasks and were asked to describe their searching methods and the challenges they faced while completing the tasks during a stimulated recall session The results found that students used a multitude of searching methods in their attempts to answer the 
questions. The experienced users used more advanced techniques to find the answers but were less successful that the inexperienced participants on most of the tasks. The participants also struggled with archival terminology as well as the websites themselves while searching for materials. However, the participants were mostly successful in searching the library websites and locating finding aids.

Cassandra P. Stanco. Identifying the Information Needs of Biomedical Equipment Technicians in the Developing World. A Master's Paper for the M.S. in I.S. degree. April, 2016. 50 pages. Advisor: Clifford Missen.

This study describes a digital survey of Biomedical Equipment Technicians (BMETs), biomedical engineers, and managers in the biomedical field that work in the developing world. The survey was conducted to determine the information needs and preferences of this community regarding digital libraries and digital information seeking. A digital survey was distributed via email, posted to the online forums Infratech and HIFA, and posted to the homepage of Engineering World Health's BMET Library (http:// library.ewh.org). The survey indicated information seeking behavior centered on print technical information, search engines, and technical forums. It illuminated specific information needs such as a desire for visual materials, specific technical information, and stable formats for digital resources.

Jeanne Stroud. The Reality of Providing Professional Development in the Work Responsibilities of School Librarians. A Master's paper for the M.S. in L.S. degree. April, 2016. 47 pages. Advisor: Sandra HughesHassell.

This study describes a survey given to school librarians regarding their provision of professional development opportunities for teachers. Librarians who are members of AASL Forum and LM_NET were emailed the survey. The purpose of this study was to investigate the time allocated and/or spent by school librarians on staff development related activities and to identify the variables within the school community which inhibit or contribute to those activities.

School Librarians' professional development activities were assessed using the AASL's Empowering Learners: Guidelines for School Library Programs. The survey results of 230 participants showed that librarians provide large group PD about 0.57 times per month and one-on-one PD about 5.3 times per month; however, most librarians would ideally provide more PD opportunities than they currently provide. Responses also showed that the most common factors contributing to and inhibiting the provision of PD were teacher cooperation and lack of time, respectively.

Sara Thomas. Plagiarism: Don't. Plagiarism As a Skill Deficiency, and Building a Better Plagiarism Tutorial. A Master's paper for the M.S. in L.S. degree. April, 2016. 76 pages. Advisor: Jonathan McMichael

Academic integrity education is often framed in the context of plagiarism, which is typically taught to undergraduates through teaching citations. While this has generated attention and conversation on college campuses, issues of plagiarism and academic integrity have remained largely unaffected. High rates of academic integrity issues in specific demographics, such as international and transfer students, suggest that our definitions of plagiarism and academic integrity are potentially culturally bound and cannot be simply transferred through submitting to an honor code. UNC-CH's R.B. House Undergraduate Library and the Office of Student Conduct have partnered to create a plagiarism tutorial that better meets the challenges of changing information uses in education and offers a more inclusive approach to academic integrity education. This tutorial focuses on skill development and uses methods and concepts prevalent in pedagogical theory to help students develop a better understanding of the issues surrounding plagiarism.

Ashlyn Velte. Activist Social Media Archiving: Practices, Challenges, and Opportunities. A Master's Paper for the M.S. in L.S. degree. April, 2016. 84 pages. Advisor: Stewart Varner

Social media has played a significant role in recent activist movements. It empowers activists to organize and communicate their experiences. Archival efforts to document narratives that are historically silenced makes activist material an attractive collecting area. However, archives trying to preserve digital ephemera like social media from activist movements face digital preservation challenges as well as ethical considerations. By conducting online surveys and semi-structured interviews with archivists working on projects collecting activist social media this study found that activist social collecting projects: 1) face ethical and collection development challenges, 2) usually follow traditional models for acquisition, description, and access, and 3) increase donor and user engagement with collections. This suggests that in the future the profession would benefit from the development of best practices surrounding ethical collection development and use of activist social media. 
Sarah M. Vlasity. The Cabinet of Curiosities: Recreating the Renaissance Experience. A Master's Paper for the M.S. in L.S degree. April, 2016. 32 pages. Advisor: Denise Anthony

The cabinet of curiosities, or collection of the exotic and the obscure, was a product of the Renaissance. Efforts by the elite to acquire and display natural and man-made marvels served a dual purpose: to illustrate prestige and to support intellectual pursuits. In regard to the latter, this paper suggests three uses of the Renaissance cabinet: as a refuge, conducive to creativity and critical thinking; as a laboratory, facilitating experimentation via the arrangement or observation of objects; and as a forum, to inspire intellectual conversation. Linking the historical cabinet to its contemporary counterparts, this paper examines similar attributes in three modern exhibits on display, or displayed, at the University of Colorado Boulder, the University of Minnesota Twin Cities, and the Canadian Museum of Civilization. It concludes that the cabinet of curiosities remains a relevant model for exhibit design, that the appeal of the unexpected is timeless.

Elizabeth M. Wachiaya. Accessibility Analysis and Redesign of the Durham County Library Website to Serve the Needs of Visually Impaired Users. A Master's paper for the M.S. in I.S. degree. April, 2016. 60 pages. Advisor: Dr. Ronald Bergquist

When it comes to web accessibility, two sets of guidelines are commonly used - Web Content Accessibility Guidelines (WCAG) and Section 508, however due to constant technology changes some rules in these guidelines become obsolete. This study seeks to add a new perspective in evaluating web accessibility - user interface/experience professionals who keep their ears on the ground for user and technology trends and focusing on users with visual impairment. It examines the Durham County Library website to find its inadequacies in catering for visually impaired users using recommendations from professional articles combined with the current guidelines (WCAG and Section 508). Results from analysis show that layout, content and navigation are the areas most lacking in accessibility while images, tables and frames are the more conforming elements. Finally, this study makes suggestions on improving the website so it is easier for the visually impaired user to access information.

Yiqi Wang. Pattern Based Information Extraction System in Business News Articles. A Master's paper for the M.S. in I.S. degree. April, 2016. 45 pages. Advisor: Jaime Arguello
Business news journals provide a rich resource of business events, which enable domain experts to further understand the spatio-temporal changes occur among a set of firms and people. However, extracting structured data from journal resource that is text-based and unstructured is a non-trivial challenge. This project designs and implements a Business Information Extraction System, which combines advanced natural language processing (NLP) tools and knowledge-based extraction patterns to process and extract information of target business event from news journals automatically. The performance evaluation on the proposed system suggests that IE techniques works well on business event extraction and it is promising to apply the technique to extract more types of business events.

Eleanor H. Weston. Online Collections for Natural History Museums: A Heuristic Analysis. A Master's Paper for the M.S. in L.S degree. April, 2016. 49 pages. Advisor: Diane Kelly

This study analyzes the websites of fifty-nine natural history museums accredited by the American Alliance of Museums in order to determine current practices in online collection information for natural history museums and its relationship to institutional qualities.

Using a heuristic content analysis, this study looks at what collection information museums put on their own websites and external websites, search and browsing features for collection information, and whether they include written policies about loans and research visits using collection materials. Using a chi-square test, this information was analyzed in relation to demographic information, such as whether the museum is a nonprofit, affiliated with a college or university, government operated, or charges for admission. The findings of this study indicate no significant relationship between these demographic factors, but strong relationships between a museum's likelihood to put collection information online and information about lending and research policies.

Rebecca J. Williams Who Lives, Who Dies, Who Tells Your Story: A Global Content Analysis of Privacy Legislation and National Archive Policies in a Digital Age. A Master's Paper for the M.S. in L.S degree. April, 2016. 50 pages. Advisor: Rebecca Vargha

This study is a content analysis examining both privacy legislation and national archives policies regarding privacy to determine global understandings of privacy in a digital age. The analysis was conducted on the laws and policies of twenty nations sampled for geographic diversity. The results show that while significant amounts of legislation 
regarding data protection have been passed around the world in the past decade; however the policies of these national archives have yet to fully adjust to a new reality of recordkeeping in the digital age.

\section{Qiongcheng Xu. Data Mining and Visualization on} Live Chat Data for Ecommerce Business. A Master's paper for the M.S. in I.S. degree. April, 2016. 55 pages. Advisor: David Gotz

The purpose of this paper is to design, build and evaluate an interactive visualization tool for data analysts to analyze as well as interact with the live chat data from a corporate website for customer relationship management. Sales lead and customer support are the major purposes of the live chat service. Data mining technologies are applied to classify the chat data into categories that can help marketing and sales teams to target their potential customers more accurately and efficiently. By interacting with the web visualization tool, data analysts will have the capability to obtain valuable information about customers' concerns and buying interests on their products and solutions. The results indicate that chat classification achieves higher accuracy on major class "Lead" but lower accuracy on minor classes due to the imbalanced distribution of dataset as well as human bias when manually labeling the training data. Based on the analytic results of chat visualization, data analysts gain the knowledge gap between customers' concern and the information provided on the corporate website, and propose new ideas to improve their digital marketing approaches as well.

Shannon M. Young. Gender Bias in the Young Adult Publishing Industry: Too Many "Girly" Books? A Master's Paper for the M.S. in L.S degree. April, 2016. 31 pages. Advisor: Brian Sturm.

This study describes a content analysis of the cover art of 175 young adult books published within the last four years. The study was done to determine whether or not there is a gender bias in favor of girls in the young adult publishing industry. Educators across the English-speaking world are beginning to notice that teen boys are falling behind their female counterparts in reading, and some claim that this gap is due to lack of reading material for boys. This sample shows that there is a slight bias in favor of girls in young adult publishing, but the difference is not significant enough to support such claims.

Chongrui Zhang. Implementation and Usability Evaluation of an Electronic Health Record system based on patients' temporal visiting data. A Master's Paper for the M.S. in I.S degree. April, 2016. 43 pages. Advisor: Javed Mostafa

Electronic Health Record (EHR) systems have become highly important in health care and consequently in Health Informatics research. Although, some advances have been made, users' experience of modern commercial EHRs remain challenging at best and unsafe at worst. This paper implements a prototype of EHR system to visualize the history of patient visits in the context of psychiatric care. It reports on a usability study which compared the use of the simulated EHR system by subjects of various experience levels. The study has verified the importance of prior knowledge in the field of EHR. It proposes several suggestions to improve the usability of EHR systems by implementing a temporal data organization scheme to present critical data.

Wanchun Zhao. Spam Detection on Twitter: A Comparison between Content-based and Graph-based Features. A Master's Paper for the M.S. in I.S degree. March, 2016. 44 pages. Advisor: Bradley M. Hemminger

The popularity of social media has triggered the development of spammers, which produces useless information and costs normal user more time in information seeking process. In this paper, Twitter is studied as an example of spam detection in social media. Using Twitter APIs, contentbased and graph-based features were extracted from datasets and analyzed with users' level of spam. Combining two kinds of features with J48, NaïveBayes and SVM classifiers, content-based features with J48 have the best performance in evaluation.

Yongsu An. The impact of the MERS Outbreak in Daily Lives: Sentiment Analysis of Korean Tweets using Time-series Methods. A Master's Paper for the M.S. in I.S degree. April, 2016. 35 pages. Advisor: Jaime Arguello

This study examines the correlation between sentiments in tweets and the number of passengers in the subway as the social index during the MERS outbreak in South Korea. The observation that motivated this study in the social context was that people tended to avoid their social lives outdoors by the fear of being infected during the situation. Two time-series datasets were processed for the purpose of getting rid of seasonal patterns. The result showed that they are correlated with each other with 169 hours. It indicates that the sentiments in social media can be a good way of mirroring people's behaviors ahead of time. 
Kimberley M. Henze. Look Closely, See Creatively: Identifying Threshold Concepts for a Visual Literacy Framework for Higher Education. A Master's Paper for the M.S. in L.S degree. April, 2016. 80 pages. Advisor: Jonathan McMichael

Models for teaching information literacy have multiplied in the last decade in dutiful response to the digital barrage and increasing ubiquity of information. Meanwhile, models for visual literacy, despite an even greater proliferation of images in this same environment, have lagged behind. Although information literacy frameworks partially address the skillset for visual information, there are nuanced competencies critical to visual literacy that are wholly unaddressed by current conceptions of information literacy. This study pinpoints and articulates those visual literacy-specific skills by activating and analyzing the pedagogical content knowledge of experienced instructors of visual media and gauges those findings against ACRL's Framework for Information Literacy. Discoveries move the author to propose two major threshold concepts, articulated through the frames Close and Critical Looking and Creative Vision, which are critical and specific to visual literacy.

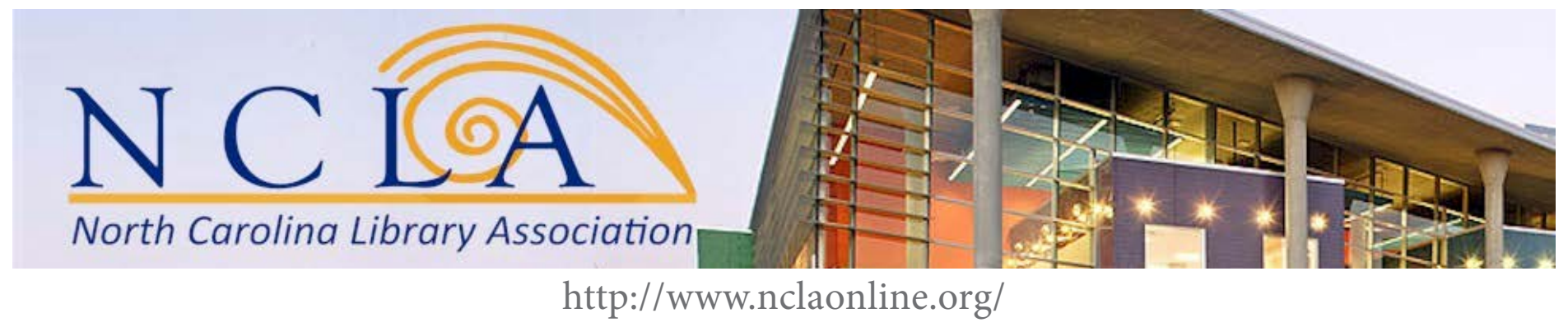




\section{College STAR for Librarians}

$\mathrm{P}$ ersons with learning disabilities face particular challenges when using academic libraries. As libraries seek to improve this situation, knowledge of current programs and relevant theories outside of library science can inform our choices. For librarians in the University of North Carolina system, a program of particular interest is called College STAR.

College STAR (Supporting Transition, Access, and Retention: A UNC System Project Supporting Students with Learning Differences) is a program intended to improve higher education success rates for students with formally-identified learning disabilities through direct interventions, faculty innovation, and research. Initiated by its principle investigator, Dr. Sarah Williams of ECU, the project is dedicated to the development and implementation of educational models that better meet the needs of students who encounter unnecessary barriers in traditional higher education methods. College STAR includes opportunities for participation and learning for librarians, presenting a potential opportunity to meaningfully improve library services for a population whose needs may have been neglected or poorly understood.

College STAR is funded by grants from the OAK Foundation and the North Carolina GlaxoSmithKline Foundation with the aim of making University of North Carolina (UNC) campuses more welcoming to students with diagnosed learning disabilities, Attention Deficit Hyperactivity Disorder (ADHD), or learning differences that may not fit an established diagnostic model, all of whom may benefit from an environment with more inclusive teaching strategies. The program consists of two components. Component A concerns the development of support programs such training in time management skills and study habits for students with learning differences whose needs have not been adequately addressed in the past. This component includes the identification and recruitment of students who will communities whose shared research aims to explore technologies and techniques of UDL for use in teaching. On the UNCG campus, ACCESS (Accessing Campus Connections and Empowering Student Success) is a three year research project designed to help students with ADHD develop the skills needed to succeed in the college environment. At ASU, AS-U-R is a support

\section{C College STAR is funded by grants from the OAK} Foundation and the North Carolina GlaxoSmithKline Foundation with the aim of making University of North Carolina (UNC) campuses more welcoming to students with diagnosed learning disabilities 9

be provided appropriate support during their undergraduate years. Component $B$ focuses on the development of improved instructional strategies and encourages faculty support to expand the understanding and implementation of Universal Design for Learning (UDL). Three UNC campuses, East Carolina University (ECU), the University of North Carolina at Greensboro (UNCG), and Appalachian State University (ASU) currently have active College STAR programs and expansion to other campuses is planned.

Participating campuses design their own local programs. At ECU, the program consists of Project STEPP (Supporting Transition and Education through Planning and Partnerships) which provides academic and life-skills support for a group of students with learning disabilities, and Pirate CREWS (Collaborating for Retention and Engagement With ongoing Support), a number of faculty learning program for students with Executive Function Challenges (EFC) that includes cognitive skills training and supervised study. ASU also has faculty learning communities and on-going training opportunities for course redesign and UDL. There are plans to expand the College STAR program to other UNC campuses and the program aims to benefit the community college system and K-12 education as well.

College STAR's educational philosophy is founded on Universal Design for Learning. UDL advocates offering learners multiple means of representation, of action and expression, and of engagement. (Please see cast.org for a complete explanation) Simply put, UDL advocates offering students options in the way information is communicated, in the way knowledge and learning are demonstrated, and in the way they are engaged in the learning process. Libraries can focus attention on representation and 
engagement. For representation, keep in mind that there are many learning styles and preferences. If we can offer the same information in multiple ways, i.e. print, video, audio, more users will have access. Engaging patrons should also give them options. Some may prefer email, chat, or phone to inperson reference, for example. The benefits reach beyond patrons with learning disabilities, of course. It is easy to imagine a person with a speech or hearing impairment welcoming the option of chat or email, for example. Likewise, those with mobility issues will surely appreciate the ability to communicate remotely, rather than coming to the library.

Underlying the UDL philosophy is that for some students, failure is caused by pedagogical design rather than lack of effort or ability. An analogy of a physical disability is a useful way to explain it. Consider the case of a person who relies on a wheelchair for mobility. If he finds himself unable to enter a building because of a step and a manual swinging door, the fault of this inability (or disability) lies with the design of the door, not with his method of ambulation. The door and step were designed with persons of certain abilities in mind, those who can walk and have the strength to open the door. But, if the goal is to provide entry to the building rather than to test peoples' ability to mount steps and open swinging doors, the design has failed to meet everyone's needs because the person in the wheelchair is unable to achieve the goal. However, it is possible from the beginning of the design to consider the needs of a wider range of people than those who can walk. Designing with a wheelchair user in mind will benefit others as well. People who can walk are not slowed or inconvenienced by entering a building through an automatic door with a flat entrance surface. They are likely to find the design superior to the step and swinging door. Parents pushing strollers and people with full hands will find the improved design as welcome as a wheelchair user.

In libraries, the goal is to maximize access to information for all patrons. Considering the needs of as many people as possible in the initial design of services, instruction, tutorials, research guides, etc. will support this goal. For example, since we know that some patrons will have difficulty processing written instructions, it is a simple modification to offer video instructions as well. As technology advances and our understanding of the needs of diverse learners expands, our ability to offer alternatives grows. We should be focused on design that meets the needs of all. Libraries have largely responded to the needs of patrons with mobility challenges, and their needs are now considered in building design. The needs of those with learning disabilities can likewise be accommodated.

The example of the College STAR is inspiring in itself. There are, however, more tangible benefits of the program for libraries. Librarians on campuses with College STAR programs (ECU, UNCG, and ASU), may participate in College STAR's Shared Learning Conference. The conference includes presentations and poster sessions about UDL applications being developed in the UNC system. The College STAR website makes information of this type available to all through learning modules hosted on its website. The website includes modules that are applicable to the practice of academic librarianship such as "Promoting Student Engagement" and "Using Clickers." Librarians on participating campuses may join or start supported learning communities to research UDL issues. All librarians have access to learning modules linked from College STAR's website and on the companion cast.org which includes some more general modules such as "Post-secondary Education and Universal Design for Learning."

As academic libraries work to improve access for people with learning disabilities, examples such as College STAR can offer guidance and inspiration. The theories and practices of UDL can help us widen our design practices to include patrons differing abilities and talents.

\section{References}

1 The terms 'learning differences' and 'learning disabilities' are both in current usage. They are used interchangeably in this essay

2 Information about College STAR in this essay is taken from http://www.collegestar.org/

${ }^{3}$ Information about Universal Design for Learning in this essay is taken from http://www.cast.org/index.html 


\section{Intellectual Freedom? Censorship in North Carolina, 1981-1985}

\section{From the pages of North Carolina Libraries}

by Barbara A. Thorson

v.44, no. 4 (Winter 1986), pp. 230-232

\section{$\mathrm{T}$} The 1960's was known for demonstrations on college camsocial issues led to attempts to restrict speech. Intellectual freedom was not an issue.

The 1980's have brought a new emphasis on intellectual freedom. Censorship attempts have been made both in educational and non-educational institutions. The purpose of this article is to present a brief overview of censorship from 1981 to May 1985 in North Carolina. In the 1980's, endeavors by a variety of groups brought censorship to a peak. The information is based on reported incidents to the American Library Association's Office of Intellectual Freedom and published in the Newsletter on Intellectual Freedom. This article includes statistics regarding the annual number of cases, location of attempts, sources or initiators of attempts, reasons, affected institutions, the objects of the censored attempts and the outcome for libraries.

Table 1: Number of reported cases

\begin{tabular}{|c|c|c|}
\hline 1981 & & 7 \\
\hline 1982 & & 6 \\
\hline 1983 & & 0 \\
\hline 1984 & & 0 \\
\hline 1985 & & 2 \\
\hline & Total & 15 \\
\hline
\end{tabular}

Between 1966 and 1980, twenty-five cases in North Carolina were reported to ALA. Of the twenty-five, six were reported in $1980 .{ }^{1}$ From January 1981 to May 1985, fifteen cases were reported. (see Table 1) Eighty-seven per cent of the total number of incidents occurred during 1981 and 1982. In 1981 the Moral Majority launched a state-wide campaign in North Carolina to target and remove materials deemed unfit. ${ }^{2}$

A survey conducted in 1983 by North Carolina People for the American Way reported 243 censorship attempts since $1980 .^{3}$ This information was collected by distributing questionnaires to public school educators. North Carolina People's survey could account for the lack of reports to ALA during 1983 and 1984.

Barbara A. Thorson is media coordinator at Union Grove Elementary School, Union Grove, N.C.

230 - North Carolina Libraries

Table 2: Locations of Censorship Attempts

\begin{tabular}{|l|l}
\hline Buncombe County & 2
\end{tabular}

Charlotte 1

\begin{tabular}{l|l}
\hline Farmville & 1
\end{tabular}

Gastonia 1

\begin{tabular}{l|l} 
Haywood County & 1
\end{tabular}

Lincolnton 1

\begin{tabular}{|l|l} 
Mars Hill & 1
\end{tabular}

New Hanover County 1

\begin{tabular}{l|l} 
Raleigh & 2 \\
\hline
\end{tabular}

$\begin{array}{ll}\text { Statesville } & 1\end{array}$

Troutman

Winston-Salem

1

The majority of endeavors was aimed at public schools. While the survey included all areas of the state, including large and small towns, smaller rural areas were predominant. (see Table 2) Unlike previous reports, the only postsecondary town was the rural town of Mars Hill. The two attempts in Winston-Salem were at the public library.

Table 3: Sources of Attempts

\begin{tabular}{|l|l|}
\hline Citizen & 4 \\
\hline Student & 1 \\
\hline Parents & 7 \\
\hline County Commissioner & 1 \\
\hline College Coach & 1 \\
\hline Unknown & 1 \\
\hline Principal & 1 \\
\hline
\end{tabular}

Parents were the primary source of censorship attempts, and earlier research reflects this fact. (see Table III) Five of the seven attempts by parents were from rural areas. Two of the cases were in Iredell County. Run Shelley Run was removed from the middle school but was considered appropriate for the high school level. ${ }^{4}$ Having been presented with a vast amount of information and numerous book reviews, the Ire-dell County Board of Education placed Huxley's Brave New World back in the classrooms. ${ }^{5}$

Another case involved the principal of a church school, and he opposed The Living Bible because the book had been criticized by fundamentalists as being a "dangerous corruption" of God's word.

Citizens' attempts at censorship were usually initiated without group 
pressure, but one instance concerned a group of school district residents led by several fundamentalist ministers who questioned the school's selection policy. ${ }^{7}$ Specific titles were not protested but works such as The Grapes of Wrath and Andersonville were indicated as being "indecent".

Table 4: Reasons for Censoring

\begin{tabular}{|l|l|}
\hline Language & 4 \\
\hline Pornography & 2 \\
\hline Sex & 3 \\
\hline Nudity & 2 \\
\hline Immorality & 1 \\
\hline Religion & 1 \\
\hline Perverted & 1 \\
\hline Wickedness & 1 \\
\hline Indecency & 1 \\
\hline Illustrations & 1 \\
\hline Values in classroom & 1 \\
\hline Criticism of Organization & 1 \\
\hline
\end{tabular}

The total number of reasons exceeds the number of attempts because it is hard to categorize cases, and often more than one reason was given. Although most of the causes in the broad range of reasons could be categorized neatly, others were a matter of interpretation. (see Table 4) Several categories are closely related: language, pornography and sex, but such terms as "immoral" could refer to sex or pornography.

Parents were the primary source of censorship attempts.

"Rough language" was given as a reason to remove It's OK if You Don't Love $M e{ }^{8}$ The decision to purchase the book was made from past experiences with Norma Klein's works. The decision by the board was unanimous to remove the book. A parent and a local minister in Farmville questioned the "objectionable language" in The Catcher in the Rye; however, on the basis of parental approval, the board voted to retain the book.
Table 5: Institutions Affected

\begin{tabular}{|l|l|}
\hline Public Library & 3 \\
\hline Elementary/Middle School & 6 \\
\hline High School & 4 \\
\hline College/University & 1 \\
\hline Christian School & 1 \\
\hline
\end{tabular}

Compared to the previous research by Woods, there was a shift in institutions affected by censorship attempts. In the above-mentioned research, $48 \%$ of all the attempts were made at the high school level. ${ }^{10}$ Of those cases reported to ALA between 1981 and 1985, 26\% were in high schools, and $40 \%$ occurred at the elementary and middle school level. Compared to six cases prior to 1981 , only one college, in a small town, appeared in the report. In his editorial, the athletic trainer who was also the editor of the school paper "blasted"11 the head coach for criticizing the football team. The coach fired the trainer for his comments.

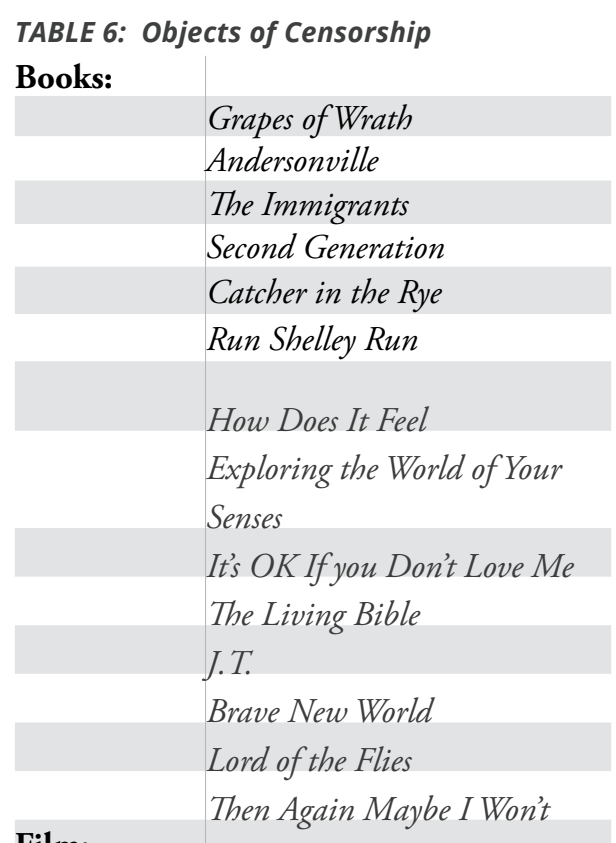

Film:

Newspaper:

LaCage Aux Folles

\begin{tabular}{l|l} 
& Hilltop (college newspaper) \\
Magazine: & \\
& Playboy
\end{tabular}

Books headed the list of censored material. As expected classics were among the most frequently censored titles. Andersonville and Catcher in the Rye appeared in earlier research also. There were no reported attempts on textbooks, and one film was censored by a county commissioner. La Cage Aux Folles, the French version of Birds of a Feather, was not shown at the Forsyth County Library because it was not "appropriate for general audiences," but Sister Michele Powell, a Catholic nun and Christian counselor, said she felt "mature enough to decide whether to do something" (watch the film). ${ }^{12}$ Also at Forsyth County Library, a parent, concerned that his daughter might be exposed to dirty pictures, objected to the presence of Playboy. ${ }^{13}$ The various censored materials had no similarities to one another.

\section{Table 7: Disposition of Attempts}

\begin{tabular}{|l|l|}
\hline Successful & 4 \\
\hline Partially successful & 2 \\
\hline Unsuccessful & 6 \\
\hline Unknown & 3 \\
\hline
\end{tabular}

The figures in Table 7 indicate a shift from Wood's report. ${ }^{14}$ Wood's research revealed $64 \%$ of all censorship cases were successful or partially successful and $24 \%$ were unsuccessful. Since 1981 only $40 \%$ of the cases reported to ALA were successful or partially successful and $40 \%$ were unsuccessful. The number of "unsuccessful" cases has increased.

A censored attempt achieved with or without judicial or court action is considered "successful". A "partially successful" attempt is one that is compromised from the original intent of the censor. As an example of the latter, the books The Immigrants and Second Generation were first removed from a school library but later made available to students with parental permission. ${ }^{15}$ While this will limit access to the titles 
the compromise will allow the books to remain in the library.

No doubt many of the individuals and groups feel it is their duty to censor materials they consider unsuitable.
Since North Carolina is located in the "Bible Belt" and is a target for groups such as the Moral Majority, librarians and citizens need to keep abreast of activities aimed at diminishing

\section{References}

${ }^{1}$ L.B. Woods and Alesandra M. Schmidt, "'First in Freedom? Censorship in North Carolina, 1966-1980," North Carolina Libraries, 41, no. 1 (Spring 1983): 23.

2 Newsletter on Intellectual Freedom 30 (March 1981): 1.

3 Ibid. 53 (January 1984): 3.

${ }^{4}$ Newsletter 31 (March 1982): 45.

5 Newsletter 30 (March 1981): 48.

${ }^{6}$ Newsletter 30 (July 1981): 105.

7 Newsletter 30 (May 1981): 74.

${ }^{8}$ Newsletter 31 (March 1982): 44.

${ }^{9}$ Newsletter 31 (March 1982): 58.

${ }^{10}$ Woods, 25.

${ }^{11}$ Newsletter 31 (March 1982): 50.

${ }^{12}$ Newsletter 30 (March 1981): 40.

${ }^{13}$ Newsletter 34 (March 1985): 59.

${ }^{14}$ Woods, 26.

${ }^{15}$ Newsletter 31 (November 1982): 158.

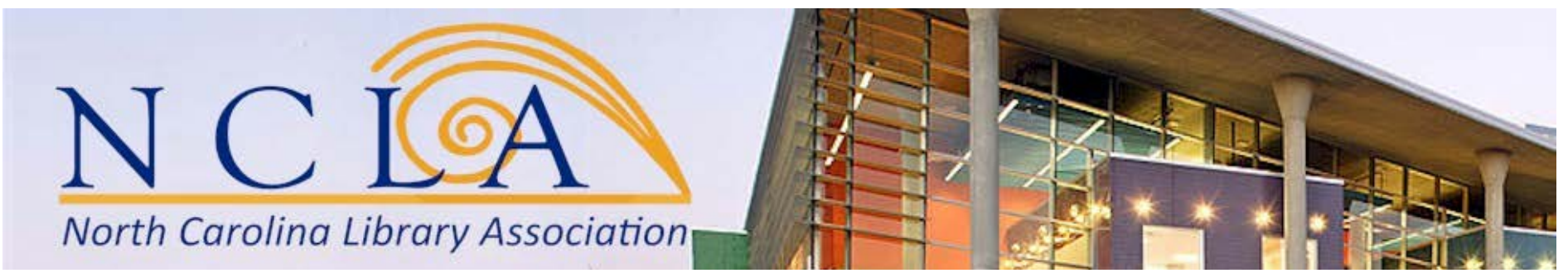
http://www.nclaonline.org/ 


\section{North Carolina Books}

Al Jones, compiler

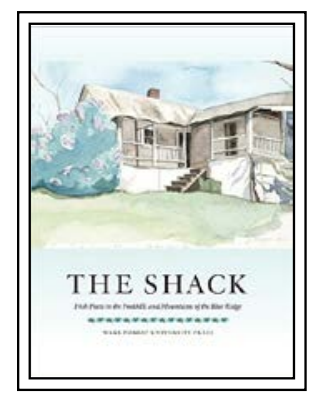

The Shack: Irish Poets in the Foothills and Mountains of the Blue Ridge

By Wake Forest University Press (Author), Jefferson Holdridge (Editor).

Winston-Salem: Wake Forest University Press, 2015 71 pp. \$15.95. ISBN 978-1-930630-71-0.

Cor 40 years, Wake Forest University
Press has been bridging the worlds of Ireland and North Carolina as the foremost publisher of Irish poetry in North America. Dillon Johnston, a retired Professor of English at Wake Forest University, who founded the press and ran it alongside his wife, Guinn Batten, saw the press as "a mediator between the American reader's consciousness, the world we inhabit, and another world we otherwise could not." This anthology is a celebration of Wake Forest University Press and more specifically, an homage to Johnston and Batten.

This slim anthology brings together the works of 11 Irish poets as they explore the connected worlds of their homeland in Ireland and the Piedmont region of North Carolina. The look and feel of the book are quite lovely with its large format accompanied by beautifully illustrated watercolors by North Carolina composer and artist, Kenneth Frazelle. It includes poetry and prose by Paul Muldoon, Eiléan Ní Chuilleanáin, David Wheatley, John Montague,
Elizabeth Wassell, Vona Groarke, Ciaran Carson, Medbh McGuckian, Conor O'Callaghan, Michael Longley, and Derek Mahon. All but one of the contributors have had their work previously published by the press and several have been visiting professors at Wake Forest University.

The anthology opens up with Paul Muldoon's Promises, Promises, as he dabbles in the exploration of Sir Walter Raleigh and the lost colony of Roanoke. From there, the anthology takes the reader on a walk through North Carolina's landscape from David Wheatley's paintball canvas Carolina Sky in ROYGBIV to Vona Groarke's persimmon tree in Away and Conor O'Callaghan's blizzard of dogwood blossoms in Swell. Ciaran Carson and Medbh McGuckian provide meditations on North Carolina musical traditions from his tale of oldtime music in Fiddlin' John's Big Gobstopper and her hearkening back to early Carolina love songs. Poems are interspersed with the authors' tales of their visits to Wake Forest University, Johnston and Batten's home in Virginia, the titular Shack, or their experience writing poetry for Wake Forest University Press. John Montague and Elizabeth Wassell write of their visit to the Shack, Johnston and Batten's poetry refuge in Virginia, in A Stoots Remembrance as they find "Dillon himself, on a swing beneath a venerable tree, flying back and forth, up and down, a scholar and a gentleman, but also like a child."

Though its individual elements are a bit disparate, Wake Forest University Press itself and the poets' connections to Johnston and Dillon act as the core thread of this anthology. The Shack is suitable for young adults and adults, those interested in Irish poets, poetry about the Piedmont region of North Carolina or those with specific interest in Winston-Salem and Wake Forest University. Recommended primarily for university libraries and public libraries in or around Winston-Salem and libraries with a special interest in Irish poetry.

\section{Kristan E. Shawgo \\ University of North Carolina at Chapel Hill}

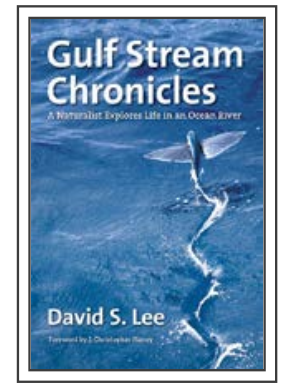

Gulf Stream Chronicles: A Naturalist Explores Life in an Ocean River

By David S. Lee.

Chapel Hill: The University of North Carolina Press, 2015. 282 pp. \$28.00. ISBN 978-1-4696-2393-1.

$M$ any popular nature books focus on the seashore and its inhabitants. With GulfStream Chronicles, author David S. Lee takes readers beyond the shore and into pelagic, open-sea waters that even frequent beachgoers may never have the opportunity to visit. In the preface, Lee writes: "People who spend entire summers at the beach mistakenly think they are familiar with the sea. Thirty miles offshore it's a totally different world, or at least the edge of one."

In the chapters that follow, Lee 
introduces readers to this new and different world. He describes the Gulf Stream as a river within the ocean, flowing its way up along the eastern coast of the United States before veering out into the northern Atlantic. Lee understands the interconnected nature of the oceanic world, and though he focuses his discussion on the waters off the coast of North Carolina, he wisely does not limit himself to the inhabitants or effects of the Gulf Stream there.

The text mixes scientific observations with anecdotes from years of research. Lee introduces many pelagic animals and plants, highlighting creatures such as the Portuguese man-of-war, the Bermuda petrel, the American shad, the ocean sunfish, and the pilot whale. In one chapter, Lee explains the incredible physiology of the leatherback sea turtle-a reptile that regularly swims and dives in subarctic waters where temperatures would kill other reptiles (and, indeed, many mammals). This is a truly specialized animal, and a truly endangered one. But there is hope--Lee points to the success of some conservation efforts, while recognizing that there is far to go in saving the species.

The text is accompanied by blackand-white maps, photographs, and line drawings. The appendix provides a guide to common and scientific names, as well as further discussion of species that may be found in the various oceanic zones that Lee highlights. There is also a chapter-by-chapter list of suggestions for further reading, as well as an index.

Lee spent thirty years working at the North Carolina State Museum of Natural Sciences, where he served as Curator of Birds and conducted numerous research projects to document the state's birds, reptiles, fish, and other creatures. An avid naturalist and conservationist, he has authored over four hundred articles in scientific journals and popular magazines. Gulf Stream Chronicles is his first book.
Sadly, Lee passed away before the publication of this book, but his work lives on through his research and his many contributions to conservation efforts in North Carolina and beyond. Over the course of Gulf Stream Chronicles, Lee describes and illuminates many amazing creatures that are worth saving. In the postscript, he touches on some of the serious problems the western North Atlantic (and indeed all of the seas) are facing, and asks readers if they are ready to contribute to the cause of helping to save the seas. With Lee's work as a guide, the answer should be a resounding yes.

Gulf Stream Chronicles is recommended for library collections in North Carolina and beyond.

\section{Anna Craft \\ University of North Carolina at Greensboro}

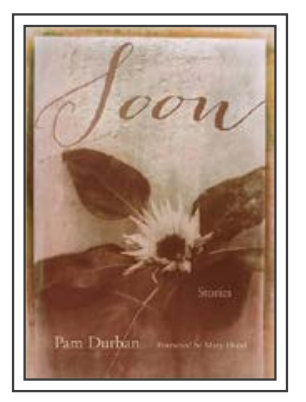

\section{Soon: Stories}

By Pam Durban.

Columbia: University of South Carolina Press, 2015. 115 pp. \$22.95. ISBN 978-1-61117-533-2.

CS e kind, for everyone you meet is fighting a hard battle." This quote, variously attributed to Plato, Philo of Alexandria, and Scottish theologian Ian Maclaren, would certainly apply to the protagonists of the eleven stories in the latest collection by Pam Durban, the Doris Betts Distinguished Professor of Creative Writing at the University of North Carolina at Chapel Hill.

"Rowing to Darien" traces the panicked flight of English actress Fanny Kemble from an unhappy marriage in
pre-Civil War Georgia. An Ohio housewife looks back over her long marriage to a veteran of World War II in "The Jap Room.” A recently adopted ten-year old boy struggles with memories of his negligent mother in "Birth Mother"; a terminally ill cancer patient faces his mortality while engulfed in the darkness of Mammoth Cave in "Hush." In "Gravity" a daughter visiting her ailing mother at an assisted living establishment in Charleston reflects on the place their black housekeeper, Mamie, occupies in their family history. "Soon," the title story (selected by John Updike for inclusion in the anthology, The Best American Short Stories of the Century) illuminates the complicated relationship between a mother and daughter.

Some of the stories are told from the first person point of view, others from the third. They are set primarily in the South with an occasional foray into the Midwest; locations include Georgia, North and South Carolina, Ohio, and West Virginia. The characters are often but not always older, reflecting back on their lives as they search for meaning and hope. All the stories are beautifully written, with a keen eye for the telling detail that offers insight into secondary as well as principal characters.

A native of Aiken, South Carolina, Pam Durban cofounded the literary magazine Five Points. Her novels include The Laughing Place, (winner of the Townsend Prize), So Far Back (winner of the Lillian Smith Book Award), and The Tree of Forgetfulness. She is also the author of an earlier collection of short fiction, All Set About with Fever Trees and Other Stories. Highly recommended for academic and public libraries where literary fiction and short stories are in demand, particularly those who own the author's earlier works.

\section{Janet Lockhart \\ Wake County Public Libraries}




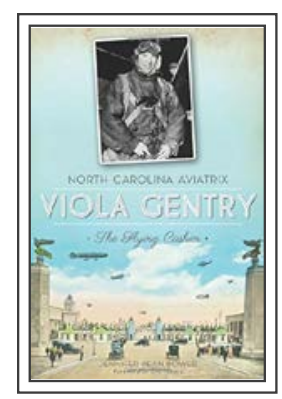

North Carolina Aviatrix Viola Gentry: The Flying Cashier Jennifer Bean Bower.

Charleston, SC: The History Press, 2015.

179 pp. \$19.99. ISBN 978-1-60949-695-1.

A handful of names-Amelia Earhart, Jacqueline Cochran, Sally Riderepresent the history of women's flight for most of us. But scores of lesser-known women were involved in aviation's beginnings in the early twentieth century. Author Jennifer Bean Bower profiles one of these forgotten luminaries, a woman once as recognizable as Earhart.

Viola Estelle Gentry was born in modest circumstances in 1894 in Gentry, a small town in Rockingham County, North Carolina. By 1902 Gentry's mother had died, and the family moved to Danville, Virginia. Bower notes that Gentry was a spirited child who became known as "that naughty Gentry girl." By age sixteen, she had made two failed attempts to run away: once to join the circus and another to elope with a mill hand. Afterwards Gentry's father placed her with relatives and friends. While staying with relatives in Jacksonville, Florida in 1911, Gentry took her first airplane ride. The flight made a lasting impression.

While working as a San Francisco switchboard operator in 1919, Gentry witnessed a Hollywood stunt pilot land his plane on a hotel roof. Gentry thought, "If a man can do it, certainly a woman could." She committed herself to aviation by reading books, talking to pilots, and saving for her first flying lesson in 1924.

Determined to make a name in aviation, Gentry paid for the expense by cashiering at a French restaurant in New York. Gentry performed her first aerial stunt flying a rented Curtiss Oriole under the Brooklyn and Manhattan Bridges. National newspapers reported the stunt, making "the Flying Cashier" a celebrity. In 1928 she set the firstrecorded women's solo endurance record. She was one of the first women to receive a federal pilot's license, and the first from North Carolina.

Ensuing decades found Gentry facing career and personal disappointments. She struggled as a hotel receptionist and housekeeper to fund her flying and was hurt during a 1929 endurance flight that killed her co-pilot. Bower argues that the long-term effects of Gentry's injuries closed many doors. Nonetheless she continued to fly when possible and promoted women's aviation as a charter member of the Ninety-Nines. Because of her connections to early aviators, Gentry helped form the History of Aviation Collection at the University of Texas. In 1975 she self-published her research in Hanger Flying: Stories of Early Flyers in America.

Bower won a 2015 Willie Parker Peace History Book Award for this accessible, carefully-researched, and richly illustrated book. This volume represents years of research at historical and aviation-related organizations and libraries, as well as interviews with Gentry's family. Because this is the first Gentry biography, Bower relies heavily on newspaper articles as sources, leaving periods of time unaccounted for. Bower has written three other books related to North Carolina's lesser-known people, places, and events. Despite its title, this book is not about North Carolina. Viola Gentry will be of particular interest to readers interested in women's aviation history, but this engaging, accessible book should appeal to a general readership. It would be appropriate in high school collections and public and academic libraries. In addition, Bower performs a first-person costumed narrative for younger audiences.

\section{Linda Jacobson \\ University of North Carolina at Chapel Hill}

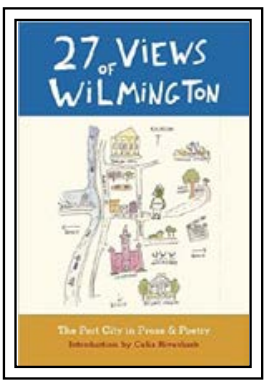

27 Views of Wilmington: The Port City in Prose \& Poetry Hillsborough: Eno Publishers, 2015. 205 pp. \$15.95. ISBN 978-0-9896092-3-4.

27 Views of Wilmington, with an Celia Rivenbark, is a collection of both prose and poetry selections that detail the history, culture, and people of Wilmington, North Carolina. Specifically, Wilmington is known as a center of the film industry with several popular shows like One Tree Hill and the TV show Matlock having been filmed nearby. Additionally, Wilmington is the location for several popular tourist attractions such as the USS North Carolina, the annual North Carolina Azalea Festival, Fort Fisher, and the popular Cape Fear River waterfront. Besides these facts, Wilmington is the birthplace of popular TV personalities, namely, David Brinkley, Charles Kuralt, and Charlie Daniels. Visitors to Wilmington can also view loggerhead turtles on Wrightsville Beach, take scenic riverboat tours on the Cape Fear River, or enjoy the local nightlife along Front Street or Market Street. Like other cities, Wilmington has overcome some unrest during its historical development. Specifically, on November 10, 1898 , several local businessmen and the 
North Carolina "Redeemer" Democratic Party used local armed guards (named "Red Shirts") to keep black residents from voting. Despite some turbulent chapters in its historical development, Wilmington has become in modern times a popular state retirement center.

This book is the final installment of the popular Eno Publishers 27 Views series. Other titles are as follows: 27 Views of Greensboro, 27 Views of Charlotte, 27 Views of Raleigh, 27 Views of Durham, 27 Views of Asheville, 27 Views of Chapel Hill, and 27 Views of Hillsborough. In 27 Views of Wilmington, twenty-seven different authors from the Wilmington area contribute both prose as well as selections of poetry to the compilation, and give their unique perspectives of the Wilmington area. Interestingly, the contributors include UNCWilmington faculty in the Creative Writing or Master in Fine Arts Program, Cape Fear Community College faculty, a former UNC-Wilmington Chancellor, the widow of the co-pilot for United Airlines Flight 93, and a local radio station commentators. Each selection in 27 Views of Wilmington ends with a short biography of the contributor. The book is divided into specific sections entitled, "A place called home," "Close-Ups," "A World Apart," "Street Scenes," "Views from before," "Views from 1898 \& beyond," and "Views in Fiction." Although the book does not contain any specific illustrations, one illustration on the book's cover does depict popular Wilmington area landmarks, including Airlie Gardens and the Bellamy Mansion.

Ultimately, 27 Views of Wilmington offers a glimpse into the daily lives of the "Port City's" residents. After completing this book, readers can begin to understand the events which have shaped Wilmington's past and which may serve a valuable role in its future. Because of its specific scope and subject matter, 27 Views of Wilmington would be suitable for inclusion in a public or academic library with a local history focus.

\section{David W. Young \\ University of North Carolina at Pembroke}

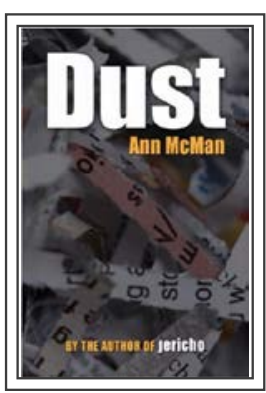

\section{Dust}

By Ann McMan.

Fairfield, CA: Nuance : Bedazzled Ink Publishing

Company, 2011

252 pp. \$14.95. ISBN 978-1-9344-5273-8.

$D$ ust is a fast-paced, plot-driven tale of political intrigue centered on Evan (Evangeline) Reed, a woman who professionally digs up dirt on politicians. Evan is asked to vet an irreproachable, environmentalist state senator whose political party sees him as a promising presidential candidate for the next election cycle. Evan gets more than she bargained for when she investigates Senator Andy Townsend in this mystery/ thriller, including murder, aliases, affairs, and unlikely alliances. No twist is more surprising to her than how quickly she falls for the senator's estranged wife, Julia Donne, a woman who has taken the reins of her family's successful international publishing firm.

This third person narrative with multiple perspectives predominantly trails Evan Reed between her home in Chadds Ford, Pennsylvania, to Julia's home of New York City with side trips across all parts of the United States (Colorado, Delaware, Florida, and Washington, D.C.) and even across the pond to London.

Wrapping up in just over 250 pages, I longed for a bit more development and background for her compelling cast of characters, including her childhood best friend, Father Tim, her teenage daughter, Stevie, and the two men who handed her the Townsend job, one of whom is Stevie's cantankerous father. Evan herself is fairly well fleshed out. She's an expert in her profession--smart, able to easily tease out details as she interrogates, and a savvy researcher to boot. Librarians, in fact, may quite enjoy that the story kicks off with her conducting research at the Library of Congress. Evan's personal life is more of a disaster as she is easily emotionally frazzled and prone to bouts of cursing. Also, much of Evan's romantic entanglement with Julia is implied, rather than directly conveyed to the reader.

Written in 2011, Dust is the second novel of award-winning author, librarian and North Carolina resident, Ann McMan, that followed up her highly praised book, Jericho. For her lesbian literary fiction and mysteries, Ms. McMan has been awarded the Alice B. Lavender Certificate, a Rainbow Award, a Golden Crown Literary Society award, and been elected to the The Royal Academy of Bards Hall of Fame. Dust was published by the independent press, Bedazzled Ink Publishing, which is "dedicated to literary fiction, nonfiction, and children's books that celebrate the unique and underrepresented voices of women."

Dust is recommended for collections of North Carolina authors, LGBT authors, adult mystery/thriller, literary fiction and/or LGBT protagonists. Great addition, along with McMan's other work, to public, school and academic adult or YA collections, though, perhaps best suited to older teens due to profanity and brief violence.

Kristan Shawgo

University of North Carolina, Chapel Hill 


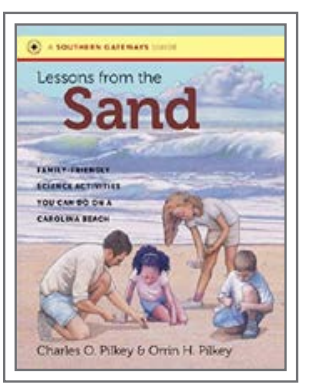

Lessons from the Sand: FamilyFriendly Science Activities You Can Do on a Carolina Beach

By Charles O. Pilkey and Orrin H. Pilkey. Chapel Hill: University of North Carolina Press, 2016. 221 pp. \$19. ISBN 978-1-4696-2737-3.

A nyone who has ever done research Aon the ecology, geology, or politics of the North Carolina coastline has probably encountered Dr. Orrin H. Pilkey's research. Dr. Pilkey, Professor Emeritus of Geology at Duke University (and Founder and Director Emeritus of the Program for the Study of Developed Shorelines), has for decades challenged the effectiveness of beach nourishment, jetties, and seawalls in combatting beach erosion, asserting that humans can neither accurately predict nor permanently change the effect of wind and wave on shorelines.

Lessons from the Sand contains fortyone hands-on activities developed by Orrin and his son Charles to raise awareness of the forces that shape North and South Carolina beaches and the organisms that inhabit them. Photographs and maps supplement the warm coloredpencil illustrations provided by Charles, an artist and sculptor. Each activity is prefaced with a literary quote, reinforcing the connection between art and science.

The first chapters in the book consider the characteristics of waves and erosion and then move on to the nature of sand, shells, plants, and animals. Other chapters discuss the human impact on the environment and provide rainy day alternatives to the outdoor activities.
Most families will already have all the required equipment (trowel, plastic bags, magnifying glass, etc.) to conduct the experiments. A hydrometer is the only unusual item, and this can be purchased for about $\$ 10$ wherever aquarium supplies are sold. A microscope can add a different perspective, but is certainly not essential.

The book is geared towards elementary and middle school students, but beachgoers of all ages will find activities that both satisfy and stimulate their curiosity. The introduction includes a disclaimer that the book is not a field guide, but the text and illustrations should be able to answer most beachgoers' "What is that?" questions related to sand, shells, wildlife, and plants. Readers looking for a more in-depth scientific study of coastal dynamics (without the hands-on experiments) might want to consider the senior Pilkey's book How to Read a North Carolina Beach (UNC Press, 2004).

The book is not an overt forum for Pilkey's views, and most readers (or at least the ones who don't have an expensive beach house in danger of collapsing into the ocean during the next hurricane) will find his delivery and thought-provoking questions balanced. Vacationers who read the book without moving off their beach rental's deck will still be enlightened by the content and challenged by the questions. If the authors are successful in their ambitions, both children and their parents will come to understand that beaches are not simply piles of sand next to salt water, but vibrant, ever-changing ecosystems.

Recommended for public libraries, school media centers, homeschoolers, and every beach rental house from Corolla to Dafuskie Island.

\section{Arleen Fields \\ Methodist University}

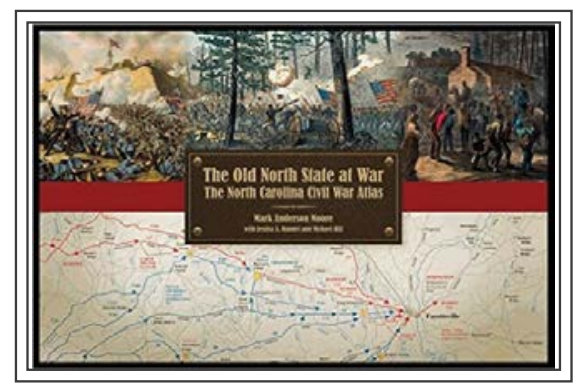

The Old North State at War: the North Carolina Civil War atlas

By Mark Anderson Moore.

Raleigh, N. C. Department of Cultural Resources, 2015. 190pp., illustrations, maps, portraits.

Torth Carolina has long needed an 1 atlas that graphically shows the imprint that the American civil war made on the entire state. Individual battles such as the one for Fort Fisher can be studied through appropriate mapping found on monographs on the battle, but viewing the war in its entirety in a single volume has never been possible up until now. With the sesquicentennial coming in 2010, the North Carolina Division of Archives and History began almost ten years ago looking for a way to commemorate this event. A committee was formed in 2004 by Deputy Director Jeffrey J. Crow to plan for this atlas. The Old North State at War is the outstanding result of that effort. Written by Mark Anderson Moore with the help of Jessica Bandel and Michael Hill, the atlas contains ninetynine highly detailed large scale maps of significant civil war locations. Mark Anderson Moore, the primary author for the project, was an IT specialist with the North Carolina Office of Archives and History and currently focuses on his work as an author and mapmaker. Jessica Bandel works for the North Carolina Office of Archives and History researching Civil War battles and creating educational smartphone content. Michael Hill is Supervisor of Historical Research for the Office of Archives and History. 
The scholarship for the atlas is outstanding. Many of these large scale maps are accompanied by civil war era illustrative materials. The content of the maps and illustrations are simply amazing. This reviewer was particularly impressed by the illustration of the "powder vessel" USS Louisiana used in the Union attack on Fort Fisher in December of 1864. An illustration of this vessel has never before been seen, and we see that the design of the vessel conveys the method of attack in a way that mesmerizes the reader. Similarly the Sawyer Obstructions on Cape Fear River come alive in an illustration/map of the Confederate river defenses of the area. Many of the maps of the Eastern and Western theatre of the war were previously available only via Confederate and Union originals. The maps of these areas enlighten readers as to the entire scope of the war in the state, while other treatments of the war tend to focus only on the major battles. The maps on the Battle of Plymouth and the Albemarle Sound area show events that were only available before in small scale illustrations. Not only are battles and skirmishes shown in maps, but topics such as the Bread Riots of 1864, the Freedman's Colony of Roanoke Island, the Confederate prison at Salisbury, Thomas' Legion of Cherokee troops, the massacre of Unionists at Shelton Laurel, and an essay on Parker Robbins lend an outlook to the war that most North Carolinians have not yet heard. The depiction of other lost episodes such as numerous Federal atrocities in the Western part of North Carolina and Eastern Tennessee during the war also add depth to the work. The atlas also includes full page biographies of important personalities such as: James I. Waddell, John Newland Moffitt, and Ambrose E. Burnside. Tables, such as a list of military installations in North Carolina 1861-62, total war death by county, prices of market goods 18611865, Union Enlistments by date 18621865 , and county by county returns for President and Governor, also make this volume highly useful to our understanding of the conflict.

Archival sources and newspaper accounts of the period were consulted for the atlas, and this resulted in the creation of a number of important data bases on the period. Confederate maps drawn by James Francis Gilmer for example were related against the earliest state county highway road maps and then matched to modern GIS mapping to create accurate and up to date mapping of illustrated areas. Online digital resources such as the National Archives and ancestry.com were consulted for background letters and information. Collecting this type of background information enabled the authors to create a significant publication on the Civil War in North Carolina. The volume is in an attractive format and makes use of appropriate coloring that is both easy to read and pleasing to the eye. Many map publications in the age of GPS are produced using the cheapest design possible, leading to difficultto-read mapping. This work will stand as a model for how to produce clear and easy to read maps. The text of the book is both informative and concise in presentation. Page layout is very well done and makes traveling through the book (It is arranged in a chronological order) easy and comfortable for the reader. The binding is very sturdy and uses a good quality buckram that will stand up over time. The jacket layout is very attractive and conveys an accurate account of the type of material contained in the book.

This book will stand as a model of what state-specific depictions of a civil war atlas should look like. K-12 schools as well as university libraries will find the atlas useful in classroom situations. The Old North State at War: the North
Carolina Civil War Atlas is a unique resource for the citizens of North Carolina and the nation. Overall the accounts given in the book are accurate and from original sources where possible. It is unfortunate that space limits the treatment of some accounts. For example this reviewer would like to have seen a more graphic account of the assaults on the women at the Shelton Laurel massacre, but this is a book for a general audience and we will have to be content with descriptions of the murders of the men. Adding the women would have added a gender-based view and broadened the horror of the attack.

\section{Ralph Scott \\ East Carolina University}

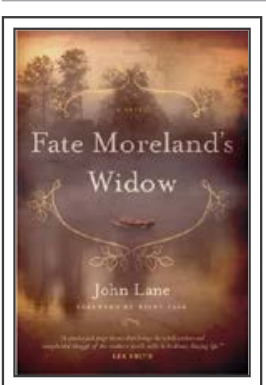

\section{Fate Moreland's Widow}

By John Lane. Columbia, SC: University of South Carolina Press 2015. 184 pp. \$24.95. ISBN 978-1-61117-469-4

Tn his foreword, Wiley Cash places the time and setting for John Lane's novel Fate Moreland's Widow and provides a glimpse into the perspectives of the main character, Ben Crocker. Crocker, son of a mill worker, is a man caught in the middle in his new somewhat isolated position as the right hand man of his boss, a wealthy textile mill owner. George McCain, Jr., the current mill owner in a long family line of privilege, has little concern for those he employs, including Ben Crocker's friends and family, beyond how productive they can be in the textile mill.

In the mid-1930s, mill workers were engaged in labor strikes across the 
country attempting to organize unions to enhance their bargaining power and improve working conditions. Mill owners like McCain were highly resistant. Crocker, from a mill-working family, now finds himself to be a "company man" at odds with all he has held dear, particularly the organization of unions. Further he is forced to act on his boss's behalf in laying off workers, targeting those engaged in labor union efforts, and removing them from their mill-owned homes, generally finding himself burdened by the resulting moral and ethical conflicts. As the story unfolds, mill owner McCain becomes embroiled in a legal dispute, charged with murder for recklessly causing an accident that resulted in the drowning of Fate Moreland, his young son, and another person on the local lake property owned by the McCain mill family. The Morelands represent all that the McCains do not. They are seen as hardworking, caring members of the community as opposed to the McCain family with their wealth and disregard for the common man. There are also tantalizing hints of the involvement of George's despised older brother Angus in this tragedy, leaving readers to wonder who really caused this accident, but these questions are not advanced.

Crocker, however, is called upon to serve, once again, the best interests of his boss. These include paying off the widow of Fate Moreland and others. In the process of this unethical involvement, Crocker's feelings are complicated by his increasing infatuation with the young widow. Even so Crocker holds true to his status as a "company man," squelching his personal feelings and doing what he has to do.

It is in the latter part of life, with time to reflect, that he continues to be burdened by how he allowed himself to be used in the quest for his own personal success. Crocker questions the value of what he did and whether or not he actu- ally helped to improve anyone's life.

In Fate Moreland's Widow, John Lane skillfully shares historical fact, local drama, and unanswered questions. Perhaps Lane is planning a sequel to answer some of these questions, especially in regard to the older McCain brother.

This book is recommended for anyone interested in historical fiction from the southern region. There is clear evidence of the inequities of social class and family status that readers may find interesting, particularly as related to a pre-modern rural southern setting. Public and academic libraries that collect North Carolina or South Carolina history or literature should definitely have John Lane's Fate Moreland's Widow in their collections. High school libraries may wish to acquire this book as well.

\section{Kaye Dotson \\ East Carolina University}

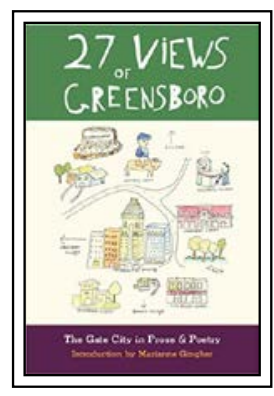

27 Views of Greensboro: The Gate City in Prose \& Poetry Hillsborough, NC: Eno Publishers, 2015. 193 pp. \$15.95. ISBN 978-0-9896-0921-0.

$\mathrm{D}_{\mathrm{s}}$ id you know that Greensboro was the Atlanta airport of the railroad era? So many railroad lines went through it that you couldn't get anywhere without going through Greensboro along the way. The latest in a series of books on different North Carolina cities, 27 Views of Greensboro, is rich in historical tidbits and personal reminiscences of the city. Most of the selections are essays, with a handful of poems and a single short story, and contributors include journalists, professors, poets, novelists, and other writers. Together, they make up a portrait of the city's past and present.

Many of the selections can be divided into two categories: those of Greensboro natives and those of residents who found a home there later in life. Of the former category, one of the most moving essays is Allen Johnson's "Our House Has Two Stories," where he describes his black family moving into a formerly white neighborhood in the late $1960 \mathrm{~s}$. The couple they bought their house from were kind and gracious, and yet were undoubtedly part of an epidemic of white flight. Decades later, Johnson met the family's son, near his own age, who confesses his guilt at the actions of his parents. Among several other stories of segregation and the civil rights era is Linda Beatrice Brown's "A Nice Nasty Town.” Brown describes Greensboro as a city that maintained a veneer of being more liberal and less segregated than other parts of the South, until the 1960 Woolworth lunch counter sit-ins opened up Greensboro's internal discontent to the rest of the world.

Of the essays by writers who have adopted Greensboro as their hometown, Tina Firesheets's opening sentence, "I hadn't intended to stay here," sums up the theme of many. In "Sayf," Diya Abdo writes of being forced to leave her native Jordan for a job at Guilford College after her academic work is deemed inappropriate for an Islamic university. Though she considers herself a city woman who will never be comfortable in a small place like Greensboro, she finds an unexpected home there. In "On a Rocky Inland Coast," Lee Zacharias describes ending up at UNCG more or less by accident and feeling certain that she'd never stay past the first year. Despite the initial strikes against Greensboro (an overly suburban feel and lack of mountains), she is still there almost forty years later. 
The 27 selections (plus an introduction by Marianne Gingher) approach Greensboro from a number of different angles_-personal or historical, prose or poetry, humorous or serious - and they come together to create a whole that will be interesting to both the Greensboro resident and the outsider who wants to learn more about a different part of the state. It is recommended for libraries in the Greensboro area, and for libraries elsewhere in the state that collect North Caroliniana.

\section{Michelle Cronquist University of North Carolina at Chapel Hill}

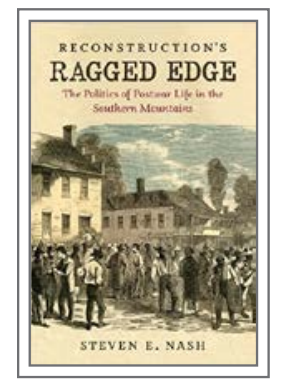

Reconstruction's Ragged Edge: The Politics of Postwar Life in the Southern Mountains

By Steven E. Nash.

Chapel Hill: University of North Carolina Press, 2016

1988. 288 pp. \$39.95. ISBN 978-1-4696-2624-6.

T he perception that the mountain South was a Unionist stronghold during the Civil War, and displayed a more egalitarian spirit after the war, has been an enduring one. Built largely on the assumption that a lack of plantation culture led to a relatively small slave population and therefore less robust support for the institution of slavery, and coupled with the independence of spirit thought necessary to carve a living out of relatively difficult circumstances, this belief has remained fixed, though never unchallenged, in the narrative of the Civil War and the postbellum period.

Historian Steven Nash, in his excellent and nuanced study, provides yet more evidence that the North Carolina mountains were of a piece with the state and the region, and that the assumption of egalitarianism was no more evident in the this part of North Carolina than anywhere else, though it differed in the types of occupations and infrastructure needs that the region's geography imposed. Through six chronological chapters, covering the antebellum period through about 1880 , plus a detailed introduction and conclusion, Nash carefully builds up a detailed picture of these needs, as well as the political and social forces that sought to either meet or exploit them. Individual cases, culled from primary sources such as letters, diaries, Freedman's Bureau files, and contemporary newspapers, create a compelling picture of an area as hard hit as any other by the war and its aftermath, and additionally handicapped by difficult terrain and relative lack of political clout in a state still seemingly dominated by eastern elites. Nash details the relative powerlessness of the newly enfranchised, who, enabled by the support and active intervention of Federal troops and Freedmen's agents, benefited for a time from the broader representation that national policies and new political alliances had made possible. These same contemporary accounts, however, give greater evidence of the strong, sometimes violent, and ultimately successful conservative backlash which reversed these tenuous gains.

Some may find the work to be a difficult read, though this will have nothing to do with the quality of the book nor the persuasiveness of Nash's contentions. True, Nash's book, while lucidly argued and impressively sourced, is not aimed at a general readership. More than this, though, one must concede that Nash's picture of the Reconstruction period, particularly as it illustrates the general conditions and treatment of the newly freed African American population, does not show the United States at its best, though occasional glimpses of nobility of purpose and a quest for true equality do indeed shine through, and the author is at pains to bring such instances to the foreground. Nevertheless, to read of injustice and inhumanity, even if couched in sturdy academic prose, and surrounded by a welter of painstakingly gathered statistics and detailed notes, cannot help but leave the reader dispirited, though always more fully informed.

Recommended for academic libraries and libraries with strong history collections.

\section{Steven Case \\ State Library of North Carolina}

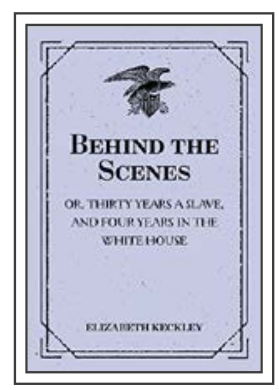

Behind the Scenes:

Or, Thirty Years a Slave and Four Years in the White House

By Elizabeth Hobbs Keckley.

Hillsborough, NC: ENO Publishers, 2016

161 pp. \$10.00. ISBN 978-0-9896092-7-2.

Girst published in 1868, this is ElizaC beth Hobbs Keckley's candid account of her life prior to purchasing her own freedom, and later, of her four years of service as a seamstress in the White House. Keckley spent several cruel years as a young adult slave in North Carolina's Hillsborough before she was moved to Virginia to continue life as a slave. She later purchased her own freedom and then her son's freedom. Her talents and skilled fingers provided an income and earned Elizabeth some renown as a dressmaker. She was called upon by all the best ladies of St. Louis where she was then living. 
This narrative provides a view into the real lives of the Abraham Lincoln family, particularly that of Mary Todd Lincoln for whom Keckley served as personal dressmaker. This reality of larger than life persons such as members of presidential families can be difficult to find even in the biographies and fiction that are often written about them. Keckley's account, however, shows the anxieties, frustrations, and emotions many biographies fail to expose. Mary Todd Lincoln, wife and widow of Abraham Lincoln, becomes an ordinary wife and mother for readers through the eyes of Keckley. Her dependence on Keckley and the bond of their friendship transcended the mores and social strata of the time. Their relationship was perhaps viewed as too close, and too interwoven, as is evidenced by the family's efforts to squelch this publication, and the resulting severing of ties between Mrs. Lincoln and Mrs. Keckley. This narrative is both informative and humanizing, giving readers an intimate view of a very difficult time in the life of one of America's revered First Ladies. Historians may be grateful that this volume was not hidden from the public eye.

Readers will further appreciate the introduction by Dolen Perkins-Valdez as he served a similar role as Keckley in that he gave greater substance to Keckley than she gave to herself, much as Keckley did for Mary Todd Lincoln.

This book is recommended for historians and biographers interested in the Civil War and presidential families. Public and academic libraries should definitely have Behind the Scenes: Or, Thirty Years a Slave and Four Years in the White House in their collections. High school libraries may wish to acquire this book as well.

\section{Kaye Dotson}

East Carolina University

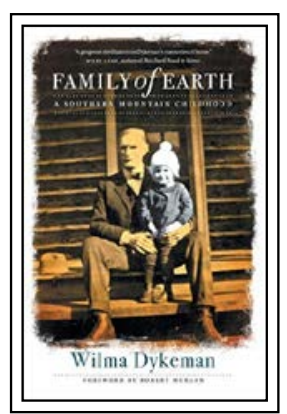

\section{Family of Earth: A Southern Mountain Childhood}

By Wilma Dykeman

Chapel Hill: University of North Carolina Press, 2016. 208 pp. \$18.00. ISBN 978-04696-2914-8.

utobiography can often be seen as Asimultaneously selfish and selfless. Chronicling one's own life, at least with the idea that others will be interested enough to read about it, smacks of profound egotism and eagerness to be scrutinized, even as it speaks to an equally profound willingness to stand exposed and defenseless before that scrutiny. Yet, beyond this undoubted dichotomy, one may find a different view, where a single life examined may, in the right hands, expose and illuminate larger truths.

Such is the case with Family of Earth: a Southern Mountain Childhood, a moving and deeply felt memoir by Wilma Dykeman detailing the first 14 years of her life. Written when she was only in her mid-20s, and only found and published after her death, Dykeman's story of her own childhood in the North Carolina mountains in and around Buncombe County reveals a time and a world that are, if not vanished, at least elusive and largely unattainable for modern readers-even those for whom the mountains are home. Following a generous and heartfelt introduction by Robert Morgan, the author unveils both her own impressions of the world as she grew up, and the moral and spiritual lessons that life in the mountains taught to her. No Pollyanna, Dykeman unflinchingly examines the struggles of daily living in the mountain south, a life which was, if not exactly hardscrabble, certainly attenuated and circumscribed by the prevailing economic conditions. But whereas it might be trite in the hands of other writers to contrast the relative lack of material riches with the richness of life, and especially nature, in her surroundings, Dykeman's luminous and finely wrought prose creates no such feeling of cliché, and her story makes it clear that no such contrast existed for her. Her childhood was neither free from want nor free from grief-and indeed, the memoir ends with the death of her father, which essentially represented the death of her childhood-but there is throughout an underlying sense of amazement and gratitude for the environment in which she grew and matured.

Given that the text was written so early in her career, the reader will not be surprised to find that, even as Dykeman the memoirist sought to unblinkingly convey the sorrows and joys of a young life, Dykeman the budding author was exploring the power of words, seeking their expressive potentiality and their richness as a medium with which to both immerse readers in her individual experience, and to teach them the greatness of the world around them. In her later works of both fiction and non-fiction, Dykeman explored this world more fully, and this memoir makes manifest the imaginative wellspring from which she drew her inspiration.

Recommended for all libraries, and highly recommended for middle and high school media centers.

\author{
Steven Case \\ State Library of North Carolina
}




\section{Browsers}

M any people thought that apps would kill web browsers. Instead of generic search tools, these apps would take the user directly to whatever they wanted to do. Apps do serve a purpose, for example my fitness tracker uploads data using an app. Some software vendors however have actually discontinued apps. For example the special collections web based registration and item tracking system Aeon, had an app in an earlier software version, but recent versions lack this handy tool. Yet according to some studies over $40 \%$ of web based users still use Microsoft's Internet Explorer. So clearly browsers are here to stay, at least for the near future.

For Microsoft Windows users there are better browsers than Internet Explorer (IE). IE is slow and since updates are no longer issued, about as secure as an unattended backpack. What would I want in a better browser? Speed would be nice, as would security and safety. The ability to connect seamlessly between devices would be nice, use less power (while on Netflix) and oh, I'd like it to be easy to use. It would also be nice if it would not crash or give me those " 404 file not found" errors. In fact Microsoft's newest browsers, Edge is considerable faster and uses less computer resources than IE. Edge only comes currently with the Windows 10 operating system and there are no plans by Microsoft to make
Edge versions for Windows 7 or Windows 8. While Edge still has a rough "edge" to it, developers are planning to add new applications for the browser. Many users prefer Google's Chrome browser, which runs much faster than IE and even Edge (unless you have an underpowered laptop in which case Edge uses less power). Some users prefer Firefox or Opera, but these two browsers are getting increasingly old and clunky. Opera works sometimes on machines that have limited memory, but most newer computers will run the much better Chrome browsers.

Mac Computer users have a choice of Safari or Chrome. Most Mac users select Apple's proprietary browser Safari because it is faster and uses less power. Many Mac users prefer the more popular Chrome because it makes fighting with and selecting tabs easier. Chrome developers are trying to make new releases run faster and use less power, but so far Safari has won the race. If you have lots of extra power you might try Chrome on your Mac.

Android users have a number of browsers to select from: Chrome, Flynx, Ghostry, Mercury, Naked (yes Naked Browser!), Opera, Firefox, Puffin and Dolphin (all are free downloads). Opera, Firefox and Puffin beat Chrome in terms of speed, however again many users prefer the Chrome interface. Puffin has an odd feature (enhancement?) that allows you to only use Adobe Flash for 12 hours each day however. The "Android Authority" rates these browsers in this order: Dolphin, Firefox, Flynx, Ghostry, Chrome, Mercury, Naked, Opera, and Puffin. With all this selection, it's no wonder that the Android operating system is now making inroads into low cost laptops and tablets. Microsoft watch out!

Clearly there is an interesting array of browsers to choice from currently. Many users will stay with the old familiar standbys: Chrome, Safari, Firefox, and Microsoft's new Edge. Others will enjoy browsing with Naked or Opera. Undoubtedly the various features that you like about your current browser will change over time and you will need to re-visit the vast array of new choices again.

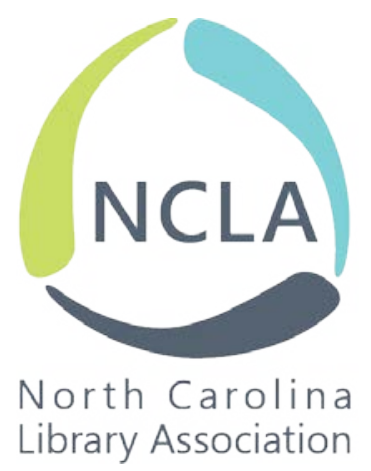




\section{The Charles Waddell Chesnutt Collection at Fayetteville State University}

7 he history of Fayetteville State University and its Charles W. Chesnutt Library are intimately connected with one of the most important writers from North Carolina. Charles Waddell Chesnutt, 18581933, was a celebrated short story writer and novelist who tackled issues of race and class in ways that still resonate today.

Fayetteville State University was founded by a group of seven African American men in 1867 as the Howard School. One of these men was Andrew Jackson Chesnutt, the father of Charles W. Chesnutt. Andrew Chesnutt was from Cleveland, Ohio, and had settled in Fayetteville after the end of the Civil War to raise his children near his parents. Andrew Chesnutt opened a grocery store and later a dry goods transportation business. ${ }^{1,2}$ Chesnutt's son, Charles, and daughters Lillian, Anne, and Sara attended the school he helped found, a school which quickly grew in importance to Fayetteville and the state.

The Howard School was renamed the State Colored Normal School in 1877, and subsequently became Fayetteville State Teachers College with the ability to grant Bachelor's degrees in education in 1933. It was renamed Fayetteville State University, and then in 1972 made a part of the University of North Carolina system. ${ }^{3}$ The original Charles W. Chesnutt Library opened its doors in 1937 in a building which now houses university telecommunications. The second Chesnutt Library, built in 1968, is now the Helen Chick Building. ${ }^{4}$ The current building was constructed in 1987 and named after Charles Waddell Chesnutt. The 30-strong staff welcome students, faculty, and researchers to their 4-story, 70-000 square-foot facility.

Charles Waddell Chesnutt was a student and teacher at the Howard School in Fayetteville which was later renamed the State Colored Normal School. After a stint teaching in Charlotte, he returned to serve as assistant principal in 1877, and then he became principal in 1880. Chesnutt spent a brief time in New York and then moved permanently back to Ohio. There, he passed the bar and worked as a lawyer and later a stenographer. Although his first short story "Uncle Peter's House" was published in the Cleveland News and Herald in 1885, Chesnutt's literary career took off in 1887 when his short story "The Goophered Grapevine" became the first African-American publication in the Atlantic Monthly. 5 This story was collected in his 1899 book, The Conjure Woman. The same year he published a second book of short stories, The Wife of His Youth and Other Stories of the Color Line. These and other short stories Chesnutt wrote address issues of race and class, passing and miscegenation-themes of expression that are also in his novels.

In 1900, Chesnutt's first novel The House Behind the Cedars was published by Houghton Mifflin. A novel that tells the story of an African American woman who moves to the same city as her brother, both passing for white until the sister's fiancé discovers her secret. Chesnutt's second novel was The Marrow of Tradition, published in 1901. The Marrow of Tradition is based on the Wilmington race riots of 1898. It is significant that Chesnutt's novels were published at the same time that Jim Crow laws were exerting tremendous political clout in North Carolina and other Southern states. Chesnutt's third and final novel was The Colonel's Dream, published in 1905. After that time, he stopped writing commercially, but involved himself more in civic affairs.

Chesnutt participated in the Niagara Movement meeting at Oberlin College in 1908, delivering the welcoming address on August $28 .{ }^{6} \mathrm{He}$ also participated in the founding of the NAACP in 1909, serving on the General Committee. In 1928, he was awarded the NAACP's Springarn Medal for "for his pioneer work as a literary artist, depicting the life and struggle of Americans of Negro descent".

Among the treasures in Chesnutt Library is the Charles Waddell Chesnutt Collection, which contains materials from 1821 to 1967 . The 


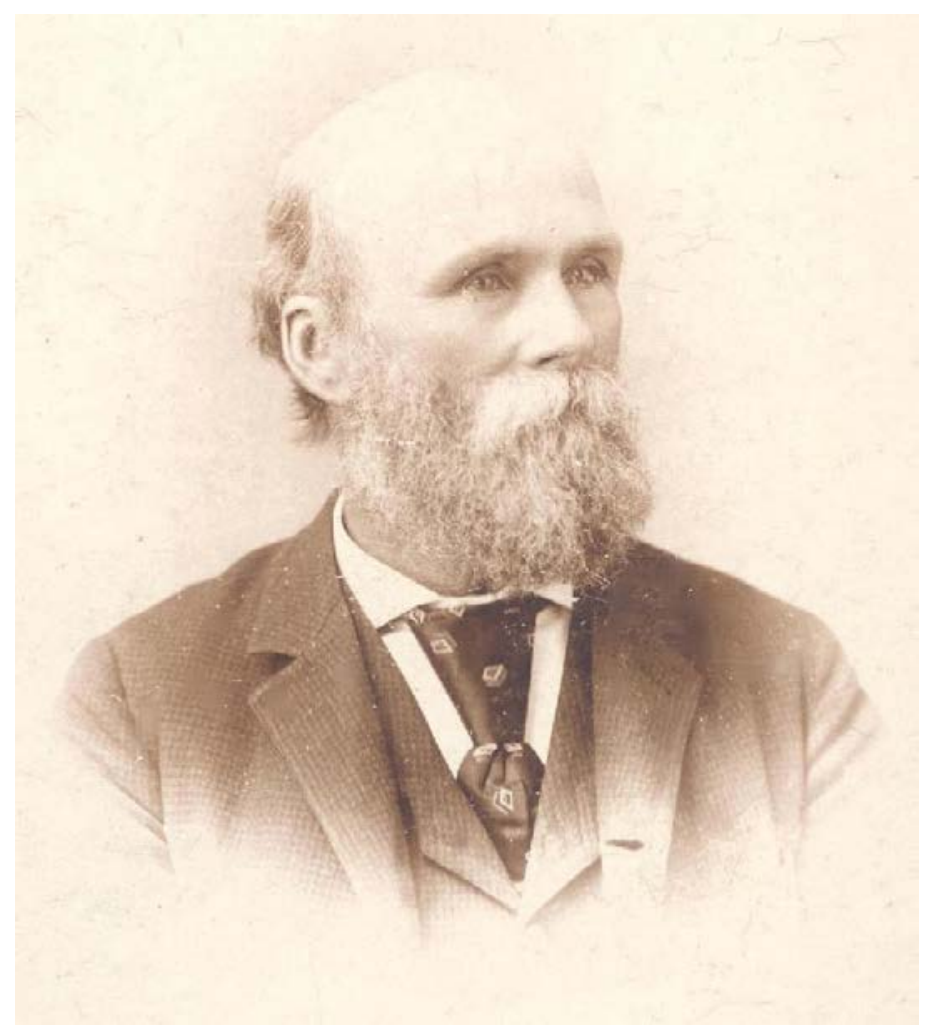

Image 1: Andrew J. Chesnutt

Chesnutt Collection includes correspondence of Charles Chesnutt, letters and records of his sisters Anne C. Waddell and Sara Chesnutt, pictures of family and friends, newspaper and magazine clippings, and postcards. Finding aids for all three are available online, along with selected digitized materials. Correspondents for Chesnutt includes famed educator and author Booker T. Washington, wellregarded editor and fellow North Carolinian, Walter Hines Page, and William Dean Howells, editor of the Atlantic Monthly, who was also called the "Dean of American Letters." Charles's sisters, Sara and Anne, also attended Fayetteville State and were active educators in Fayetteville. In fact, Anne Chesnutt Waddell served as a teacher, principal and superintendent, and had a high school (now a middle school) named after her. ${ }^{8}$

The Chesnutt Collection has several items digitized through an LSTA award in 2003. Mr. Bobby Wynn, Director of the library, describes the reason the Chesnutt Collection was selected for this grant application: "The Charles Chesnutt Family collection provides a historical look into an effort by one family to provide for the education of their children and other African American children" during the Reconstruction period between the end of the Civil War and the end of the Nineteenth Century. ${ }^{\text {? }}$

According to Ms. Nicholle Young, University Library Technician for Archives, researchers have come from UNC Chapel Hill, Fisk University, and Bowdoin College to consult the Chesnutt Collection. Some of her favorite items in the collection are the photographs of the Chesnutts' travels around Fayetteville, to Cleveland, and abroad. Moreover, she enjoys sharing Charles Chesnutt's handwritten letters, helping patrons create a personal connection with the author. In common with Chesnutt, she loves the city and wants to see it grow and thrive. Among the most requested items from the Chesnutt Collection are correspondence of Anne and Sara Chesnutt, especially for researchers of the history of education in Fayetteville.

The Chesnutt Collection fits well with the library's mission to provide students primary materials related to the university's history, its transition through the years and its place within state and national history, especially during the Great Depression and the World Wars, two a time of significant change at Fayetteville State. Ms. Young and her colleagues are beginning to prepare for the University's sesquicentennial, so she is looking at materials from the presidents' papers. For the Special Collections as a whole, additional heavily-requested items include presidential speeches, particularly from Dr. Rudolph Jones and Dr. James Ward Seabrook, who presided over critical transition points in the history of the university. She believes that Charles Chesnutt, Dr. Jones and Dr. Seabrook, among others, have held similar visions for the University to provide education and service to the city and state.

The Chesnutt Collection provides rich primary source materials related to education in Fayetteville and issues of race and class. Interested readers can find Chesnutt's works at Documenting the American South, and in the Chesnutt Digital Archive. ${ }^{10}$ There are also Charles Chesnutt Collections at Western Reserve Historical University in Cleveland, Ohio, and Fisk University in Nashville, Tennessee. But Ms. Young, Mr. Wynn, and the other librarians at Chesnutt Library invite everyone to visit Special Collections at Charles W. Chesnutt Library at Fayetteville State University.

Thanks to Nicholle Young, University Library Technician for Archives, Charles W. Chesnutt Library, Fayetteville State University 


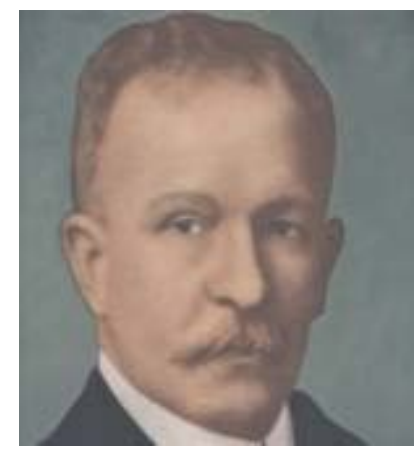

Image 2: Charles W. Chesnutt, 2nd Principal of Howard School (later Fayetteville State University)

\section{References}

1 "History of Fayetteville State University," Charles W. Chesnutt Library Archives and Special Collections, Fayetteville State University, http://library.uncfsu.edu/archives/fsu-history.

2 Amber Covington, "FSU History: Founding Fathers," Charles W. Chesnutt Library Archives and Special Collection, Fayetteville State University, September 25, 2014. http://chesnuttlibrary.tumblr.com/post/98404702706/fsu-history-founding-fathers-in-a-short-letter.

3 "History of Fayetteville State University," ibid.

${ }^{3}$ Joan Milligan et al, "Chronological History of Fayetteville State University Buildings and Structures 1867 - Present Date," Charles W. Chesnutt Library Archives and Special Collections, Fayetteville State University, http://library. uncfsu.edu/archives/history-of-fsu-campus-buildings.

4 "Digitization Project Background Information," Charles W. Chesnutt Library Archives and Special Collections, Fayetteville State University, http://library.uncfsu.edu/archives/digitized-collections/digitization-project-backgroundinformation.

5 "Biography," The Charles Chesnutt Digital Archive, http://www.chesnuttarchive.org/classroom/biography.html.

6 "The Niagara Group," Electronic Oberlin Group, http://www.oberlin.edu/external/EOG/Niagara\%20Movement/ niagaramain.htm.

7 Samuel W. Black, "Researching the African-American Experience at the Western Reserve Historical Society," Crooked River: An Electronic Journal of Social and Urban History 3 (December 2000). Available at http://academic.csuohio.

edu/clevelandhistory/Issue3/articles/RESEARCHING_THE_AFRICAN_AMERICAN_EXPERIENCE_AT_THE_ WESTERN_R.html.

${ }^{8}$ Darwin Hedrick, "Brief History of Anne Chesnutt School," Anne Chesnutt Year-Round Middle School, March 2, 2015, http://acms.ccs.k12.nc.us/category/school-history/.

9 "Digitization Project Background Information," ibid.

${ }^{10}$ Browner, Stephanie, "The Charles Chesnutt Digital Archive," http://www.chesnuttarchive.org/. "Charles Waddell Chesnutt, 1858-1932," Documenting the American South. University of North Carolina at Chapel Hill, http:// docsouth.unc.edu/southlit/chesnuttcolonel/bio.html.

See also Alice Thrasher, "New Generation Learns to Appreciate Chestnutt's [sic] Work," Fayetteville Observer February 8, 1998, http://www.fayobserver.com/living/new-generation-learns-to-appreciate-chestnutt-s-work/article_9049eb083aae-5193-967c-54916c6f10af.html. 


\section{North Carolina Libraries Editorial Board}

$\begin{array}{rll}\text { EDITOR } & \begin{array}{l}\text { Ralph Lee Scott } \\ \text { Joyner Library, ECU } \\ \text { scottr@ecu.edu }\end{array} & \\ \text { ASSOCIATE } & \text { Terry W. Brandsma } & \\ \text { EDITORS } & \text { Jackson Library, UNC-Greensboro } \\ \text { twbrands@uncg.edu } & \begin{array}{l}\text { Jane S. McAllister } \\ \text { Davie County Public Library } \\ \text { jmcallister@daviecountync.gov }\end{array} \\ & \text { Anne Coleman } & \text { John Raynor } \\ \text { Asst. Dean for Research Services, } & \text { High Point Public Library } \\ \text { UNC Pembroke } & \text { john.raynor@highpointnc.gov } \\ \text { anne.coleman@uncp.edu } & \text { Allan Scherlen } \\ & \begin{array}{l}\text { Denelle Eads } \\ \text { Atkins Library, } \\ \text { UNC Charlotte } \\ \text { deads@uncc.edu }\end{array} & \text { scherial Sciences Librarian, ASU } \\ \text { Al Jones } & \text { Elizabeth H. Smith } \\ \text { Professor of Library Science, ECU } & \text { Professor Emerita, ECU } \\ \text { jonesp@ecu.edu } & \text { smithe@ecu.edu } \\ & \\ \text { Diane Kester } & \text { Jennifer Smith } \\ \text { Associate Professor Emerita, ECU } & \text { Belk Library, Elon University } \\ \text { kesterd@ecu.edu } & \text { jsmith41@elon.edu } \\ \text { Michael Reece } & \\ \text { Joyner Library, ECU } & \\ \text { reecem@ecu.edu } & \end{array}$

W. Joseph Thomas
Joyner Library, ECU

thomasw@ecu.edu

Catherine Tingelstad

Public Services Librarian, Health Sciences Library, Wake Tech Community College cjtingelstad@waketech.edu

Jamane Yeager

Reference / Electronic Resources

Librarian, Elon University

jyeager@elon.edu

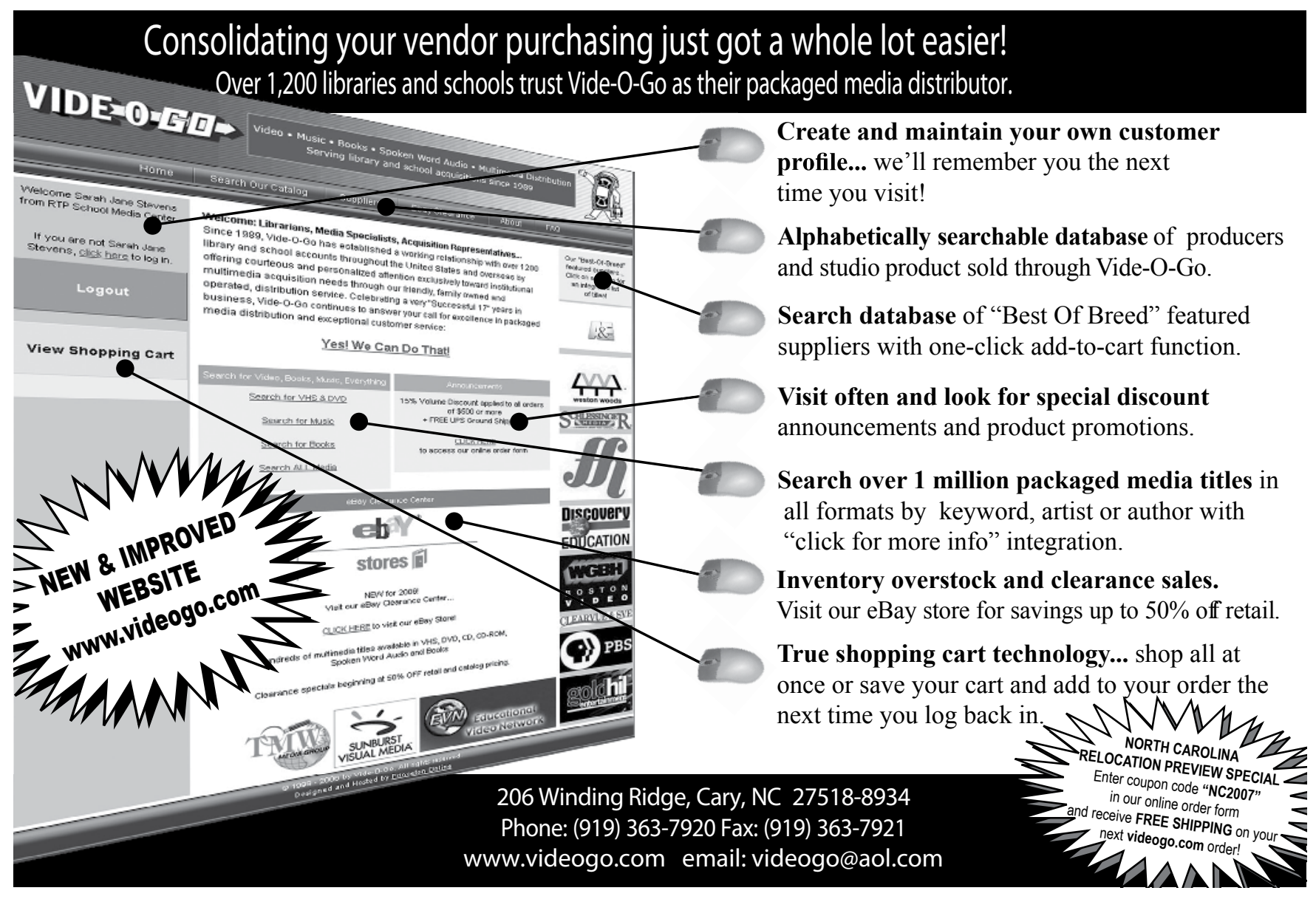




\section{North Carolina Library Association Executive Board, 2016}

\begin{tabular}{|l|}
\hline Officers \\
\hline President \\
Rodney Lippard \\
rodney.lippard@rccc.edu \\
\hline Vice President/President-Elect \\
Michael A. Crumpton \\
macrumpt@uncg.edu \\
\hline Secretary \\
Julie Humphrey \\
humphreyj@durhamtech.edu \\
\hline
\end{tabular}

Treasurer

M. J. Wilkerson

mwilkerson@alamancelibrar-

ies.org

Treasurer-Elect

Lorrie Russell

ncla.treasurer@gmail.com

Regional Director (Eastern)

Alan Bailey

baileya@ecu.edu

Regional Director

(Central/Triangle)

Amy Harris

a_harri2@uncg.edu

Regional Director (Piedmont)

Mary Sizemore

mary.sizemore@highpointnc.gov

Regional Director (Western)

Alan Unsworth

unswortha@surry.edu

ALA Council

Dana Eure

deure@cmlibrary.org

SELA Representative

Wanda Brown

brownwa@wssu.edu

Editor, NC Libraries

Ralph Scott

scottr@ecu.edu

Past President

Dale Cousins

dalenbill@gmail.com

Executive Assistant

(Ex Officio)

Kim Parrott

nclaonline@gmail.com

State Librarian (Ex Officio)

Cal Shepard

cal.shepard@ncdcr.gov

\section{Section Chairs}

Business Librarianship

Lydia Towery

ltowery@cmlibrary.org

College and University

Amy Brake

abrake@ncwc.edu

Community and Junior Col-

lege Libraries

Staci Wilson

swilson@cvcc.edu

Government Resources

Michele Hayslett

michele_hayslett@unc.edu

Library Administration and

Management

Mark Sanders

sandersm@ecu.edu

Public Library

Decca Slaughter

slaughdr@forsyth.cc

Reference and Adult Services

Jeanne Hoover

hooverj@ecu.edu

Resources and Technical

Services

Anna Craft

arcraft@uncg.edu

Youth Services

Tanika Martin

tmartin@dconc.gov

\section{Round Table Chairs}

Literacy

Jane Blackburn

jblackburn@arlibrary.org

New Member

Sarah Lyon

sarahvlyon@gmail.com

NC Library Paraprofessional

Association

Cathy Wright

cwright@alamancelibraries.org

Ethnic Minority Concerns

Shamella Cromartie

scromartie@robeson.edu

Special Collections

Jennifer Motszko

j_motszk@uncg.edu
Women Issues in Libraries

Jenny Barrett Boneno

barretj@forsyth.cc

Technology and Trends

Jenny Dale

jedale2@uncg.edu

STEM Librarianship in NC

(officers pending)

Karen Grigg

ksgrigg@unc.edu

\section{Committee Chairs}

Archives

Denelle Eads

deads@uncc.edu

Conference 2017

Michael A. Crumpton

macrumpt@uncg.edu

Constitution, Codes and

Handbook Revision

Laura B. Davidson

Davidson@meredith.edu

Continuing Education

Brandy Hamilton

brandy.hamilton@wakegov.

com

Development

Dale Cousins (co-chair)

dalenbill@gmail.com

Susan Brown (co-chair)

sbrown2@townofchapelhill.

org

Finance

Paul Birkhead

paul.birkhead@rowancoun-

tync.gov

Intellectual Freedom

Marian Lytle, Chair

marian.lytle@rowancountync.

gov

Leadership Institute

Michael A. Crumpton

macrumpt@uncg.edu

Legislative and Advocacy

Anthony Chow (co-chair)

aschow@uncg.edu

LaJuan Pringle (co-chair)

lpringle@cmlibrary.org
Marketing

Stephanie Willen Brown

CogSciLibrarian@gmail.com

Nominating

Dale Cousins

dalenbill@gmail.com

Operations

Jennifer Taft

jtaft@methodist.edu

Librarians Build

Communities

Sandra Lovely

slovely@dconc.gov

Scholarships

Libby Stone

stone.libby@gaston.edu

Website and Technology

Support

Erin Holmes

erin@nclive.org 


\section{East Carolina University}

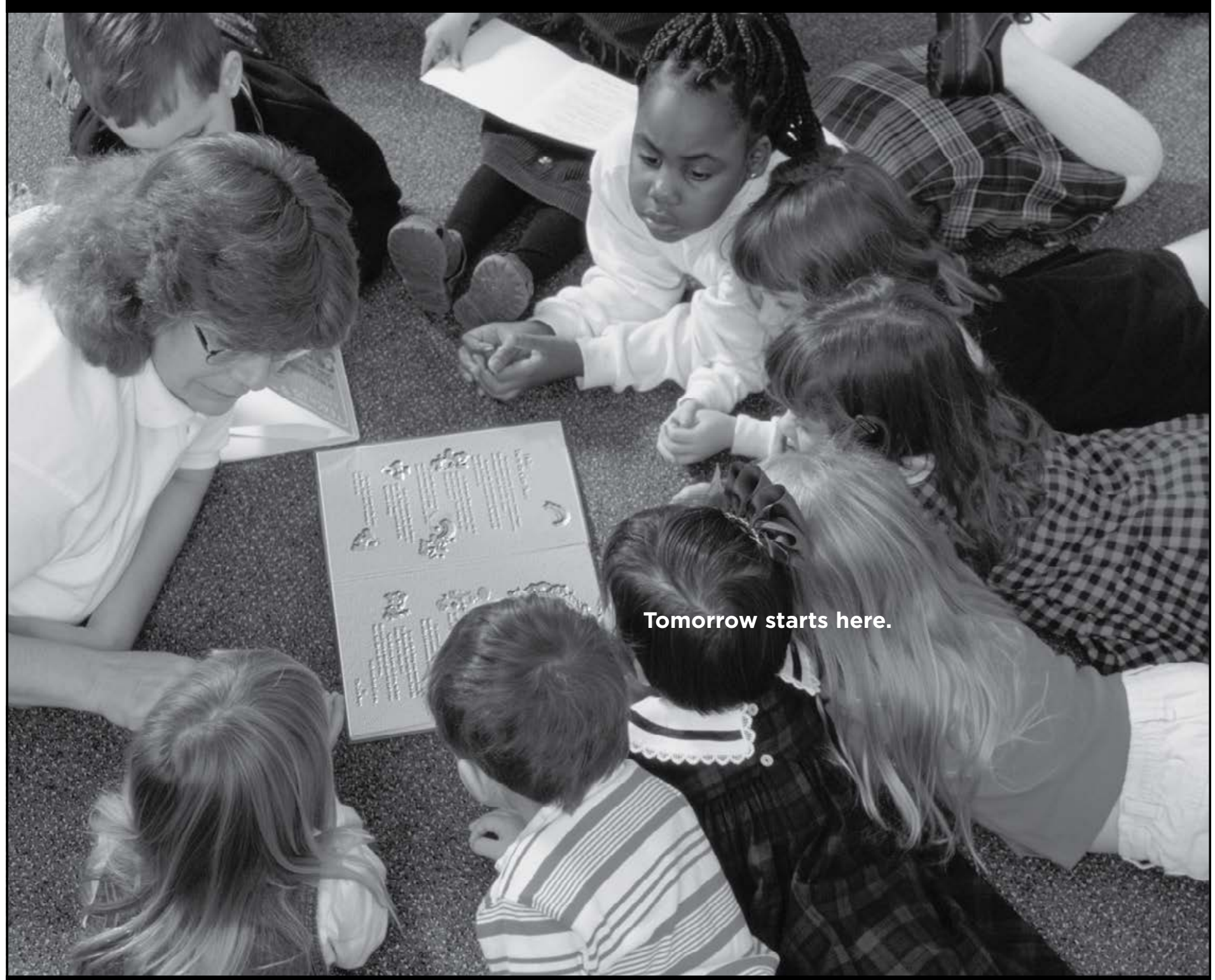

\section{Master of Library Science}

\section{Earn your degree $100 \%$ online.}

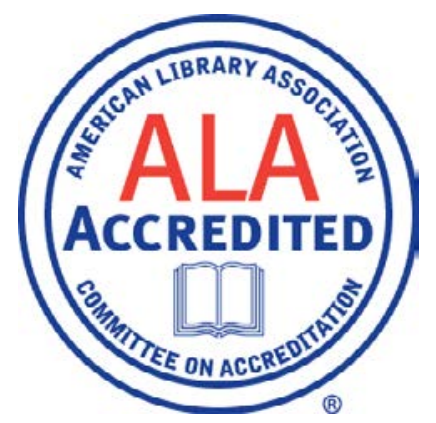

http://www.ecu.edu/educ/idp/lsed/

$$
\text { 252-328-4373 }
$$




\section{DEPARTMENT OF LIBRARY \& INFORMATION STUDIES}

"Consociating People, Information and Libraries"

\section{Master of Library and Information Studies}

The MLIS program prepares people for professional employment in public, academic, and special libraries as well as other careers in information work. The program also offers preparation leading to licensure as a School Library Media Coordinator (076), and Instructional Technology Specialist-Computers (077) through the North Carolina Department of Public Instruction.

Courses leading to the MLIS are offered in Greensboro, Charlotte and Asheville. For complete information visit http://lis.uncg.edu or call (336) 334-3477. 